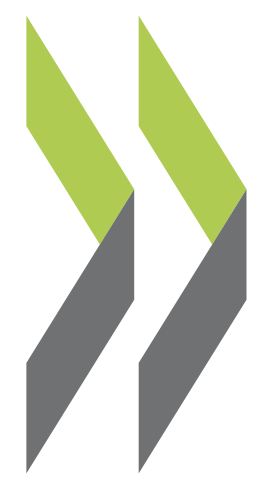

OECD Health Working Papers No. 99

Readiness of electronic health record systems to contribute to national

\title{
Jillian Oderkirk
}

health information

and research 
Organisation de Coopération et de Développement Économiques

Organisation for Economic Co-operation and Development

30-Nov-2017

DIRECTORATE FOR EMPLOYMENT, LABOUR AND SOCIAL AFFAIRS

English text only

HEALTH COMMITTEE

\section{Health Working Papers}

OECD Health Working Paper No. 99

READINESS OF ELECTRONIC HEALTH RECORD SYSTEMS TO CONTRIBUTE TO NATIONAL HEALTH INFORMATION AND RESEARCH

Findings of the 2016 OECD HCQI Study of Electronic Health Record System Development and Data Use Jillian Oderkirk*

JEL classification: 11,03 and $O 5$

Authorized for publication by Stefano Scarpetta, Director, Directorate for Employment, Labour and Social Affairs

(*) OECD, Directorate for Employment, Labour and Social Affairs, Health Division.

All health Working Papers are now available through the OECD's website at: http://www.oecd.org/els/health-systems/health-working-papers.htm

JT03423892

This document, as well as any data and map included herein, are without prejudice to the status of or sovereignty over any territory, to the delimitation of international frontiers and boundaries and to the name of any territory, city or area. 


\title{
DIRECTORATE FOR EMPLOYMENT, LABOUR AND SOCIAL AFFAIRS
}

\author{
www.oecd.org/els
}

\section{OECD HEALTH WORKING PAPERS}

\author{
http://www.oecd.org/health/health-working-papers.htm
}

OECD Working Papers should not be reported as representing the official views of the OECD or of its member countries. The opinions expressed and arguments employed are those of the author(s).

Working Papers describe preliminary results or research in progress by the author(s) and are published to stimulate discussion on a broad range of issues on which the OECD works. Comments on Working Papers are welcomed, and may be sent to health.contact@oecd.org.

This series is designed to make available to a wider readership selected health studies prepared for use within the OECD. Authorship is usually collective, but principal writers are named. The papers are generally available only in their original language - English or French - with a summary in the other.

This document and any map included herein are without prejudice to the status of or sovereignty over any territory, to the delimitation of international frontiers and boundaries and to the name of any territory, city or area.

The statistical data for Israel are supplied by and under the responsibility of the relevant Israeli authorities. The use of such data by the OECD is without prejudice to the status of the Golan Heights, East Jerusalem and Israeli settlements in the West Bank under the terms of international law.

(C) OECD 2017

You can copy, download or print OECD content for your own use, and you can include excerpts from OECD publications, databases and multimedia products in your own documents, presentations, blogs, websites and teaching materials, provided that suitable acknowledgment of OECD as source and copyright owner is given. All requests for commercial use and translation rights should be submitted to rights@oecd.org. 


\section{ACKNOWLEDGEMENTS}

This OECD study was undertaken by the OECD HCQI (Health Care Quality Indicators) Expert Group as part of the 2015/16 programme of work of the OECD Health Committee. The authors would like to acknowledge the representatives of the countries who make up the HCQI Expert Group, all of whom gave generously of their time to provide input and guidance to this study. Additional thanks and recognition is extended to the experts from participating countries who provided responses to the survey upon which this study is based. The OECD would like to acknowledge the contributions of Jillian Oderkirk, Niek Klazinga, Luke Slawomirski, Lukasz Lech and Duniya Dedeyn who endeavored to make this report possible. Appreciation is extended to Stefano Scarpetta, Mark Pearson and Francesca Colombo for supporting and directing this study. 


\begin{abstract}
All countries are investing in the development of electronic health (clinical) records, but only some countries are moving forward the possibility of data extraction for research, statistics and other uses that serve the public interest.

This study reports on the development and use of data from electronic health records in twenty-eight countries. It reports on the prevalence of technical and operational factors that support countries in the development of health information and research programmes from data held within electronic health record systems, such as data coverage, interoperability and standardisation.

It examines data quality challenges and how some countries are addressing them and it explores the governance of electronic health record systems and data, including examples of national statistical and research uses of data.

The report provides an overall assessment of the readiness of countries to further develop health information from data within electronic health record systems and describes the outlook for the future. Ten countries are identified as having high readiness that enables them to develop world-class health information systems supporting health system quality, efficiency and performance and creates a firm foundation for scientific research and discovery.
\end{abstract}

\title{
RÉSUMÉ
}

Tous les pays investissent dans le développement de dossiers médicaux électroniques, mais seuls certains parmi eux avancent la possibilité d'extraire des données à des fins de recherche, de statistiques ainsi que d'autres utilisations servant l'intérêt public.

Avant tout, la présente étude rend compte de l'évolution de l'utilisation des données de santé provenant des dossiers médicaux électroniques dans vingt-huit pays. Elle fait état de la prévalence des facteurs techniques et opérationnels qui aident les pays dans le développement des programmes d'informations et de recherche sur la santé à partir de données détenues dans les systèmes électroniques de données de santé, tels que la couverture des données, l'interopérabilité et la normalisation.

Deuxièmement, en examinant les défis liés à la qualité des données et la façon dont certains pays les relèvent, cette étude évalue la gouvernance des systèmes et des données électroniques de santé incluant les exemples d'utilisations des données nationales à des fins statistiques et de recherche.

Enfin, ce rapport donne une évaluation globale de la disponibilité des pays à développer davantage d'informations sur la santé à partir de données provenant des systèmes électroniques de dossiers de santé et il décrit les perspectives pour l'avenir. Dix pays ont été identifiés comme étant prêts pour développer des systèmes d'informations sur la santé de classe mondiale qui soutiendraient la qualité, l'efficacité et les performances des systèmes de santé et créeraient une base solide pour la recherche et la découverte scientifiques. 


\section{TABLE OF CONTENTS}

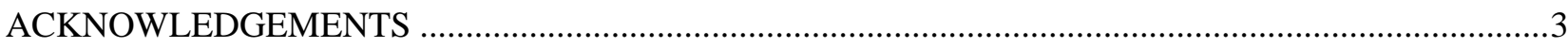

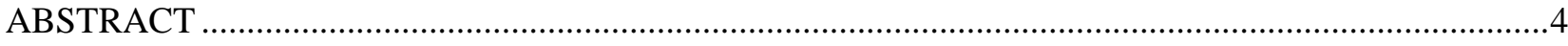

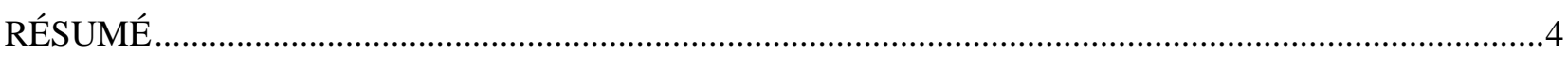

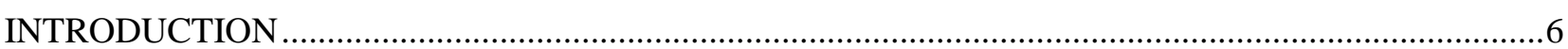

2016 OECD Study of Electronic Health Record System Development and Data Use...........................7

1. TECHNICAL AND OPERATIONAL FACTORS SUPPORTING STATISTICAL AND RESEARCH

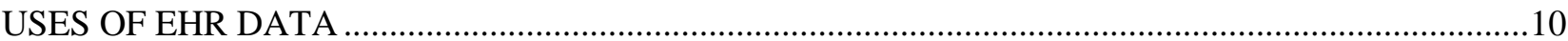

1.1 Use of electronic clinical records in physician offices and hospitals is improving ........................11

1.2 Most countries are implementing one "country-wide" electronic health record system ..................11

1.3 Patients' can access their own electronic health records in over half of countries ...........................18

1.4 Minimum datasets defined in 26 countries .......................................................................20

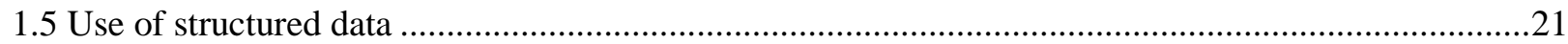

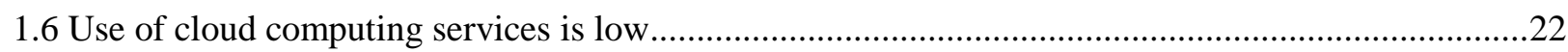

1.7 Widespread use of a unique patient ID number in electronic health records.................................23

2. DATA QUALITY CHALLENGES THAT LIMIT DATA USE AND EFFORTS TO ADDRESS

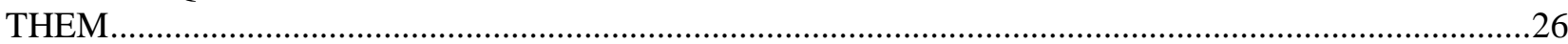

2.1 Most countries are challenged by multiple standards in use for the same key data elements.............27

2.2 Most countries have a national authority responsible for the EHR system that sets and maintains

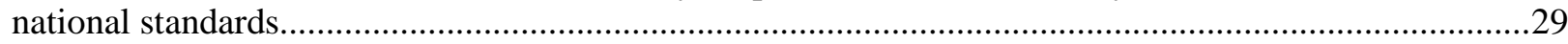

2.3 Efforts to address the consequences of multiple minimum dataset specifications ...........................3

2.4 Policy levers requiring or encouraging adoption and maintenance of high quality electronic health

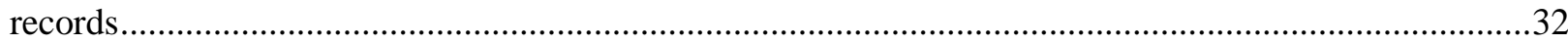

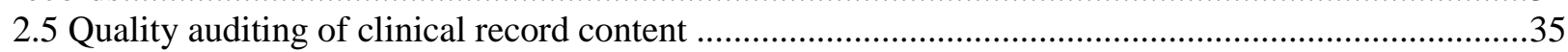

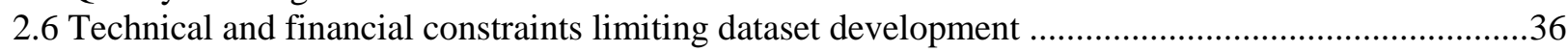

3. HEALTH DATA GOVERNANCE READINESS VARIES GREATLY AMONG COUNTRIES .........37

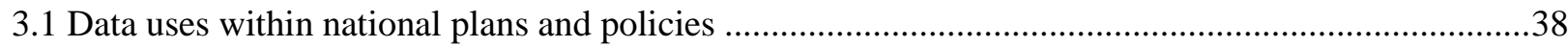

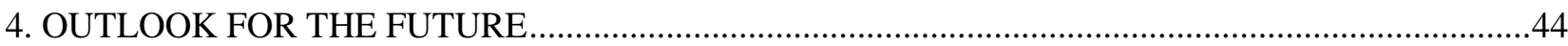

4.1 Strategic investments to advance the availability of data from EHRs for health system monitoring

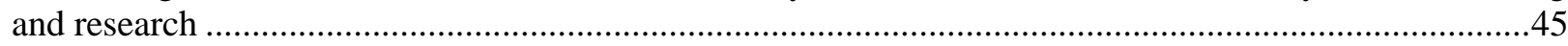

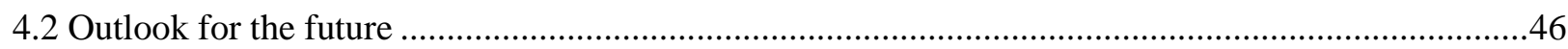

4.3 International cooperation supports harmonisation toward common best practices .........................47

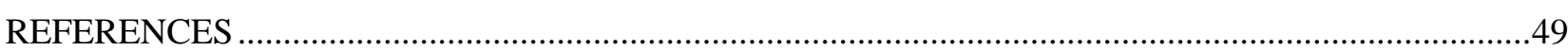

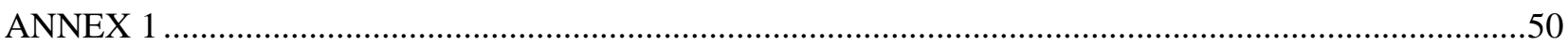

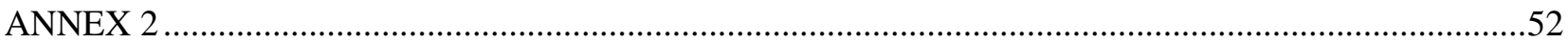

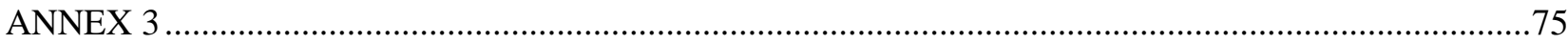




\section{INTRODUCTION}

1. Countries that develop electronic health record systems that combine or virtually link data together to capture patients' health care histories have the potential to realise an unprecedented advancement in health care quality, efficiency and performance and in the discovery and evaluation of preventative care and treatments, including precision medicine. The depth and breadth of such data far exceeds that available from traditional survey, administrative or research sources and supports new big data research techniques that can search for patterns and anomalies in populations (Figure 1).

2. Further, when longitudinal EHR data can be linked to information about treatment costs and deaths; such data then supports detecting unsafe health care practices and treatments; rewarding high quality and efficient health care practices; and detecting fraud and waste in the health care system (OECD, 2013, 2015a).

3. When longitudinal EHR data can be linked to patients' behavioural, environmental and biological (genetic) characteristics; such data then supports identifying optimal responders to treatment and personalising care for better patient outcomes; and discovering and evaluating new health care treatments and practices. If such data is available for very large and representative patient populations, then it can support selecting cohorts of patients for clinical trials; and conducting long-term follow up of clinical trial cohorts (OECD 2015b, 2015c).

\section{Figure 1: Multiple uses of data within clinical electronic health record systems}

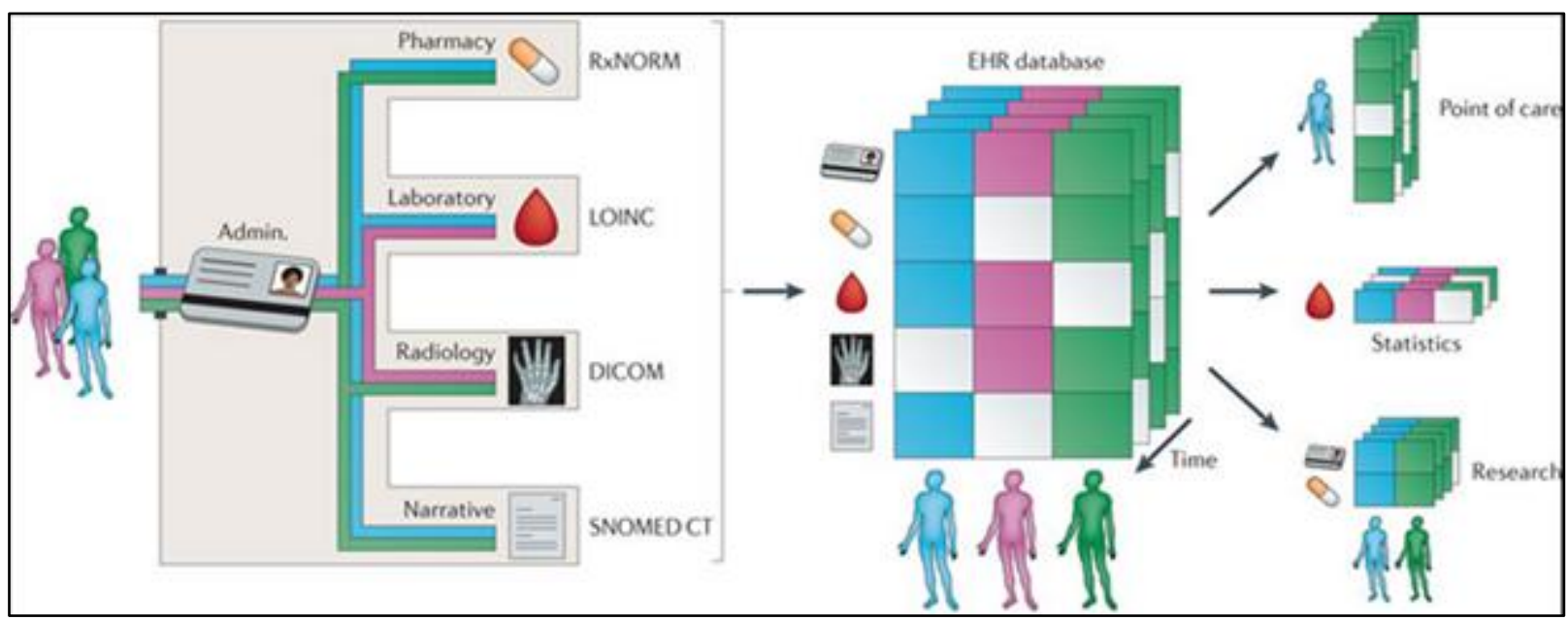

Source: Jensen, P.B., L.L. Jensen and S. Brunak (2012), "Mining Electronic Health Records: Towards Better Research Applications and Clinical Care", Nature Reviews - Genetics, Vol. 13

4. All countries are investing in the development of electronic clinical records, but only some countries are moving forward the possibility of data extraction for research, statistics and other secondary uses. Those progressing toward analytical uses of data are overcoming challenges ranging from ensuring adequate financial and human resources, to managing culture change, to effective public engagement, to ensuring data usability, quality, security and privacy protection. 


\section{OECD Study of Electronic Health Record System Development and Data Use}

5. With a mandate from the 2010 meeting of OECD Health Ministers, the Health Care Quality Indicators Expert Group (HCQI) began surveying countries in 2011 regarding the development of national health data assets and their use to improve health, health care quality and health system performance (OECD, 2013). We found that while all countries are investing in data infrastructure, there were significant cross-country differences in data availability and use, with some countries standing out with significant progress and innovative practices enabling privacy-protective data use, and others falling behind with insufficient data and restrictions that limit access to and use of data, even by government itself.

6. This study included a survey of countries' development and secondary use of data from electronic (clinical) health records that uncovered significant differences in the design, implementation and governance of EHR systems between the 13 countries whose national plans or policies called for at least four different data uses and the twelve countries who were planning on fewer or no secondary data uses.

7. In 2016, this survey was administered again to report on the current status of EHR implementations and data uses and to monitor progress since 2012. Twenty-eight countries responded to the survey including Australia, Austria, Canada, Chile, Croatia, Czech Republic, Estonia, Finland, France, Greece, Iceland, Israel, Japan, Latvia, Luxembourg, Mexico, New Zealand, Norway, Poland, Singapore, Slovakia, Spain, Sweden, Switzerland, United Kingdom and United States (Annex 1). Three members of the United Kingdom are included in this study: England, Northern Ireland and Scotland. ${ }^{1}$

8. Eighteen of these countries also took part in this survey in 2012: Austria, Canada, Denmark, Estonia, Finland, France, Iceland, Israel, Japan, Mexico, Poland, Singapore, Slovakia, Spain, Sweden, Switzerland, the United Kingdom (England and Scotland) and the United States. For these countries, results from 2016 are compared with those of 2012, where appropriate.

9. In the HCQI studies, an Electronic Health Record (EHR) refers to the longitudinal electronic record of an individual patient that contains or virtually links records together from multiple Electronic Medical Records (EMRs) which can then be shared (interoperable) across health care settings. It aims to contain a history of contact with the health care system for individual patients.

10. Part 1 of this report reviews the technical and operational factors that would support countries in the development of national health information and research programmes from data held within electronic health record systems. The factors examined include:

- Coverage of electronic health records;

- National EHR systems with comprehensive record sharing;

- Patient data access;

- Minimum datasets;

- Use of structured data and clinical terminology standards; and

- Unique IDs for patients and providers in EHRs.

\footnotetext{
${ }^{1}$ The data governance and operational and technical capacities of members of the United Kingdom have important differences that are of interest to OECD countries and, as a result, they are presented separately in this report.
} 
11. The countries in the top tier with respect to technical and operational readiness to enable the statistical and research use of data from EHRs are identified.

12. Part 2 examines data quality challenges that limit data use and the efforts that have been made in some countries to address them. These include a lack of standards, poor record keeping practices, multiple definitions of the minimum dataset, and multiple terminology standards for the same data elements. This section describes national efforts to:

- Map data elements to a consistent terminology,

- Set national governance of clinical terminology and interoperability standards,

- Engage stakeholders in standards setting,

- Foster the use of one national minimum dataset,

- Legislate or incentive health care providers to adhere to standards, and

- Audit EHRs for clinical content quality.

Technical and financial constraints that are limiting dataset development are also described.

13. Part 3 of this report explores the health data governance readiness of OECD countries. Factors examined include:

- Identification of statistical and research uses of data within national plans and priorities for EHR systems,

- Implementation of plans for data uses,

- Legislative frameworks that enable statistical and research uses of data, subject to safeguards, and

- Investments in national health information from data within EHR systems.

14. Datasets and statistical projects in leading countries are summarised and the top tier of countries with respect to health data governance readiness are identified.

15. Part 4 of this report concludes with an overall assessment of the technical, operational and health data governance readiness of countries to further develop health information from data within EHR systems and the outlook for the future, including recent strategic investments. Countries in the top tier for both data governance and technical and operational readiness are identified. The need for on-going monitoring at the international level and for harmonisation toward best practices are emphasised, so that more countries can benefit from data within EHR systems to improve health care quality, health system performance, patient experiences and outcomes, and to further medical research and other public policy objectives.

16. In parallel to these HCQI surveys has been an effort within the OECD to develop a questionnaire that could be used to benchmark internationally the development and use of information and communications technologies in the health sector. Unlike the HCQI project where country experts respond to the survey, this benchmarking effort is aimed toward surveying representative samples of health care providers and organisations within OECD countries in a comparable manner. First results from pilot data 
collection in a large number of countries provides interesting insights that complement the findings of this HCQI study (See Box 1).

\section{Box 1: OECD project to internationally benchmark ICT adoption and use}

An OECD pilot study has compiled results for 38 countries for a subset of measures of the availability and use of information and communications technologies (ICT) in health care. ${ }^{1}$ Data for the study were obtained from new or adapted country-specific or multi-national surveys of health care providers and organisations from 2012 to 2015. Data elements were selected for the study by assuring they matched or were comparable with a set of survey questions that were previously developed by the OECD for the international benchmarking of ICT adoption and use.

The study found widespread use of electronic clinical records at the point of care; however, the exchange of electronic clinical records across health care organisations and settings was less common. There were also large variations in the availability and use of telehealth services across countries, such as services linking patients living in rural and remote locations to their health care teams via the use of technologies. Also, in many countries, patients were not able to access their test results online, book appointments electronically, renew prescriptions electronically or exchange secure messages with their health care providers.

'Zelmer J, Ronchi E, Hyppönen $\mathrm{H}$ et al (2016), International health IT benchmarking: learning from cross-country comparisons, Journal of the American Medical Informatics Association, 22 August. 


\section{TECHNICAL AND OPERATIONAL FACTORS SUPPORTING STATISTICAL AND RESEARCH USES OF EHR DATA}

17. This study examined a set of key technical and operational factors supporting the development of EHR systems that will contain high quality data that would be suitable for national monitoring and for research. These are among the same factors that would be considered when evaluating the quality of data within any statistical system and include: data coverage, completeness, accuracy, and usability.

18. Figure 2 presents a summary of where countries stand in relation to technical and operational readiness to support statistical and research uses of EHRs (See also Table 1 in Annex 2). Countries with the highest technical and operational readiness, such as Finland, Singapore, Estonia, Slovakia and England (United Kingdom) are in the best position to develop national health information from data within EHRs. This is not to indicate that all of these countries intend to advance the statistical or research use of EHR data, nor that they have the financial resources or plans in place to move forward, as will be further discussed in Section 3.

Figure 2: Technical and operational readiness to provide national health information from EHRs

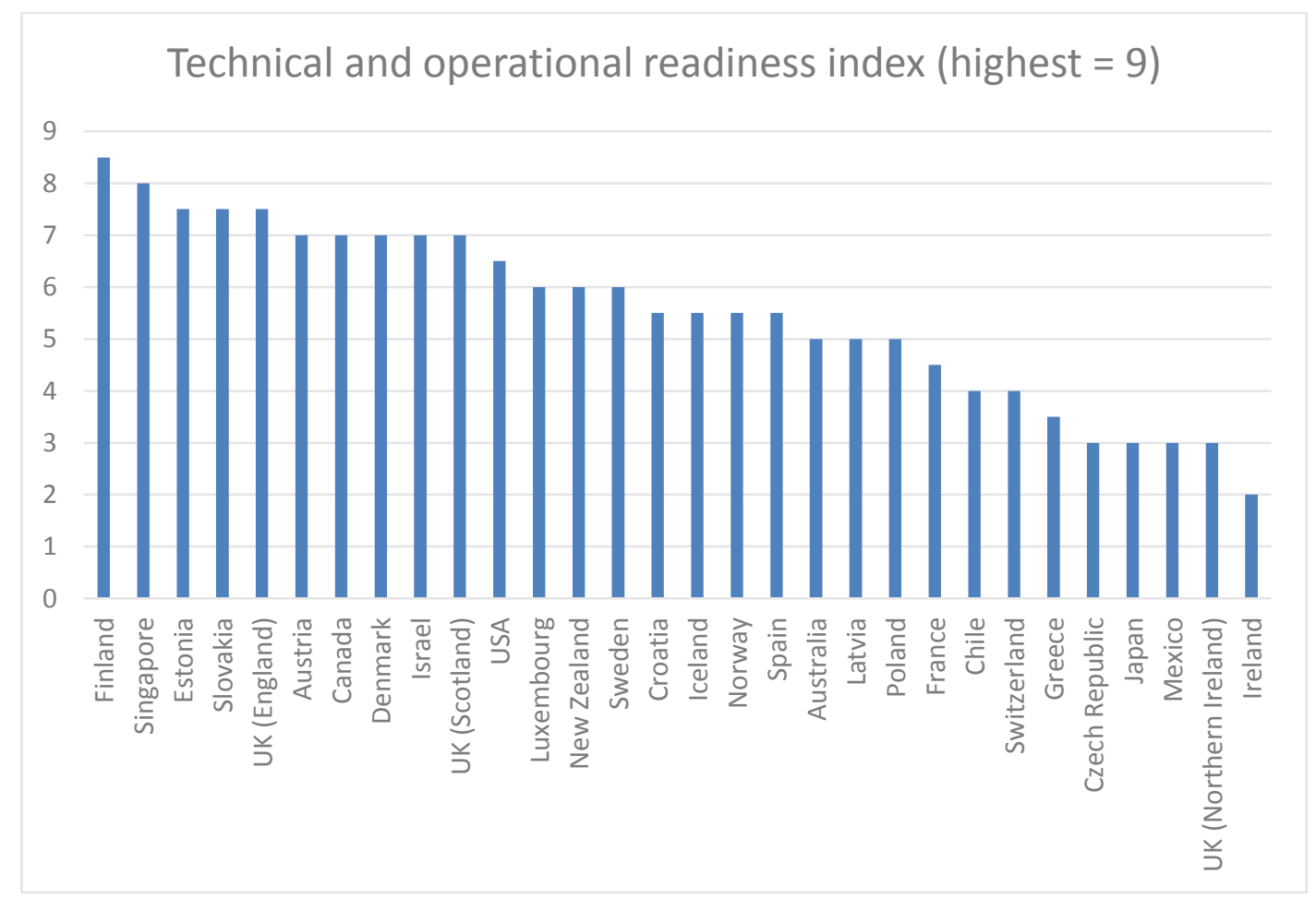

Note: Cumulative score of nine indicators each valued at one point: EMR coverage, information sharing among physicians and hospitals, defined minimum dataset, use of structured data, unique record identification, national standardisation of terminology and electronic messaging, legal requirements for adoption, software vendor certification and incentives for adoption (see Table 1 for the technical and operational readiness indicators).

Source: HCQI Survey of Electronic Health Record System Development and Use, 2016 


\subsection{The use of electronic clinical records in physician offices and hospitals is improving}

19. OECD countries vary greatly in the degree to which general practice physician offices, medical specialist physician offices and hospitals are using electronic clinical records (Table 2). Countries with high coverage of the patient population will have a significant advantage in the development of health information from data extracted from EHRs.

20. Seventeen countries reported that at least $90 \%$ of hospitals are capturing diagnoses and treatment information within electronic patient records. Seventeen countries reported that at least $90 \%$ of primary care physician offices are capturing patient diagnosis and treatment information in electronic medical records. Fewer countries reported such a high penetration of electronic record keeping in hospital emergency rooms (13 countries) and in medical specialist physician offices ( 9 countries).

21. Conversely, Croatia, Mexico and Poland reported that less than one-third of primary care physician offices are using electronic medical records and Australia reported that less than one-third of hospitals are using electronic patient records for in-patients. Further, several countries lacked the data to estimate the penetration of electronic clinical record keeping, particularly for medical specialists (five countries) and hospital emergency rooms (eight countries).

22. Many countries with a low penetration of electronic clinical record keeping in 2012 were significantly improved in 2016. A near-doubling or better in the proportion of physician offices with electronic medical record keeping were reported in Canada, Denmark, Japan, Mexico, Poland, and Singapore. Similar gains were reported for medical specialist physician offices in Canada, Denmark, Japan, Poland and Spain; for hospital in-patients in Japan and Poland; and for hospital emergency rooms in Spain.

23. Further, data about the penetration of electronic record keeping has improved. Eight countries reported data in 2016 for categories where data were unavailable in 2012.

\subsection{Most countries are implementing one "country-wide" electronic health record system}

24. Twenty-three countries reported that they are implementing an electronic health record system at the national level (Table 3). Most of these countries indicated that they are implementing or have implemented one country-wide EHR system. Countries not implementing, or not yet implementing, an electronic health record system at the national level are Chile, Croatia, Czech Republic, Denmark, Japan, Mexico, New Zealand and the United States.

25. Where capacity exists to identify a longitudinal patient history regarding diagnosis, treatment and outcomes there is fundamental strength enabling health information about health care pathways and outcomes.

\subsubsection{One "country-wide" EHR system with comprehensive record sharing-One patient, One record}

26. Part of the benefits of electronic clinical record sharing includes enabling treating professionals to have a comprehensive view of their patients' complete history of diagnosis, medications, procedures, laboratory tests, and medical images from the multiple providers that may have treated their patients. Such sharing reduces unnecessary duplication of tests and images, avoids inappropriate prescribing and can benefit more appropriate decision-making about treatment options. Further benefits of record sharing include more efficient service provision, through automated requests for referrals, admissions, medications, tests and images; and better communication with patients through record sharing portals. 
27. Eighteen countries reported comprehensive record sharing within one "country-wide" system designed to support each patient having only one electronic health record (Table 3). These countries are Australia, Estonia, Finland, France, Greece, Iceland, Ireland, Israel, Latvia, Luxembourg, New Zealand, Norway, Poland, Singapore, Slovakia and United Kingdom (England, Northern Ireland and Scotland). In these countries, plans call for patient records to be shared among physician offices and between physicians and hospitals regarding patient treatment, current medications, and laboratory tests and medical images. Some have already achieved this functionality, while others are progressing toward it.

28. In Australia, the My Health Record system is a nation-wide electronic health record system that contains a summary of a patient's health information. Patient information (in the form of clinical documents) are uploaded to the system by participating healthcare providers from across the private and public sectors. About one quarter of primary care physicians in Australia can electronically exchange patient summaries and test results with doctors outside of their practice. Most primary care physicians can, however, receive lab test and image results electronically. Medical specialist offices in Australia, however, are typically not exchanging information electronically. Australian states are in different stages of implementation of state-wide electronic records for hospitals, with the state of New South Wales being the most advanced and having integrated 100 hospitals within the state-wide EMR ${ }^{2}$. All states have also begun sharing discharge summaries, diagnostic documents, specialist letters, prescription documents, dispense documents, event summaries, and shared health summaries within the national EHR system. In three states, the majority of hospitals are contributing to the national EHR system.

29. In Estonia, there is one national Health Information System (TIS). There are agreed data standards and functionalities in use at the locations where data are entered and the system is supported by an efficient framework for data processing that includes relevant national applications. The goal is to achieve the accessibility of standardised digital data for all users. In Estonia, primary care and medical specialist physician offices and hospitals are able to send and receive laboratory test or medical imaging results electronically; are able to see and update an electronic medications list for their patients that includes any current medications prescribed by other physicians; are able to see hospital in-patient and emergency room records for their patients electronically; and are able to see and update an electronic health record for their patients including diagnosis and treatment information from multiple physicians and over time.

30. Finland has a national electronic patient record depository and interoperable data while enabling health care providers to have their own EMR or EPR systems. Finland has fully implemented a national health information system for sharing patient data at the regional level and the system is obligatory for public sector primary care and medical specialist physicians and hospitals. Physician offices in the private sector are permitted to join the national system and their implementation into the system has started. Functionality includes sharing full plain text medical records, ePrescriptions and sending and receiving laboratory tests and medical images; and medication lists.

31. France established a national shared patient record called the Personal Medical File (DMP) by law in 2004. The DMP is a computerised medical record that is created and accessed by health professionals with the consent of the patient. A patient's DMP includes diagnosis, treatment, emergency records, prescriptions, laboratory tests and imaging results, and hospital discharge summaries. The DMP system permits record sharing among primary care physicians, medical specialists, hospitals and with some health care workers, such as nurses and physiotherapists. The DMP has been available on-line since 2011 and by 2014 about 400000 files had been created. The DMP system was deemed to meet general information security standards (RGS) in 2015.

\footnotetext{
${ }^{2}$ For more information about the NSW Health EMR program, visit: http://www.ehealth.nsw.gov.au/programs/clinical/emr
} 
32. Luxembourg's primary care and medical specialist physicians and hospitals share patient summaries, laboratory test and medical imaging results, prescriptions and hospital discharge letters.

33. The EHR systems of every hospital and primary health care clinic in Iceland are interconnected enabling patient health information to be shared among different health care organizations country-wide. All health care providers have access to e-Prescriptions and dispensed medication on a national level. All primary care physician offices and all hospitals share digital patient information across health care institutions and geographical boundaries. Electronic prescriptions and dispensed medications are shared on a national level among primary care physicians, medical specialists and hospitals. Medical specialist offices in Iceland benefit from the sharing of laboratory tests and medical images and physician referrals electronically but only some have electronic access to hospital in-patient and emergency room patient records. Preparations are underway now to fully connect medical specialists' offices.

34. The national health information exchange platform in Israel (OFEK) has been implemented in all acute care hospitals in all HMOs and in all public mental health and geriatric hospitals. Hospital medical specialists are in the process of being electronically connected to the platform. When specialists want to view all information on a patient, collected from all HMOs and hospitals in Israel, they can import the relevant data from the platform. Within each HMO, electronic patient records are shared among physicians and hospitals. Functionality includes requesting and receiving laboratory tests and medical images, maintaining medication lists, and diagnosis and treatment information.

35. Hospitals, primary care and medical specialists in New Zealand all have local or regional electronic medical records (EMR) that will share information with the national EHR. Currently most hospitals, primary care and medical specialists have local access to patient records including tests results, images, demographics, eDischarge summaries, eReferrals and clinic letters. Primary care systems are largely electronic and some primary care physicians allow other health care providers, such as hospitals and emergency departments, to view patient information through a portal. Referrals and hospital discharge summaries are exchanged electronically between hospitals and primary care. Primary care physicians can transfer patient records to a new primary care practice electronically through a national information exchange system. Most primary care providers can access lab test results electronically and some can access medication histories. Hospitals and medical specialists within hospitals in New Zealand have access to patients' electronic records including tests results, images, demographics, eDischarge summaries, eReferrals and clinic letters. A few hospitals have electronic prescribing systems and can share a patients prescribed medicines. Some hospitals send out-patient clinic letters electronically. Most clinical notes, however, are still paper based in hospitals. Medical specialists outside hospitals have local EMRs that are not shared. They may, however, be able to access a central data repository to see test results and, in some cases, medical images.

36. Norway has had a national infrastructure for electronic messaging since 2004 (National Health Net) for primary care and medical specialist physicians. This includes electronic messaging for laboratory tests and image orders and replies; ePrescriptions, electronic referrals to specialists and hospitals; and discharge summaries from hospitals. The national infrastructure extends to hospitals; however, not all hospitals have implemented the system or started using the functionality. Most hospital groups share a common EPR system but the sharing of electronic information across groups has been challenging and is a major driver behind the development of a new national eHealth strategy.

37. Poland is implementing the national Internet Patient Account as part of the "Electronic Platform for Collection, Analysis and Sharing of Digital Medical Record" project. Some regions in Poland have developed a regional platform; however not all medical entities in those regions have joined them. In Poland, groups of primary care physicians concentrated within the same regional platform are sharing laboratory tests and imaging results. Two private healthcare networks are sharing medical record data 
about visits and laboratory results among primary care and medical specialist physicians. Some hospitals that are concentrated within regional platforms, are sharing laboratory and medical imaging results with physicians in the same platform. There have been some interoperability standards created but there is not yet much sharing of data electronically in hospitals. Medical information exchange will advance in the near future as a regulation requires all providers to use electronic records by 2017.

38. A country-wide National Electronic Health Record (NEHR) system has been implemented in Singapore and includes an Electronic Medical Record Exchange (EMRX) and a national database of patient allergy information. In Singapore, all public sector primary care and medical specialist physician offices share information nationally as part of a 'One Patient, One Health Record' vision. There is an increasing proportion of private sector physician offices obtaining access to electronic information, although their contribution to shared information is limited by current IT capabilities. The sharing of electronic information among hospitals is facilitated through a centralised exchange solution for public sector institutions.

39. Information sharing among primary care and medical specialist physician offices and hospitals in the United Kingdom, England is intended to be comprehensive, however, not all physicians and hospitals have the full range of information sharing capabilities yet. In the United Kingdom, England, the national summary care record has been implemented and currently covers $96 \%$ of the population.

40. Similarly, the United Kingdom, Scotland has a summary of every patient's primary care record that is shared at national level. A single type of Patient Management System is being implemented by National Health Service hospitals throughout Scotland although the functionality varies locally. There is no full national interoperability, and primary care, out-of-hours care and other sections of the health service use different systems. Clinical portals and data stores are in place for sub-national sharing of records, such as images and test results. Many parts of a patient's electronic health record are captured in systems which do not link to core National Health Service systems, e.g. community pharmacist and dentist systems. Summary patient records from primary care physicians, including a list of prescribed medications, are routinely shared with other parts of the health service including hospitals for all patients except those who have actively opted out. In addition, more extensive patient summaries are shared more widely for patients with long term conditions or complex care needs. Prescriptions from primary care physicians are electronically shared with dispensing pharmacists. Primary care physicians' access hospital discharge letters, and most images and test results electronically. Similarly, medical specialists, who are all within hospitals, can view lab and imaging results through a central database either in a specific store or via clinical portals within hospitals. Hospital physicians and specialists can see key information from primary care records, including a list of medications prescribed, through routinely shared electronic summaries and hospital medical specialists in some regions can also view a shared patient record through a clinical portal. Most medical staff in hospitals are able to update patient records electronically but only those in a few areas in Scotland are able to update medications electronically as this is still mostly on paper.

41. In the United Kingdom, Northern Ireland has a shared electronic care record among primary care physicians, medical specialist physicians and hospitals that includes lab test and medical imaging results; discharge, clinic and primary care physician letters; patient care summaries; out-of-hours and emergency care encounters; prescribed medicines; and adverse reactions and allergies. Plans are underway to allow the recording of diagnosis and to manage prescription medicines within the shared record. All primary care and medical specialist physicians receive laboratory tests and medical images electronically.

42. In Latvia, the United Electronic Health Information System is a national system that is expected to become available in 2016. The system is authorised by regulation and will be mandatory for health care institutions and pharmacies. By the end of 2016, health care institutions and pharmacies will be required to conclude a contract with the National Health Service and commence using e-prescription and e-sick-leave 
functions. On 1 July, 2017, other functionalities of the Electronic Health Record System, such as e-referral and patient summaries will be required. Patients will be able to access the system via an e-health portal, and health care institutions and pharmacies will access the system via the e-health portal or a web-based data exchange with the organisations' information system. ${ }^{3}$ Currently in Latvia, electronic sharing of patient data occurs mostly within single medical institutions and hospitals. It is common practice for laboratory results to be provided back to referring physicians electronically. In some cases, medical images are shared among medical institutions.

43. In Slovakia, a country-wide electronic health record system has been implemented and is undergoing pilot testing in 2016. In Slovakia today, many primary care and medical specialist physicians receive laboratory test results electronically and some receive images electronically. Slovakia is developing its system to allow for the sharing of patient consolidated medications lists and the sharing of patient records among physicians, between physicians and hospitals, and among hospitals.

44. Norway is developing a strategy for an integrated national EHR system which includes the sharing of health information among all health care providers, integrated decision-support systems, and a patient administrative system. Norway has already implemented a national ePrescription system. A summary care record is being used for acute and elective care in hospitals and is available for use in primary care, although adoption in this sector is low. The summary care record is a web based system which extracts information from the population registry, primary care, hospital and ePrescription databases. Norway also has an electronic messaging system with semi-structured content standards.

45. Greece has national information sharing for instructions and eReferrals for prescription medications by primary care and medical specialist physicians. The national system for ePrescribing in Greece is web-based.

46. A business case is awaiting approval to launch the national electronic health record system in Ireland. ${ }^{4}$ Primary care physicians and a minority of medical specialists in Ireland are able to receive laboratory test and medical imaging results electronically and to make eReferrals for hospital appointments. Some hospitals also have electronic ordering of tests and images. There is a national project to enable the secure exchange of information among hospitals, health care agencies and primary care physicians.

\subsubsection{National EHR system with sub-national exchange of comprehensive records}

47. A few countries have one national EHR system, but within it, some key aspects of record sharing are sub-national only, such as within provinces, states, regions or networks of health care organisations (Austria, Canada, Sweden, Spain and Switzerland; Table 3). Among them, all but Canada, have implemented or are implementing a national information exchange that enables key elements to be shared country-wide.

48. In Austria, there is one national system that virtually links patient records through a national health information exchange. The system enables physicians and hospitals to receive laboratory test results, medical imaging results and hospital discharge letters electronically. The sharing of electronic patient or medical records is at a regional level.

\footnotetext{
3 The manager of the system is National Health Service (http://www.vmnvd.gov.lv/en/644-about-nhs). The development of the system was started in 2009/2010 and it will be available for patients, health care institutions and pharmacies in 2016.

${ }^{4}$ See http://www.ehealthireland.ie/Strategic-Programmes/Electronic-Health-Record-EHR-/ .
} 
49. In Sweden, the National Patient Summary provides an overview of patient data by virtually linking connected EMRs and does not store the summary data. In Sweden, patient data is mainly being shared between different care units (hospitals and primary care) within the same health authority (county council). In most cases, care givers contracted by the health authority may share patient data with other health care providers within the health authority's system.

50. Spain has a National Health Record System in order to enhance interoperability of clinical information systems among regions. The aim is to facilitate access to electronic clinical information regardless of the location in which the patient demands healthcare, increasing healthcare quality as well as patient safety. In Spain, a central national node acts as a hub for messaging services between Health Services in each territory. Territorial nodes concentrate EHR information from diverse systems through integration platforms that are managed by each healthcare authority. Document coverage is not yet complete; however it progresses significantly each year. It includes a selection of 9 document types, and is not covering all documents that are available in local systems. In Spain, electronic information sharing is mostly within health centres and primary care networks or within hospitals and hospital networks. In some regions, hospitals share records with a central record system including clinical summaries and, in some cases, laboratory test and medical imaging results and other reports.

51. In Switzerland, the national EHR law was approved in summer 2015 and will come into force in 2017. The law enables health data exchange among health care institutions at the national level. Health care providers (primary care physicians, hospitals and others) are required to become certified before being granted access to a secure national health data exchange system. Participation in the system is not mandatory for patients and the exchange of patient data is subject to patients' consent. Statutory health service providers are obliged to join the system after a transition period of 3-5 years (depending on the type of institution). For primary care physicians, participation in the platform is voluntary. Health data in the system will remain at the regional/local level. In the current situation in Switzerland, about two-thirds of primary care physicians use their electronic systems primarily for administrative purposes (e.g. billing). There are some regional projects enabling primary care physicians to access patient data repositories within hospitals. Primary care physicians receive laboratory test and medical image results electronically.

52. In Canada, health care is a provincial/territorial responsibility and each of the thirteen jurisdictions has their own Electronic Health Record (EHR) deployment project underway. While there is no national EHR system, many jurisdictions have modelled their system according to a common blueprint established by Canada Health Infoway. General practitioners in some Canadian provinces and territories access patients' lab tests, images and prescription medications, and receive hospital discharge summaries and some can also request medications, lab tests, and images electronically. In 2014, a national survey indicated that about $82 \%$ of primary care physicians and $78 \%$ of medical specialists had an electronic interface to request and receive laboratory and medical imaging results. The majority of primary care and medical specialist physicians, however, did not report an external interface to pharmacies, nor a provincewide exchange of medication information among care providers. Most primary care and specialist physicians can, however, connect directly to provincial/territorial drug information systems where the pharmacies record dispensed information. The most common form of electronic sharing of data by hospitals is the sharing of discharge summaries and other clinical documents with primary care physicians. For example, the Connecting Ontario system brings together local, regional and provincial assets in different parts of the province -- connecting them to improve patient care.

\subsubsection{Limited Record sharing in most countries that are not aiming toward a national system}

53. Seven countries indicated that they are not aiming to implement an EHR system at the national level at this time (Chile, Croatia, Czech Republic, Denmark, Japan, Mexico, and the United States; Table 3). Croatia and Denmark report aspects of record sharing that are comprehensive at the 
national level. In the other countries, sharing arrangements differ among health care organisations or regions.

54. In Denmark, the five regions are responsible for hospitals and the implementation of the EHR system is a regional responsibility. Each region has implemented a coherent system and are able to exchange large amounts of information through a joint information exchange infrastructure and the integration of platforms. Danish patients can access their own health information from all parties through a joint portal "sundhed.dk". Danish primary care and medical specialist physicians can access a comprehensive electronic health record for their patients and are able to send and receive laboratory tests and send prescriptions. All primary care and medical specialist physicians use ePrescribing in Denmark. Further they have electronic communication with hospitals, other physicians and specialists, physiotherapists and municipalities. The five regions have also implemented a joint EPR for the acute-care sector. All hospitals electronically share all discharge summaries, outpatient notes, casualty-ward notes, laboratory test orders, and laboratory test and medical image results between and among hospitals and with primary care and medical specialist physicians. These records are electronically accessible for professionals and patients through a national repository. Fully updated medication lists are shared automatically among hospitals and primary care and medical specialist physicians, and with patients, through a national medication database that includes medications dispensed by private (non-hospital) and hospital pharmacies. Medical image results are currently shared regionally, however, a national repository is being implemented.

55. Croatia enables primary care physicians to request ePrescriptions and to submit eReferrals to laboratories and to medical specialists in hospitals for diagnostic procedures. Pharmacies receive ePrescriptions and send dispensation information to a central system. Laboratories and hospitals return eFindings to the system, which are then retrieved by the primary care physician offices. Medical specialists in Croatia also benefit from e-Referrals for laboratory tests and medical images but rarely share diagnostic and other medical record information with other physicians. More advanced hospitals can store and exchange documents such as eReferrals and eFindings.

56. In Chile there is sharing of patient records among primary care physicians within healthcare districts where the physicians have the same EMR system. These systems may also allow eReferrals to medical specialists.

57. In the Czech Republic there may be some information sharing at the local level of lab test and medical image results and some interconnection among providers with the same EMR vendor. Multihospital health care providers in the Czech Republic share the same health information system within their respective hospitals. There are common national solutions for secure information and medical image exchange.

58. In Japan, the national strategy aims to implement the sharing and viewing of electronic records including examinations, prescription medicines and medical images at a sub-national level. For the new Japanese cancer registry, however, there is one national electronic system to gather the data. In Japan, sharing capabilities vary among the bodies implementing EMR systems, such as local governments, Prefectural Medical Associations or incorporated associations. Within these systems there may be sharing and viewing of medical record information among primary care physicians, medical specialists and hospitals and including prescription medicines and laboratory and medical imaging results. There is a nationally standardised format for the storage of hospital data including examination details and prescription medicines. 
59. In Mexico, major public health and social security institutions are able to share information between primary care offices, primary care units, and hospitals and related services within the same institution.

60. In the United States there is an array of different sharing capabilities that vary by state, by region and by provider network. The most prevalent types of exchange are e-prescribing, laboratory and medical imaging results, and sharing of care summary documents at the points where patients are transitioned or "handed off" between providers.

\subsection{Patients' can access their own electronic health records in over half of countries}

61. Increasingly countries are providing patients with a means to view their own electronic health records and in some cases to also interact with their records, such as the ability to input information about their status or about the outcomes, experiences or clinical incidents related to their care; or the ability to communicate with healthcare providers via a patient portal. Sharing EHR content with patients electronically opens an opportunity to record and maintain patient preferences regarding the use of their data to advance the quality and performance of health care systems and for medical research. A few countries have noted that they are using their patient portals to record the consent or preferences of patients regarding the sharing of records for direct care and for organ donation.

62. Thirteen countries reported that patients could both access and interact with their own electronic health records (Australia, Canada, Denmark, Estonia, France, Greece, Latvia, Luxembourg, New Zealand, Spain, Sweden, Switzerland and United Kingdom (Scotland), Table 4). A further nine countries reported that patients' can view their electronic health records and, in some cases, also interact with them in a limited way (Austria, Finland, Iceland, Mexico, Norway, Singapore, Slovakia, United Kingdom (England) and the United States).

63. In Australia, patients can access their "My Health Record" information online and can upload certain information about medicines, allergies and adverse reactions, emergency contacts and advance care directives. Individuals can also set privacy controls around their record.

64. Patients in Denmark have access to their own data through sundhed.dk. They can view information regarding medications, laboratory tests, hospital treatments, GP visits, measurements etc. Where Patient Reported Outcomes Measures (PROM) are implemented, patients can also input details about their own health status and the information is made available to their clinician.

65. The United Kingdom (England) provides patients with on-line access to their primary care record, the ability to book appointments and to order repeat prescriptions.

66. Patients in Estonia can view their own health records, grant permission and manage access to their records, view access logs, enter contact and demographic information, declare their preferences regarding blood transfusion, organ donation and donation of their body for scientific research after death; and apply for a health certificate.

67. In Sweden, the national Health Care Guide service $1177^{5}$ is an on-line service that includes an eService "Journal" which allows individuals to read their personal medical record on-line. However, the records available are not comprehensive. This service is currently available in 16 counties and regions and will be available nationwide by the end of 2016. The service includes read-only access to medical records, scheduling appointments, specialist referrals, prescription renewals and the ordering of some tests. Patients

\footnotetext{
${ }^{5}$ http://www.1177.se" www.1177.se
} 
can also choose a preferred family doctor or medical centre to set up safe communication with. "Health for me" is a national personal health account that is due for release in 2016. This account will make it possible for individuals to add personal information, health data from apps, and possibly other records in the future.

68. In Latvia, patients can view their data via a patient portal, they can also use the portal for an interactive consultation with their doctor, input contact details, and deny access to their data.

69. In France, patients can view their EHR record on-line and can request changes to their record. The health care professional who entered the data, however, must update the record for the patient. There are also areas in the record where patients can enter comments about their medical situation.

70. Similarly, in Luxembourg, patients can view their EHR, manage health care providers' access rights to their EHR, and input medical details and any self-measurements of their health through a "personal expression zone".

71. Patients in Finland can access their EHR electronically via the national data depository; and they can provide and refuse consent to share their records.

72. Austria provides a web portal where patients can access their own data. Patients may hide or delete documents from their record and there is an option provided to opt-out of the EHR system.

73. In Slovakia, patients can view their own EHR record and can enter comments. Patients in Greece can view their information and provide consent to share their data. In New Zealand, there is a primary care patient portal providing patients with access to their records and to shared care plans.

74. About $55 \%$ of patients can view their own electronic information within the national EHR system in Spain and access to electronic health records within regional systems is higher. Patients can also provide or limit consent to access their data, enter comments, and, in the national system, respond to surveys regarding the quality of services. All patients in Spain, however, can access their own health records (either paper or electronic) at regional level.

75. In Canada, there are some jurisdictional patient portals. Most portals allow viewing of clinical results or other health information, prescription renewals and appointment booking. Some enable patiententered information to be included as well.

76. In the United States, a growing number of patients are able to view, download, and transmit their health information electronically. There are efforts to promote the ability of patients to also input patient generated health data into their records.

77. Patients in Singapore can view some information via a "one-stop" online health information and service portal.

78. Switzerland will offer patients electronic access to their own records and will include the opportunity to consent to health care providers' access to their records, set levels of confidentiality applying to data within their record, supress records and input or upload data and information to their record. Patients can also request to close their record, and in consequence, the data will be deleted.

79. Iceland is planning to offer patients access to their EHR via the national patient portal. Currently, the portal allows patients to view prescribed and dispensed medications, renew prescriptions, view immunisation data, schedule primary care appointments, securely communicate with their health provider, express organ donation wishes, enter blood pressure measurements, and view access logs. 
80. In Norway, patients have the right to a paper-based transcript of their records at all levels. If they want to edit the information in their records, they must apply for the change to the health care organisation that entered the information into their record. If their application is denied, they can appeal the decision with the county health administration unit. Patients can view their own records electronically in one of five regions. A second region is implementing patient digital access and a third is planning to do so. The lack of patient access to their own records electronically is a concern that has been raised in national policy documents.

81. Mexico also indicates that patients have a legal right to access their own health records.

\subsection{Minimum datasets defined in 26 countries}

82. Countries were asked if they have defined a minimum set of data that could be shared among physicians treating the same patient. Minimum datasets are developed to promote the standardisation of shared information so that clinically-relevant and important information may be easily understood by treating professionals. The standardisation required for a minimum dataset also supports the extraction of consistent information from it for monitoring or research.

83. Twenty-six countries reported defining or implementing a national minimum dataset (Table 5). Very few countries, however, reported that electronic health records of at least $90 \%$ of patients contain this minimum dataset (Australia, Croatia, Denmark, United Kingdom-England, Finland, Iceland, Israel and Singapore). Five countries defined their minimum dataset within the past five years (Australia, Finland, Iceland, Latvia and Slovakia). Among the remaining countries with a minimum dataset, most defined it between five and ten years ago. A small group of countries defined their minimum datasets more than ten years ago (Canada, France, Israel, and United Kingdom (England and Scotland)).

\subsubsection{Key elements included within minimum datasets}

84. The most common elements included within minimum datasets were patients' unique identifying information and demographics ( 24 countries each); followed by unique identifiers for health care providers contributing to patients' records; patients' clinically relevant diagnostic concerns, such as chronic conditions and allergies; and patients' current medications (23 countries each). Less universal were patients' clinically relevant procedures, such as laboratory tests and surgeries (21 countries); clinically relevant physical characteristics, such as body mass (12 countries); clinically relevant behaviours, such as smoking and alcohol use (10 countries); socio-economic characteristics, such as education and occupation (10 countries); and clinically relevant psycho-social or cultural issues, such as caregivers and stressful events (5 countries).

85. In only eleven countries, were $80 \%$ or more of the key elements investigated in this study included in the national minimum dataset: Canada, Czech Republic, Denmark, Iceland, Luxembourg, New Zealand, Poland, Slovakia, Spain, Switzerland ${ }^{6}$ and the United States.

86. A few countries identified other key data elements within their national minimum datasets. These included vaccinations (Czech Republic, Finland, Latvia); emergency/next-of-kin contacts (Czech Republic, Norway); family medical history (France); disability group (Latvia); communications disabilities (Norway); hospital history (Norway); copies of patients' clinical letters/advanced directives (United Kingdom-Scotland, Spain); risk of domestic violence or child abuse (Spain); participation in clinical research studies (Spain); patients' option to restrict access to clinical information (Spain); and patients' history of past and planned visits (Sweden).

\footnotetext{
${ }^{6}$ To become mandatory in the future through a revision to the ordinance of the new EHR law.
} 


\subsection{Use of structured data}

87. Countries were asked the degree to which key data elements within electronic health records are structured data elements. Data elements are structured by using a controlled vocabulary (a terminology standard) such as SNOMED-CT. For example, data are entered using boxes, menus, codes or other aids to ensure they are entered the same way for each patient. Structured data can be easily extracted for monitoring and research uses because the data elements are comparable.

88. Unstructured data is free-flowing text with the vocabulary of the person's choice. Unstructured data is very difficult to analyse and, to examine large volumes of unstructured data, sophisticated natural language processing algorithms are necessary to "read" through the unstructured data and try to create structure by searching for words that could refer to the same concept (Liao et al, 2015).

89. Only eight countries reported that all or most electronic health records contained structured data for five key data elements in electronic health records (patient diagnosis, medications, laboratory test results, medical imaging results and surgical procedures) (Denmark, Estonia, Finland, Iceland, New Zealand, Japan, Singapore and United Kingdom (England)). Several more countries reported four key elements were structured for all or most records (Austria, Canada, Croatia, Israel, Latvia, Mexico, United Kingdom (Scotland), and United States). There was no improvement since 2012 in this indicator in virtually all of the countries that participated in both studies (Table 6).

90. Very few countries reported that all or most records contained structured data for other important elements of electronic health records. Eight countries reported that all or most records had structured data for patients' socio-economic characteristics, five reported this for physical characteristics, two for health behaviours, and one for psycho-social or cultural issues.

\subsubsection{Use of common international standards to structure key data elements in electronic health records is high for diagnosis, medicines, tests and images}

91. Countries were asked to provide the terminology standards in use for key data elements within electronic health records. The use of international standards is high for diagnosis, medicines, laboratory tests and medical images (Table 7). For diagnosis, twenty-six countries indicated that they were using the World Health Organisation's International Statistical Classification of Diseases and Related Health Problems (ICD) revision 10 or, in some cases, revision 9; and six countries reported the Systematized Nomenclature of Medicine -- Clinical Terms (SNOMED CT). For medicines, thirteen countries indicated the use of the World Health Organisation's Anatomical-Therapeutical-Chemical Classification (ATC); and four countries indicated the use of SNOMED CT. Thirteen reported the Logical Observation Identifiers Names and Codes (LOINC) standard for laboratory tests; and four reported SNOMED CT. Fourteen countries reported using the Digital Imaging and Communications in Medicine (DICOM) standard for the sharing of medical images; and three reported SNOMED CT.

92. There is much less convergence toward a common standard for surgical procedures. Seven countries reported ICD 9 or 10; six countries reported the NOMESCO classification of surgical procedures (NCSP); and five countries reported SNOMED CT.

93. Standards are lacking for other key dimensions of electronic health records and there is little use of common international standards (Table 7). Three countries indicated the LOINC standard for patients' clinically relevant physical characteristics, such as body mass, and two countries reported SNOMED CT. Similarly, for patients' relevant health behaviours, such as smoking, four countries indicated SNOMED 
CT. Three countries indicated the Health Level Seven (HL7) standard for patients' socio-economic status, such as marital status or occupation.

94. There were no common international standards reported for clinically relevant psycho-social or cultural issues, such as caregivers and stressful events; nor for patient-reported outcomes or experiences of health care.

95. In general, countries provided a more complete picture of the national and international standards in use across the key data elements in 2016 than was the case in 2012. This does not indicate clearly, however, that there has been growth in the use of data element standards within electronic health records. This is because the results likely indicate a more complete reporting to the OECD in 2016 than was the case in 2012.

\subsubsection{Patient-reported outcomes and patient experiences data in electronic health records in nine countries}

96. Countries were asked if their electronic health records were capturing patient reported outcomes of care (PROM) or patient experiences of care (PREM). PROM provide the patient's perspective on their own health status and quality of life and can provide clinicians with a fulsome view of patient health and recovery following treatment. PREM provide patients' perspectives on their experience of health care, such as the care process and any safety-related concerns and PREM results help organisations to improve services. Both PROM and PREM provide important indications of the functioning of the health system for health care quality and health system performance monitoring and research.

97. No countries indicated that all or most records contained either PROM or PREM. A few countries, however, indicated that some electronic records in their countries have captured (or are planning to capture) elements of this nature as structured data (Canada, Chile, Denmark, United Kingdom (England and Scotland), Luxembourg, Mexico, New Zealand, Singapore and Switzerland).

98. In Denmark, two large regions (Capital and Sealand) are acquiring a system (EPIC) that will contain structured data for these types of elements. In Canada, CIHI has developed a database of inpatient experiences (CPERS) and has started to receive structured data. A few countries indicated efforts to measure PROMS and PREMS are undertaken outside of the electronic health record, such as through surveys.

\subsection{Use of cloud computing services is low}

99. The volume of EHR data tends to grow exponentially in the years following system implementation given the need to archive patient histories. Many industries with large data volumes have turned to cloud computing services for support. Cloud computing service providers offer a range of information technology services over the Internet including computer servers, data storage, virtual desktops and platforms for software development. Countries were asked if they managed, stored and processed EHR system data using dedicated on-site hardware or cloud computing services.

100. A few countries reported using cloud computing services for all or some aspects of their EHR system data (Canada, Greece, Iceland, Latvia, and Luxembourg). Canada is using cloud computing services for several provincial/territorial EHR domains (client registry, provider registry, medications, labs, diagnostic imaging, immunizations, and some reports). Slovakia is planning to use cloud computing services for data management, storage and processing.

101. Australia, Norway, Switzerland and the United States indicated that some health care organisations may be using cloud services for EHR data depending on their local EHR system vendor. In 
Norway, this most often occurs when the vendor offers a web-based EMR solution; however, web-based EMRs are rare in Norway and are only commonly adopted by psychologists. Mexico identified privatesector health care providers as users of cloud services for EHR data.

102. The United Kingdom Scotland and Mexico are considering the use of cloud services. Several countries also noted that while they are able to provide dedicated hardware now, there may come a time in the future when cloud services will be considered. Still others cited legal barriers and data security concerns as factors limiting the future use of cloud computing.

\subsection{Widespread use of a unique patient ID number in electronic health records}

103. Unique patient identification is essential to the development of a longitudinal electronic health record for patients that is complete and reliable while containing input from multiple health care providers over time. Unique identification also supports data quality checks and facilitates the linkage of EHR data to other health-related datasets for approved statistical and research projects.

104. Virtually all countries (27 countries) reported a unique patient identifier is used within electronic health records. This total is reflective of key changes in several countries since the last OECD study in 2012.

105. Austria reported in 2012 that a unique health care ID was under development. In 2016, this unique healthcare ID is in use and a master patient index has been created to match it with local IDs.

106. In Switzerland, the new law that establishes the electronic health record system authorises a unique health care patient identifier and specifies how it may be used. The ID is allowed as one of the attributes of a Master Patient Index.

107. Ireland introduced a new Health Identifiers Act in 2014 that is currently being implemented that establishes unique patient identification.

108. In France, there was unique identification in place for health care electronic records, called the INS-C. The INS-C should soon be replaced by the already existing social security number called NIR which is issued at birth.

109. In Chile, there is a unique national number to identify citizens/residents. From it, a nation-wide Master Patient Index service will be generated and provided to the health sector for use within their information systems.

110. Canada does not have unique patient identification at a national level, however Canada reports unique patient identification within each province and territory that is used in their electronic health record systems.

111. A small number of countries remain without unique patient identification at a national level (Japan and United States). Medical institutions in Japan identify patients with institution-specific registration cards. When records are shared among medical institutions, patients' names and birthdates are used to match records. The government of the United States is legally prohibited from working toward or promoting the development of a unique patient identifier. While the US private sector could voluntarily undertake to develop such an identifier, it may not be acceptable to the majority of citizens for cultural reasons. 


\subsubsection{Unique identification of health care providers entering data into EHRs is improving}

112. Over three-quarters of the countries participating in this $\mathbf{2 0 1 6}$ study indicated that they have a unique identifying number for health care providers entering data into electronic health records ( 24 countries, Table 8). While the mix of participating countries is different in 2016 from 2012, at that time, only $56 \%$ of countries reported unique provider identification for use in their EHR systems. Such identification supports health care quality monitoring and provider payment systems and also facilitates data quality checks and statistical and research uses of the data.

113. Countries that participated in the 2012 study that are now indicating a unique health care provider ID include Austria, Denmark, Israel, Mexico and United States. In Austria, there is a unique ID for healthcare providers that is registered in a health care provider index. Denmark reports that every doctor, nurse and midwife has an authorisation ID. In Mexico there is a unique professional licence number that is being used for identification. In the United States, the national provider number that is required for health care provision that is publicly reimbursed is in widespread use.

114. Further, Chile, Ireland, Spain and Slovakia are moving forward plans for unique professional identification. In Chile, there is a unique national number identifying citizens and residents. From it, a nation-wide Master Provider Index service will be generated and provided for the usage of information systems within the healthcare sector. Ireland is also developing a provider identifier, and it will be used in both the health and social care settings. In Spain, each health authority is responsible for professional identification; however, there are plans for a national registry of professionals. Slovakia is moving forward from piloting a unique professional ID card to widespread implementation.

115. In Canada, each provincial and territorial jurisdiction is responsible for its own provider identity management system. While there is widespread use of provider IDs, there is a lack of consistency across the jurisdictions in the range of provider roles that are included in jurisdictional registries. Also, most provider identity management systems rely upon information sourced from jurisdictional regulatory bodies, and how this information is provided is inconsistent. Some feasibility studies regarding a National Unique Identifier for providers have been undertaken at the national level.

116. Countries not reporting a national ID number for health care providers entering data into electronic health records are United Kingdom (Scotland), Czech Republic and Japan. In the United Kingdom (Scotland) there are different sets of provider identifiers that are being used in different care settings and they are not always used consistently in all record systems. The Czech Republic relies upon software vendors to assure unique identification as part of their agreements with providers. Similarly, individual medical record systems in Japan have authentication by ID and password and, when strict identification is needed, Public Key Infrastructure technology is used.

\subsubsection{Half of countries use smart cards for unique identification of patients and health care providers}

117. Smart cards contain an embedded microprocessor that provides for the secure identification of patients and health care providers and can facilitate secure access to records and services on-line for both groups. With this technology it is possible to store within the card itself some essential elements from patients' EHRs to assist with patient care in an emergency.

118. Fifteen countries reported issuing smart cards for the unique identification of patients or health care providers in 2016 (Table 8). Eight countries reported smart cards for both patients and health care providers (Austria, Estonia, France, Iceland, Luxembourg, Slovakia, Spain and Switzerland). Austria has implemented the use of smart cards for patient identification and for the 
identification of physician offices only. Slovakia has piloted a smart card for health care providers and is preparing to widely introduce the card.

119. In Spain, health cards provide a unique personal identification code. To access electronic clinical information, patients also need a National Identification Card, which contains an electronic certificate. The distribution of smart cards to patients in Spain has reached 80\%. The distribution of electronic certificates to professionals is in progress.

120. Switzerland issues smart cards for health insurance which could be used for identification, however, the current planning for the EHR system foresees the use of certified authentication, by means such as mobile phones. Many health care providers in Switzerland have a smart professional identify card and in some regional EHR projects, this is being used for identification.

121. Five countries have issued smart cards for health care provider identification but not for patient identification (Croatia, United Kingdom (England), Finland, Norway, and Sweden)

122. In Croatia all data submitted by physicians to the EHR system are digitally signed by their smart card. There is a plan to issue smart cards to patients but it has not yet been implemented. Finland uses smart cards to authenticate identification of health care providers but uses a different system to uniquely identify patients accessing their own records over the Internet. Israel has smart cards for providers that are issued by HMOs and it is planning to issue smart cards to patients. In Norway, there are smart citizen/resident identity cards that patients use to access digital services on-line, such as prescription renewals. However, smart cards are not used when accessing health care services. There are smart cards for health care providers in Norway, however they are not fully implemented across professional groups.

123. Australia reports using Public Key Infrastructure (PKI) technology to securely transfer data within the Electronic health record system. Such technology is used for secure transactions in eCommerce and banking. Through a registration process and the issuance of certificates, individuals and organisations responsible for electronic health records in the My Health Record system can be bound to certain keys which are then used to authenticate their identity. 


\section{DATA QUALITY CHALLENGES THAT LIMIT DATA USE AND EFFORTS TO ADDRESS THEM}

124. Countries that are investing in developing their health information systems with data from EHRs, and in making this data available to advance health and health care monitoring and research, are encountering numerous technical and financial challenges.

125. Ten countries reported that there is more than one definition of a minimum dataset in use in their country such that the content of the data is inconsistent among electronic record systems in different regions, different states or different networks of health care organisations (Australia, Austria, Canada, Chile, Ireland, United Kingdom (Northern Ireland), Norway, Poland, Sweden and United States).

126. Reasons for this heterogeneity include decentralised health care systems where different regions, states or health care networks have implemented their own minimum datasets and conform voluntarily to nationally recommended standards; a lack of national standards leading to different software vendors offering different minimum dataset specifications; having more than one nationally defined minimum dataset (such as general and disease-specific specifications); and inconsistency in the completion of the required national dataset elements.

127. Seventeen countries expressed concerns with the quality of data within electronic health record systems and fourteen countries indicated that these concerns are limiting the ability to develop datasets for monitoring or research (Table 11). Specific concerns raised by countries included:

- A lack of, or inadequate, terminology standards or the use of different terminology standards for the same terms (Canada, Croatia, Norway, Spain, Sweden, United States);

- Incomplete records or records that are not kept up-to-date (United Kingdom (England), Iceland);

- Variable quality of provider-level record keeping (Finland, Singapore, United Kingdom (Scotland));

- Lack of provider-level quality checks (Iceland, United Kingdom (Scotland));

- Low quality disease or procedure coding by some health care providers (Israel, Mexico);

- Incomplete coverage of providers (Spain, Switzerland);

- Incomplete coverage of structured patient summaries/minimum dataset (Estonia, Finland);

- Assuring the data will be fit to fulfil multiple purposes (Australia);

- Legacy systems that are difficult or impossible to adjust to required structure or standards (Austria, Canada);

- Lack of standard formats and structure for dataset creation (Canada); 
- Inadequate patient identification for record matching across providers (United Kingdom (Northern Ireland)); and

- Transitional difficulties due to maintaining duplicate paper and electronic records (Spain).

128. This section discusses these data quality concerns and focusses on the efforts and solutions that have been adopted in some jurisdictions that could potentially address some these data quality concerns. These include setting and governing national terminology and interoperability standards; creating a nationally standardised minimum dataset; and using policy levers (legislation, certification, financial incentives) to encourage or require health care providers to adopt and use EHR systems that adhere to national requirements.

\subsection{Most countries are challenged by multiple standards in use for the same key data elements}

129. Twenty countries reported that clinical terminology standards are inconsistent among electronic record systems in different regions, or different networks of health care organisations. In some countries the challenges are limited and there are strategies are in place to address them; while in other countries, the challenges are significant and they will be difficult to resolve.

130. Austria indicates that standardisation has been supported by having one terminology server that provides the health terminology used within the EHR system. Work remains to be done in Austria, however, to standardise nursing terminology and this will require resources to cover migrations costs and securing clinical buy-in to codify data. France has been similarly successful in implementing consistent standards and only reports multiple standards in use for laboratory test results. Norway also only signals multiple standards in use for laboratory tests but notes that other difficulties may be on the horizon, as it introduces and implements terminology standards such as SNOMED CT. Estonia reports that moving the sector toward consistent standards was a lengthy process and that it requires significant resources to keep up with new versions of standards over time.

131. Spain has also mandated consistent national standards through legislation establishing the minimum dataset that came into force in 2012. A transition period was established but compliance is challenged because of limited local area and national resources for development, implementation and training in the use of standards. A further challenge has been to develop a SNOMED CT translation into Spanish for Spain. Israel also indicates that local modifications to the recommended standards are a challenge and that it is moving toward national standards with SNOMED CT and ICD-10. Israel requires both resources and legislative reforms to move standardisation forward.

132. Australia indicates that some health care providers are still using proprietary terminology standards of their jurisdiction or of their software vendor and that further work is needed to ensure that all state hospitals include AMT and SNOMED CT-AU in discharge summaries uploaded to the My Health Record system. Similarly, both the United Kingdom (England) and New Zealand report working with primary health care providers and hospitals to migrate toward SNOMED CT, with New Zealand mandating the use of SNOMED CT in any new clinical record system development. New Zealand notes the challenge of adequate funding and clinical buy-in to replace legacy systems and for new implementations. The United Kingdom (England) notes the challenge of providing the necessary system support and training.

133. The United Kingdom (Scotland) will also replace national codes with SNOMED CT in the primary care sector as a first step and then work toward the harmonisation of terminology in secondary care at a later stage. Clinical buy-in is a challenge because no single coding system will be ideal for all users. 
134. Denmark indicates that the problem of multiple standards has arisen because EHR systems are delivered by the market and different software vendors have included different versions of standards in their offerings over time. With organisations having implemented systems at different times, the result is different versions of standards that are in use and that will be costly to upgrade. Canada reports a similar challenge. Canadian provinces and territories and their vendors are free to adopt standards but have, to some degree, implemented the standards differently. Further, there are constraints to upgrading standards in legacy information system applications in hospitals and other care settings that are making it difficult to adopt new versions of standards. To promote common standards, Canada Health Infoway launched a tool in 2015 known as Terminology Gateway which enables implementers to share subsets of the vocabulary in use in their jurisdictions.

135. Sweden also faces a similar challenge. The National Board of Health and Welfare provides a national information structure and a national interdisciplinary terminology. However, the regional and local health authorities independently decide whether or not to use these national resources. National Board regulations require the use of health classifications (e.g. ICD-10 SE) and the Swedish Classification of Health Interventions (KVA) for the coding of diagnoses and treatment for mandatory reporting to national health data registries (Hälsodataregister). As a result, the most successful standardisation has been for diagnoses and procedures. In Switzerland, the healthcare system is decentralised and different cantons use a variety of different terminologies. It is a long-term project to unify coding systems and it is difficult because there is no authority in Switzerland to define the standards that should be adopted. The only exceptions are the nationally unified codes for administrative/billing purposes, such as ICD-10 and CHOP.

136. Singapore is also working toward a national consensus on terminology standards for key elements including laboratory tests and medications. Greece indicates the need to develop a national framework that sets clinical terminology standards for vendors of software systems to the primary and acute care sectors.

137. Chile reports that differences in the standards of health care districts and software vendors have led to multiple standards in use. The Czech Republic noted a similar challenge.

\subsubsection{Mapping classifications used in EHR systems to a consistent terminology}

138. One strategy to cope with multiple clinical terminology standards for the same data element is to map the data to a consistent terminology standard. This step is also needed when local code sets are permitted and there is a need to map to a consistent national or international terminology standard. Not all countries require this step because they already have consistency in the terminologies used throughout their EHR system.

139. Twenty countries indicated that they are undertaking mapping of key elements in their electronic health records. Diagnosis is a commonly mapped element (16 countries). The most common code set that countries are mapping to is ICD-10 (12 countries), followed by ICD-9 ( 2 countries). Eleven countries are mapping medications to a code set, the most commonly used of which is the WHO's ATC codes (7 countries). Six countries are mapping primary health care encounters to one or more code sets, the most commonly used of which is the International Classification of Primary Care Second Edition (ICPC-2) (5 countries).

140. Two countries raised the issue that mapping exercises are not always successful. In the Czech Republic, there have been problems matching across different standards that are in use for the same data elements; and while software vendors are working to try to address these problems, their efforts are often unsuccessful. The United Kingdom (Northern Ireland) expressed a similar problem trying to map legacy terminologies to SNOMED CT that has proven difficult to overcome. 


\subsection{Most countries have a national authority responsible for the EHR system that sets and maintains national standards}

141. Twenty-seven countries identified a national organisation that is responsible for national infrastructure for the electronic health record system (Table 9). In eight countries this national organisation is focussed primarily on digital health records (Austria, Canada, Estonia, Ireland, Luxembourg, Norway, Poland and Switzerland). In most countries, however, responsibility for the implementation of EHRs at the national level is within an organisation that has broader responsibilities, such as a health ministry, a health information organisation, or a health insurance provider.

142. Countries without an organisation responsible for the EHR system at the national level include the Czech Republic, Mexico and the United States. In the United States, the Department of Health and Human Services adopts national standards and regulates the certification of EHR products. Within the Department of Health and Human Services, the National Coordinator of Health IT reports directly to the Secretary of Health and Human Services and holds responsibilities that are defined in statute. The governance of the exchange infrastructure, however, is currently being defined. The Czech Republic has a national standard for clinical record interoperability as a result of an agreement among software vendors.

\subsubsection{Most countries have a national organisation setting clinical terminology standards}

143. In twenty-one countries, the national organisation responsible for EHR infrastructure sets national standards for both clinical terminology and electronic messaging (interoperability) to enable records to be shared (Table 9). In Latvia, the national organisation is responsible for only electronic messaging standards. In France, the national organisation is responsible only for ambulatory care clinical terminology. Two other national organisations are involved in France. The Agence Technique de l'Information Hospitalière (ATIH) is responsible for clinical terminology standards in hospital records and the Agence des Systèmes d'Information Partagés de Santé (ASIP santé) is responsible for interoperability standards.

144. In Greece, Ireland, United Kingdom (Northern Ireland) and Norway, the role of the national organisation responsible for national electronic health record infrastructure does not include responsibility for either clinical or interoperability standards.

145. Ireland has two other organisations involved. The Health Information and Quality Authority sets standards for clinical terminology and Healthlink sets interoperability standards. In the United Kingdom (Northern Ireland) the legacy of multiple silos of specialist information systems results in the national organisation relying upon the standards already deployed by system vendors. In Norway, a different organisation, the Directorate of e-Health, is responsible for clinical and interoperability standards.

\subsubsection{Engagement of stakeholders in bodies governing the national EHR system}

146. Engagement of stakeholders, including payers, providers and patients, in decision making about the development and implementation of national EHR strategies is an important factor in the adoption and use of EHR systems and in their cycle of renewal and continuous improvement. Several countries described how multiple stakeholder communities are engaged in EHR governance (Australia, Austria, Canada, Denmark, Estonia, New Zealand, Spain, Singapore, United Kingdom (England)).

147. The governing Board of the Australian Digital Health Agency will include government and key digital health stakeholders. The legislative instrument establishing the Agency requires Board members to have experience and knowledge in at least one of the following fields: medical practice, healthcare delivery, delivery of private health services and consumer health advocacy. In addition, the Agency will 
have four standing advisory committees - a Clinical and Technical Advisory Committee, a Jurisdictional Advisory Committee, a Consumer Advisory Committee, and a Privacy and Security Advisory Committee.

148. In Canada, Canada Health Infoway, through its Digital Health Alliance, promotes collaboration among stakeholders including EHR vendors, health care organizations, jurisdictions, health care providers, professional associations, governments and other parties interested in developing and implementing standards-based EHR solutions. The Canadian Institute for Health Information also works closely with these same stakeholders to develop and implement data content standards for hospital acute care, primary health care and interRAI standards which are used in mental health, long-term care and home care settings.

149. In Denmark, an Advisory Committee on Standards and Architectures develops and maintains a catalogue of standards and reviews the compliance of cross-sectorial projects with regard to architecture and standards. The Advisory Committee includes representatives of the Danish Health Data Authority, Regions, Municipalities, and the joint MedCom organisation. The primary care sector is not represented on the advisory board.

150. The Estonian E-Health Foundation is a multi-disciplinary governing body that develops and publishes clinical standards, educates users, and promotes cooperation among stakeholders. Implementation is the responsibility of the Ministry of Social Affairs.

151. In Spain, the Interterritorial Council's Information Systems Sub-committee discusses policy alternatives and develops governance proposals to the Interterritorial Council regarding the Spanish EHR system. Autonomous communities (regions), health authorities and the Ministry of Health are all represented on this sub-committee. The Interterritorial Council makes decisions and sets priorities for the Spanish EHR system.

152. The United Kingdom (England, Northern Ireland, and Scotland) has a Professional Record Keeping Standards Body that defines the clinical content for electronic health records. The Body is multidisciplinary with regard to different health professional communities.

153. In Finland, the THL Code Server Steering Group includes representatives from health and social care providers, state authorities, the statistical office, the health ministry, HL7, and the league of municipalities. The Group approves codes sets and information structures for national use, with the final approval given by the National Institute for Health and Welfare (THL) whose official mandate is authorised by law.

154. In Austria, the ELGA GmbH coordinates multidisciplinary working groups to support governing the clinical content of the EHR system. Similarly, the MOH Holdings Pte Ltd in Singapore forms working groups of stakeholders as needed.

155. In New Zealand, the Health Informatics Standards Organisation is responsible for the development, production and maintenance of health IT standards. The organisation includes representatives from the primary care sector, software vendors, hospitals, cultural communities, academia, and other health sector agencies.

\subsubsection{Significant EHR governance changes since 2012}

156. Eight countries have made, or are in the process of making, major changes regarding roles and responsibilities of organisations at the helm the national EHR system since 2012 (Australia, United Kingdom (England), France, Greece, Ireland, Slovakia and Switzerland). In several of these countries, the governance changes favour the development and use of data within EHR systems for monitoring and research (Annex 3). 
157. In July 2016, the new Australian Digital Health Agency will become responsible for developing, implementing, managing, operating and continuously innovating and improving standards, systems and services in relation to digital health, consistent with the national digital health work programme to deliver a nationally consistent and interoperable digital health capability.

158. In the United Kingdom (England), NHS Digital (formerly the Health and Social Care Information Centre) was launched in 2013 and is responsible for collecting, analysing and disseminating national health and social care data. It is also responsible for building and delivering the technical systems that enable that data both to be used to support individuals' care and to deliver better, more effective care.

159. In 2016, the National Health Insurance provider in France (Caisse Nationale d'Assurance Maladie des Travailleurs Salariés (CNAMTS)) will take responsibility for the implementation of the national EHR infrastructure. CNAMTS is the main funding agent of the health care system, and is responsible for reimbursing patients, negotiating agreements with ambulatory health care professionals, setting prices for medical services and reimbursement rates. This change is consistent with the adoption of health insurance ID numbers within electronic health records, rendering the technical potential for linkage between insurance and clinical data.

160. In Greece, the E-government for Social Security Services (IDIKA) SA was launched in 2015 to develop national eHealth applications on behalf of the Ministry of Health. It evolved from the successful implementation of a national E-prescription system. A study has linked the system to improvements in services, monitoring and planning of public health, and to efforts to contain unnecessary expenditure related to medication use and improve transparency and administrative control (Pangalos et al, 2014).

161. eHealth Ireland was launched in 2015 to take responsibility for seven strategic programmes that would act as a catalyst for a change in how technology is delivered in Ireland. This work includes the electronic health record programme and the programme to create an individual patient identifier. Its vision is to develop a patient-centric longitudinal record for all clinical information which is available to all health and social care professionals and patients. While technology solutions are a key component, there will be a primary focus on how clinicians and administrative staff work with the technology in a way that aligns with and underpins the ambition for the integrated care and other national programmes. ${ }^{7}$

162. In Slovakia, as of 2013, the National Health Information Centre ${ }^{8}$ (Narodne centrum zdravotnickych informacii) became responsible for the rollout, implementation and operation of the National EHR System, setting up standards for health informatics, statistical surveys, and national health and health administrative registries.

163. Switzerland's "eHealth Suisse" promotes and recommends technical and semantic standards which are not mandatory for stakeholders. However, the new law on the EHR system that is entering force in 2017 changes the role of eHealth Suisse, as stakeholders that wish to participate in the future EHR system at the national level, will be required to become certified as conforming to a set of data interoperability standards.

\subsection{Efforts to address the consequences of multiple minimum dataset specifications}

164. Countries have implemented different strategies to improve consistency and interoperability where there are multiple minimum dataset specifications in use.

\footnotetext{
${ }^{7}$ http://www.ehealthireland.ie/Our-Team/Strategic-eHealth-Programme-Leadership/

${ }^{8}$ http://www.nczisk.sk
} 
165. Australia assures that all documents uploaded to the national My Health Record are based on the national specifications while allowing health care providers to continue using their own specifications within their own EMRs.

166. Spain has been able to attain a consistent minimum dataset by setting the requirements within national law and, in some cases, in regional laws or regulations. Switzerland notes the need for an immediate effort to avoid heterogeneity in the implementation of its new system by setting a national requirement for information exchange and then working with regional stakeholders to implement it.

167. Austria and Ireland plan to address the problem by specifying a national minimum dataset. The United Kingdom (Northern Ireland) has a similar strategy and the national minimum dataset is largely defined, however, differences in the capabilities of the systems used by laboratories, radiology, GPs and specialists, including differences in messaging formats, have made the process of defining a minimum dataset challenging.

168. The United States Interoperability Roadmap placed a priority on consistent data semantics and formats. The United States encourages consistency by specifying a minimum dataset that certified EHR systems must be able to capture and by offering "meaningful use" incentive payments to health care providers who voluntarily meet a set of requirements, including requirements for the data that are included in their EMRs. The number of providers meeting the meaningful use criteria and the software vendors offering certified systems are monitored.

169. To improve adherence to national content and interoperability standards, Canada Health Infoway has developed toolkits to help software vendors and provinces and territories manage differences between their systems and the national standards. At the same time, the Canadian Institute for Health Information continues to engage data providers across the country towards the adoption and implementation of data content standards.

170. In Poland, the National Centre for Healthcare Information Systems (CSIOZ) has been tasked to solve the problem of inconsistency among different regulations and requirements.

171. Norway is coping with different EMR vendors, each with their own specification for a minimum dataset. To solve the problem, Norway has a national strategy to enable technical and semantic interoperability.

172. Similarly, in Chile, the government will provide clinical terminology services (based on SNOMED-CT) starting with drugs, then diagnoses and procedures. There is also a plan to have a national service for patient and provider indexes.

\subsection{Policy levers requiring or encouraging adoption and maintenance of high quality electronic health records}

173. Countries may institute legal or regulatory requirements for health care providers to adopt electronic health record systems that meet national standards. Certification may be used to encourage software vendors to offer electronic health record systems that meet national standards, and incentive payments or penalties may be launched to encourage health care providers to adopt or maintain high quality electronic health record systems. Many of the countries with the most advanced electronic health record systems described in this study employ several of these policy levers to achieve their success (Table $10)$. 


\subsubsection{Laws or regulations regarding adoption of EHR systems and conforming to standards}

174. Thirteen countries reported national laws or regulations requiring health care providers to adopt electronic health record keeping (Austria, Croatia, Denmark, Estonia, Finland, France, Ireland, Israel, Latvia, Luxembourg, Poland, Slovakia, and Switzerland) and in ten of these countries, the laws or regulations require adherence to national standards for electronic messaging. Only seven countries, however, reported laws or regulations that require adherence to national standards for clinical terminology (Austria, Denmark, Estonia, Finland, Luxembourg, Poland and Slovakia). In Ireland and Luxembourg, these national laws are in the process of being drafted.

175. In Canada, some provinces and territories implementing drug information systems have introduced legislation requiring vendors of electronic record software to connect to the jurisdictional drug information systems. Some jurisdictions also require implementation of interRAI standards within systems used in home care, long-term care, and mental health care. There is a commitment among senior leaders in Canada (Conference of Deputy Ministers of Health) to support the implementation of primary health care standards.

176. In the United States, there are no federal laws or regulations that require providers to use EHRs in order to be licensed or to treat any patient population. Some states however, like New York, are starting to require e-prescribing of controlled substances.

\subsubsection{Certification of software vendors to conform to national standards}

177. Fourteen countries certify vendors of electronic health record systems (Australia, Canada, Croatia, Finland, France, Ireland, Luxembourg, Mexico, Singapore, Slovakia, Sweden, United Kingdom (England), United Kingdom (Scotland) and United States).

178. In Australia, vendors 'self-declare' conformance to My Health Record system specifications directly to the Department of Health. In Finland, certification is required for any electronic record systems that would become connected to the national EHR system. Certification of vendors in Ireland is limited to primary health care electronic record systems.

179. Pre-implementation certification of privacy and security, management controls and interoperability is offered by Canada Health Infoway for many EHR system applications. Some provinces also certify electronic medical record products that are used in physician offices, ambulatory clinics and community health centres or, alternatively, require standards during the software procurement process. In the home care, long-term care, and mental health care sectors, the Canadian Institute for Health Information conducts vendor certification of interRAI implementation.

180. In Chile, software vendors are required to conform to standards required by the Ministry of Health during product procurement processes. Similarly, in the United Kingdom (Scotland), vendors are assessed for conformity to standards during procurement processes.

181. In Iceland, the use of international terminology standards for key elements of the national EHR systems is mandated. In Switzerland, the EHR law requires that health care providers joining the national EHR system are certified as conforming to interoperability standards.

182. In Singapore, there is a certification process for electronic submission of primary care data from the private sector for several medical care schemes. Information about certified vendors is published online. There are processes in place to ensure that vendors meet requirements, including a designated team that verifies that standards are incorporated within procurement requirements and that technical specifications of systems align with standards. Structured data are required to contribute to the National 
Electronic Health Record (NEHR) and, while there is no official certification process, systems need to pass the relevant testing in order to be considered ready to contribute to the NEHR.

\subsubsection{Incentive payments or penalties to adopt and maintain high quality EHRs}

183. Thirteen countries have financial incentives or penalties in place to encourage health care providers to adopt and maintain high quality electronic health records (Australia, Austria, Canada, Chile, Estonia, Finland, Israel, Norway, Singapore, Spain, United Kingdom (England and Scotland) and the United States).

184. The United States has the most comprehensive incentive payment programme reported in this study. The Social Security Act provides several years of payment incentives for the adoption and meaningful use of certified EHR technologies by physicians and hospitals serving patients enrolled in US public health insurance programs for the elderly, disabled, and poor (Medicare and Medicaid). At a certain point, providers reimbursed by Medicare will have the option to either demonstrate meaningful use or be reimbursed at a slightly lower rate. Meaningful use incentive payment adjustments will sunset in December 2018. The programme is voluntary and the use of a certified EHR is not required to be reimbursed by Medicare or Medicaid.

185. Canada Health Infoway provides financial support to jurisdictions deploying systems and some of this support is tied to the jurisdictions offering providers incentive payments. Consumer Health Solution Projects (e.g. patient portals) that are funded by Canada Health Infoway have certification as a condition of receiving all of their funding.

186. United Kingdom (England) offers incentives including contractual requirements and financial reimbursement of IT equipment. Australia offers digital health incentive payments to primary care practices that connect with and use the My Health Record system. New Zealand encourages providers by having a business case approval process and by providing a list of preferred system vendors.

187. Austria has financial incentives for physicians and some hospitals to support the implementation or connection costs to the electronic health record system. The Ministry of Health in Israel offers an open source platform for clinic management including an EMR system. Organisations that adopt this EMR are able to use the platform for free or for pay subsidized fees. Spain provides access to public funds for investment or expenditure to local authorities adopting EHR systems that conform to national standards.

188. Estonia and Finland note incentives that refer to the laws and regulations that render participation in the EHR system mandatory.

189. Once an EHR system has been adopted, Norway offers incentive payments to providers to use the system and keep records up to date. In Chile, incentives to providers to use EMRs and keep them up to date are linked to key performance indicators for healthcare districts and hospitals.

190. The United Kingdom (Scotland) also has a comprehensive set of incentives offered by the NHS National Services Scotland. EHR systems must be purchased from a vendor included within the government's procurement framework to be eligible for funding support. Scotland has a Quality and Outcomes Framework that includes mandatory national performance indicators. Providers must conform to national standards, use structured data and maintain complete and up-to-date records in order to produce the indicators. Providers receive support from NHS NSS to achieve this.

191. In Singapore, the Ministry of Health is funding the development and use of an IT system which will facilitate data flow between the Ministry of Health and primary care physicians. In hospitals, the Ministry is funding the implementation of electronic medical records and the use of the National Electronic 
Health Record System. The Ministry is also funding IT systems in community hospitals and nursing homes.

192. Switzerland has a federal medical treatment quality strategy and is piloting a project with certain hospitals to monitor prescribed medicines. Other monitoring in future could include treatment efficiency as healthcare insurance has a right to control if a patients' treatment was economical.

\subsection{Quality auditing of clinical record content}

193. Auditing of the clinical content within Electronic Health Records is another key qualityimprovement strategy that can help to reduce inconsistencies in record-keeping practices among providers.

Nine countries reported that they have instituted auditing of the clinical content of records for quality (Australia, Estonia, Iceland, Israel, New Zealand, Norway, Singapore, Spain and United Kingdom (England) - Table 11). Among them, two countries that participated in this study in 2012, Israel and Singapore, reported quality auditing practices for the first time.

194. The Australian Commission on Safety and Quality in Health Care undertakes targeted clinical safety reviews of aspects of the My Health Record system. ${ }^{9}$ In the United Kingdom, England's NHS Digital conducts validation tests on submitted data and NHS England, as lead purchaser for healthcare services also conducts routine audits. Similarly, Estonia uses technical rules to control the quality of documents uploaded to the EHR system and the Estonian e-health Foundation conducts audits. Estonia indicates that more controls are needed, however, to improve record quality.

195. The Directorate of Health in Iceland, audits the clinical content of physician and hospital clinical records as well as InterRAI data recorded by nurses. In Israel, the Ministry of Health routinely audits the national HIE platform while local organizations also conduct quality audits on their records.

196. The Spanish Medical Inspection Body; Internal Committees in Hospitals and Healthcare Areas; and the HCDSNS Project Team all audit aspects of clinical records. Further, audits of health records are planned at each health service in Spain.

197. The Ministry of Health in New Zealand audits hospital clinical record systems for quality as well as some other health care providers' clinical record systems. It does not, however, audit the electronic clinical records of physicians. The Norwegian Board of Health Supervision audits electronic records for quality. The Singapore Ministry of Health audits physician and hospital clinical records.

198. While there isn't a quality audit in Greece per se, the ePrescription data are analysed routinely by IDIKA SA to detect fraud.

199. In France, security audits are conducted by ANSSI (agence nationale de sécurité des système d'info) and security and confidentiality reviews are also conducted by the National Commission on Information Technology and Liberties (CNIL). General inspectors of public social services (Inspecteurs généraux des affaires sociales) may also audit the quality and overall efficiency of the EHR but data quality audits are not performed for now.

200. In the United States, health care providers are subject to an audit of their electronic and/or paper records to assure the quality and safety of the services they provide, as well as the accuracy of their claims for reimbursement. Additionally, under its Certification Program, ONC can decertify systems that do not continue to meet certification requirements.

\footnotetext{
${ }^{9}$ http://www.safetyandquality.gov.au/our-work/safety-in-e-health/
} 


\subsection{Technical and financial constraints limiting dataset development}

201. Twelve countries reported that a lack of technical or financial resources is limiting dataset development (Table 11). This is because facing the challenges of improving both the availability and consistency of EHR systems' data and formatting and structuring the data to permit high quality statistics and research require financial investments and skilled human resources.

202. In the United States, some clinical data elements are captured in ways that may require normalization to compile data across multiple providers, such as unstructured data. The US engages in and sponsors research to increase the ease of routinely capturing health and clinical data in standard formats and terminologies that could eventually reduce the need for normalization. One of these techniques is developing natural language processing algorithms to structure data from free text within EHRs (which was described at the beginning of this report, Liao, 2015).

203. Spain reports certain limitations regarding technical and financial resources to address the diversity of record formats, vocabularies and terminologies that are being used. Regions in Denmark are implementing quality databases with the ambition to standardise clinical terminology and algorithms and to enable a better integration of regional EHR systems. Dataset anonymisation and pseudonymisation are often a challenge, as are delays in the adoption of standards enabling interoperability. Technical and financial resources are a concern in Latvia. When Latvia was first creating a data warehouse for electronic records, a lot of discussion took place about how to address data de-identification and adequate resources for this remain an issue.

204. In Finland, health care providers could extract more data to create national registries but they are reluctant to do so because of the high financial charges that are levied upon them by their IT system providers for updating data in the national EHR system.

205. Resource concerns in Canada include a greater need for staff skilled in the creation of databases and that can support data users to participate in the development of databases. These skillsets are still growing in Canada. There is also a need for investments in defining the scope of future data uses to support health systems; and investments in the technical infrastructure to support data uses, including addressing the impact of different clinical terminologies, technologies and system vendors across jurisdictions.

206. In Norway, technical and financial resources are expended to collect and clean data but less resources have been devoted to analysing the data and disseminating results. Mexico and Estonia also report a lack of technical resources to exploit the analytical potential of the data within EHR systems.

207. Technical and resource limitations in United Kingdom (Scotland) are felt particularly by clinicians looking to develop and interrogate datasets on patient groups or small groups of physician practices. In general, there is an on-going need in Scotland to better prioritise demands for statistical and research uses of data; to address a lack of analytical and data visualisation capacity; and to improve the interoperability of EHR systems.

208. There remain technical and financial resource constraints to dataset creation in Poland, however, there is a major national project to develop datasets as well as many regional initiatives. 


\section{HEALTH DATA GOVERNANCE READINESS VARIES GREATLY AMONG COUNTRIES}

209. This OECD study explored several key indicators of the readiness of national health data governance frameworks to support the use of data held within electronic health record systems to fulfil national health information and research objectives. This includes

- Having a legal framework that would allow data within these systems to be extracted for statistical and research purposes, subject to suitable safeguards;

- Having a national EHR plan or policy that includes the statistical and research uses of this data;

- Engaging in the extraction of data from EHR systems to create national datasets; and

- Analysing data extracted from EHR systems for key national monitoring and research objectives.

210. While EHR data governance readiness is low in seventeen countries, the top tier of countries, such as Iceland, Norway, Poland and Finland, provided key examples of how such governance can be successfully developed to advance national health information systems (Figure 3, Table 12).

Figure 3: Data governance readiness varies greatly among countries

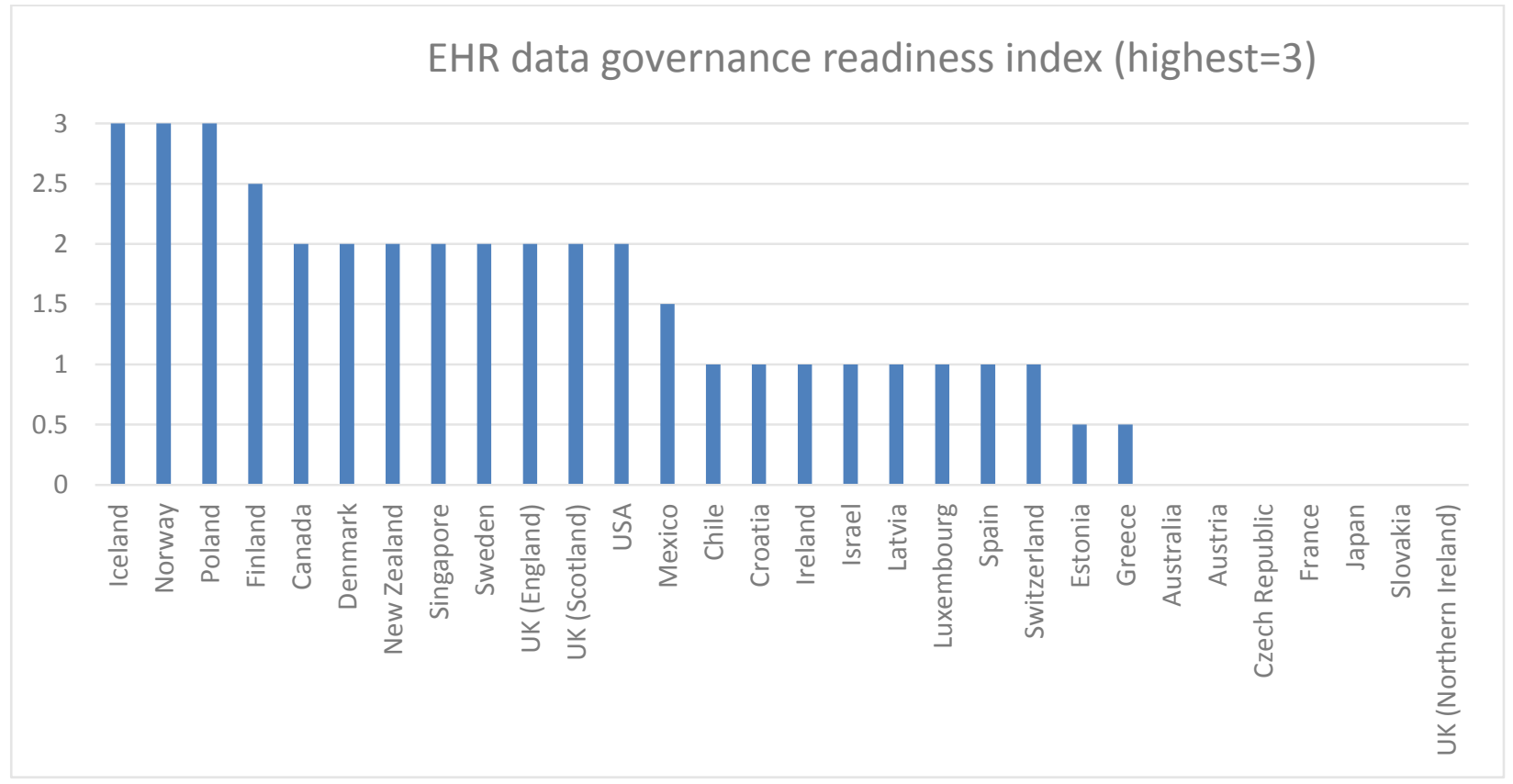

Note: Cumulative score of four indicators: national plan or priority for secondary data use, dataset creation, and contribution of EHR data to monitoring and research which are each valued at one point; and legal issues impeding dataset creation which subtracts one point (see Table 12 for the EHR data governance readiness indicators).

Source: HCQI Survey of Electronic Health Record System Development and Use, 2016 


\subsection{Data uses within national plans and policies}

211. Key results include the following:

- Twenty-one countries reported that their national plan or policy for EHR implementation included secondary uses of data extracted from EHRs (Table 13).

- Eighteen countries reported data use for public health monitoring and seventeen countries reported data use for monitoring health system performance and patient safety (Figure 4).

- Fourteen countries reported data use to support physician treatment decisions by enabling physicians to query data to inform themselves about previous treatments and treatment outcomes.

- Thirteen countries reported planning for data use to support research to improve patient care, health system efficiency or population health. Ten countries included the possibility of data use to facilitate or support the conduct of clinical trials.

212. Countries with the broadest plans for the extraction of data for secondary uses are Canada, Denmark, Estonia, Iceland, Norway, Poland, Singapore, Sweden, United Kingdom (England and Scotland), and United States. These countries included at least five of the secondary uses measured in this study within their national plans or policies (Table 13). Chile, Croatia, Finland, Ireland, Latvia, Luxembourg, Slovakia, and Switzerland reported planning for three or four of the secondary data uses measured in this study.

213. Canada's initial design for the EHR included a future ability to leverage EHR data for secondary use purposes, however secondary uses were not included within the initial EHR scope or funding. Each Canadian province or territory is at various stages of planning or implementing secondary data uses. Canada has been supporting and planning for the secondary use of EHR data for the past 2-3 years, including initiatives and demonstration projects to raise awareness of secondary data uses. In 2013, the Canadian Institute for Health Information and Canada Health Infoway published a vision paper for Canada describing multiple secondary uses of data from EHRs.

214. Australia is currently developing a secondary use framework for the EHR system and may include some of the data uses measured in this study in the future. Chile will consider a broader set of secondary data uses in the future as the EHR system matures from a pilot project to implementation. Croatia will also expand data uses in the future, beginning with data use to facilitate or support clinical trials which is included within the next phase of their current EHR project. The United Kingdom (Scotland) is also considering the secondary use of data to facilitate or support clinical trials within its Health and Biomedical Informatics Research Strategy for Scotland.

215. Denmark has national databases and registries covering many of the secondary uses measured in this study. Data are collected as extractions from HIS/EHR systems or reported by means of forms. Data are used for clinical trials, such as when testing new pharmaceutical products or for phase 4 testing, and in local surveillance programs. Similarly, Spain reports national databases covering many of the secondary use topics measured in this study; however data are not extracted from EHRs at the national level but are extracted from EHRs at the regional level. Israel's HMOs undertake all of the secondary data uses measured in this study, however data within the central Health Information Exchange are not available for secondary uses. 
216. New Zealand is implementing a national EHR to present existing health information into a single longitudinal view accessible to consumers, carers and decision-makers. It will support precision medicine, personal wellness information, and appropriate linkages to non-health data across the social sector.

217. Switzerland's strategy aims for the system to support better medical treatment quality for patients, better patient safety and greater efficiency in the healthcare sector through coordinated electronic communication. The strategy is a starting point for the national eHealth architecture and, when it was developed, it was considered too early for an explicit agenda for secondary data uses. Secondary data uses will require careful development to allay public concerns regarding the protection of data privacy.

218. Japan has introduced a new strategy for eHealth within a broader strategy for the health sector. It includes developing and implementing a Medical Information Collaboration Network to enable efficient information sharing among medical institutions and long-term care providers; and increasing the use of EMRs within hospitals. ${ }^{10}$ There are no secondary data uses within this strategy; however, a separate strategy to implement a national cancer registry will extract data from EMRs for national surveillance.

219. Czech Republic, Greece, and Mexico did not report a national plan to implement EHRs. A national e-Health strategy is under development in the Czech Republic. Mexico includes the development of health information systems and EHRs within broader national plans for the health sector.

Figure 4: Over half of countries plan on one or more secondary uses of data from EHRs and many report data uses

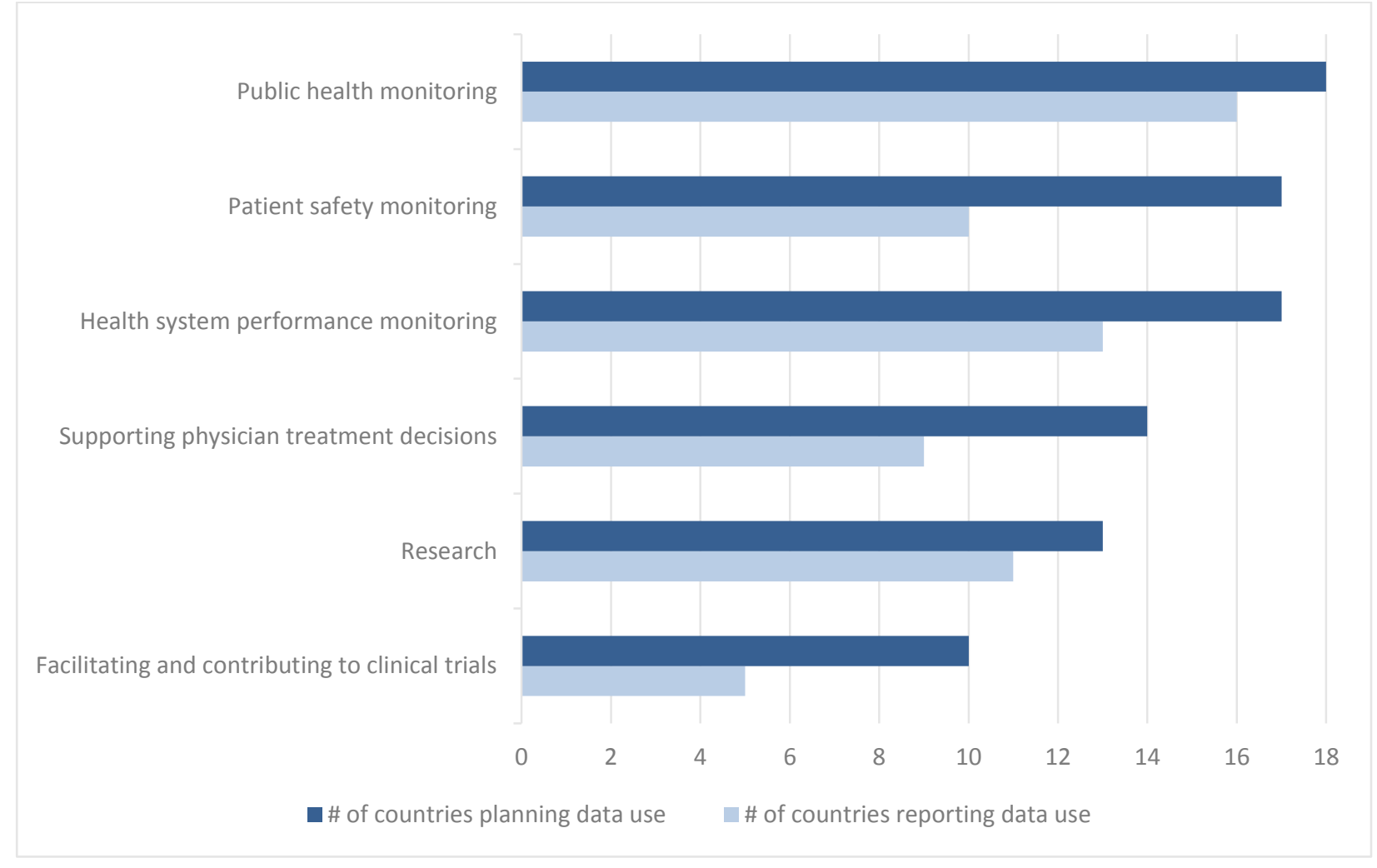

Note: See Tables 13 and 14.

Source: HCQI Survey of Electronic Health Record System Development and Data Use, 2016

${ }^{10}$ This new strategy replaces the "my hospital everywhere" EHR strategy in Japan (See OECD, 2013). 


\subsubsection{EHR data informs key national health information objectives}

220. Many countries also reported that they are proceeding to fulfil plans for secondary data use and are already making use of data extracted from electronic health record systems to inform key national information objectives (Table 14, Figure 4). Denmark, Norway, Sweden ${ }^{11}$ and the United Kingdom (Scotland) indicated that data extracted from electronic health record systems are contributing to monitoring public health, health system performance and patient safety; to health and health care research; to facilitating and contributing to clinical trials; and to supporting physician's treatment decision-making. Countries reporting that four or five of these information objectives are currently supported through data extracted from EHRs are Canada, Israel, Poland, New Zealand, Singapore and United Kingdom (England and Northern Ireland).

\subsubsection{Legislative framework permits statistical and research uses of data within EHRs}

221. Thirteen countries reported legislation that limits the ability to develop datasets for monitoring or research from data within electronic health record systems (Table 11) or noted legislative provisions and data governance obstacles that are limiting the use of data from EHR systems for health care quality monitoring.

222. Legal limitations protect patients' privacy and the security of health data and all countries responding to this study have national legislations protecting the privacy of personal data (OECD, 2015a). A key health data governance factor is assuring that the legal framework that protects the privacy of patients and the security of data within EHR systems, does so in a manner that still allows data to be extracted for approved statistical and research purposes. Many of the top tier countries have specific legislation that authorises datasets to be created from data extracted from the EHR system. This is not to indicate, however, that there are no legislative challenges to be addressed in the top tier countries.

223. In Finland, data can be extracted from the EHR system to create legally authorised registries; however, the law authorising the EHR system does not allow the data within the national EHR repository to be accessed directly for research purposes. Data within local EHRs, however, may be used for research purposes. Poland also reports unresolved issues regarding the legality of access to data within the EHR system for statistical or research purposes.

224. National health registries in Iceland are defined by law and regulations. Hence, if the Directorate of Health needs to add a new database for health monitoring; then existing law and regulations would need to be changed before data collection could begin.

225. In the United Kingdom (Scotland), the development of datasets is limited by cultural and data governance barriers to data sharing. The United Kingdom (England) reports a need to demonstrate that data processing is fair and to implement a means for patients to express their preferences regarding uses of their own data.

226. Sweden also reports difficulties securing information sharing among different jurisdictions. Further, as reporting requirements have increased with respect to health and data quality measurement, the costs of administering health systems have also risen and there is resistance to reporting data for statistical or research purposes.

\footnotetext{
${ }^{11}$ Primarily through Sweden's National Quality Registries but also through clinical databases and other health registries, with some data sources used only at the local level.
} 


\subsubsection{Legislative prohibitions and other governance obstacles to the statistical and research use of data extracted from the EHR systems}

227. Several countries reported that their national EHR systems are only legally authorised to share EHR data for medical treatment purposes (Austria, France, Ireland, Japan, Switzerland and the United Kingdom (Northern Ireland)). Spain reports a limitation to the extraction of data from the EHR system at the national level.

228. Australia, Israel and Ireland also reported efforts that are underway toward legislative reforms. Ireland is currently drafting a new Health Information and Patient Safety Bill (HIPS) which will facilitate the ability to develop datasets from EHR systems. Australia is developing a secondary use framework that will enable the System Operator (currently the Secretary, Department of Health) to make informed decisions about the benefits, risks and costs of options presented for secondary uses of My Health Record system data. Further, Australia has recently introduced legislation that adjusts the national EHR from an opt-in to an opt-out patient consent model. This change will improve the population coverage of the EHR system, increasing the viability of data from this source to contribute to statistics and research. Israel is launching a "big data" strategy that will explore the potential secondary use of EHRs through the national health information exchange.

229. Spain does not have a national legislation or regulation that addresses the technical requirements to allow the extraction of data from the national EHR system for national research or statistical purposes. As a result, databases must be administered by each Healthcare Authority (region). Spain also faces data governance barriers that limit researchers' access to electronic clinical data. These include a strong bureaucracy and a lack of written policies regarding how applicants may apply for access to data within EHR systems. Some ICT providers are reluctant to provide access to data for research and/or apply financial charges for accessing to data that may limit data accessibility. Canada also reported that legislations protecting privacy in some jurisdictions may be limiting some secondary uses of data. Other data governance issues in Canada include defining the potential secondary uses of data and securing the recognition within the health system that data uses should be a policy priority. Further work is also needed to address concerns of physicians and other stakeholders about the appropriateness of data privacy protections and the benefits of data uses. Canada also must address the legacy of specific programs "owning" their data and, as a result, creating silos of unshared information, an issue also highlighted by the United Kingdom (Scotland).

230. In Singapore, healthcare organisations contributing to or accessing data in the National Electronic Health Records System are bound by a Data Sharing Agreement. In addition to the use of data for patient care, under the Data Sharing Agreement, the Ministry of Health may approve data use for research or statistical purposes, provided relevant ethical and legal requirements are met. Healthcare quality monitoring in Singapore is currently limited to specific activities that have been legally authorised, such as clinical quality assessment. Other important aspects of health data governance that require further work in Singapore include assuring patient, provider and public acceptance of data uses.

231. The development of datasets from data extracted from electronic health record systems is restricted in Japan and Switzerland. However, both countries have recently authorised national cancer registries. In Japan and Switzerland the data will be first collected by regions and then submitted to the national registry. The data submitted to the registries will likely be extracted from local areas' electronic clinical record systems. There is the potential that these national initiatives could further future national discussions of the benefits and protections necessary to enable dataset creation for other key diseases and patient groups. 


\subsubsection{Half of countries are meeting national health information needs with data from EHRs}

232. An aspect of health data governance is demonstrated through investments in health information development from data within EHR systems. Sixteen countries indicated that data within electronic health records are currently being used to create datasets for health or health care monitoring and analysis and ten countries provided details about the datasets and the statistical projects that are underway at the health system level (Tables 11 and 15). Among them, four countries that did not report developing datasets from the extraction of EHR data in 2012, now indicate that such data is used for this purpose (Denmark, Israel, Mexico and Singapore).

233. The Directorate of Health in Iceland ${ }^{12}$ builds many national datasets that rely on data extracted from the EHR system including the Cancer Registry, Birth registry, Registry of Contacts with Primary Health-care Centres, Hospital Registry, Pharmaceutical Database, Communicable Disease Registry, Adverse Events Database, Database on Accidents and the Cardio-Vascular Disease Database.

234. Similarly, in the United Kingdom, data from the EHR system in Scotland are routinely extracted to develop many national datasets and registries. The NSS Discovery project in Scotland is an information system developed from the EHR system that provides approved users with access to a range of comparative information to support health care performance and quality improvement. In England, the National Tariff System captures EHR data from acute care providers to support statistics and reimbursement. The Calculating Quality and Reporting Service (CQRS) in England extracts data from primary care electronic health record systems to support monitoring, such as indicators for reporting progress against Quality and Outcomes Frameworks.

235. In Sweden, there are about 100 clinical research databases and Quality Registries that are developed from electronic clinical records. There are also several national health databases that include patient data from EHRs. Sweden has developed an IT tool to detect Healthcare-associated infections. When antibiotics are prescribed in Sweden, the cause is recorded in the EHRs for follow-up and inclusion in databases for monitoring and improvement.

236. Similarly, Norway's Medical Quality Registries and its National Patient Registry depend on data extraction from its EHR system. There are also municipal registries that are created from the extraction of data from local EHRs.

237. New Zealand creates a national dataset to monitor patient flows through data extraction from hospital systems. Data from hospital systems also contribute to several other national datasets.

238. In the United States, the National Center for Health Statistics (NCHS) is developing national health care surveys by requesting data submissions from the electronic clinical record systems of health care providers and hospitals. Various provider and professional organizations have also implemented clinical data registries from electronic clinical record data.

239. In Finland, a Primary Health Care Registry is populated by extracting data from the national electronic health record system and a project is underway to enable EHR data to populate the national hospital registry.

240. The National Health Fund (NHF) in Poland has developed the Electronic Platform for the Collection, Analysis and Dissemination of Digital Resources on Medical Events. It is a large database where data have been extracted from EHRs. It has the potential for multiple statistical and research uses

${ }^{12}$ http://www.landlaeknir.is 
but it is currently used primarily for immediate reimbursement purposes. A few years ago, however, a Cancer Registry was created by extracting a subset of data from this database.

241. The Canadian Primary Care Sentinel Surveillance Network (CPCSSN) is Canada's first multidisease electronic record surveillance system. It is a database of patients with a specific set of chronic diseases. To create CPCSSN, data are extracted from participating health care providers' EMRs (representing a subset of Canadian providers and patients). There are also national databases for home care, long-term care, and mental health care that include data from providers EMRs regarding inter-RAI assessments. These databases are used for health system management and quality analysis.

242. In Singapore, the National Registry of Diseases Act mandates healthcare institutions to notify cases of reportable diseases and to furnish patient data for stipulated disease registries. The required information can be obtained through direct data extraction from the NEHR. Israel develops national registries that are populated with data extracted from the electronic record systems of HMOs and hospitals. These include the Cancer Registry, Diabetes Registry, Bariatric Procedures Registry, and the Stroke Registry.

243. In Denmark, the Danish regions have established joint quality databases for 67 patient groups with data contributed from the electronic health record system. There are also other quality databases operated by the Danish Health Data Authority.

244. In Greece, the national ePrescription data are analysed routinely to detect fraud and are used to monitor chronic diseases. The system has been linked to improvements in services, monitoring and planning of public health, and to efforts to contain unnecessary expenditure related to medication use and improve transparency and administrative control (Pangalos et al, 2014).

245. At a regional level in Spain, some authorities are establishing datamarts (data sub-sets) or data repositories to support monitoring public health, system management, evaluation or related uses. The use of regional data in research projects, however, remains quite limited.

246. In Chile, the largest health and social security institutions extract data from their electronic medical record systems to create databases for statistical, epidemiological and health planning purposes.

247. eHealth Ireland has conducted several case studies demonstrating how the extraction of data from EHRs supports dataset creation. 


\section{OUTLOOK FOR THE FUTURE}

248. This 2016 OECD Health Care Quality Indicators Expert Group study was conducted in thirty countries to explore the data governance and technical and operational factors that support the development of national health information and research programmes from data held within electronic clinical health record systems.

249. The results indicate that many countries are poised to make significant advancements in both national health information and research as a result of the considerable investments they are making in EHR systems and in associated policy-relevant data and information products. While most countries were at the beginning of a journey to advance the statistical and research uses of data from EHR systems in 2012 (OECD, 2013), twelve countries are now able to report having developed data sets and published health information from EHRs to support better quality health care and improved health system performance (Table 15).

250. Countries are, however, at very different points on this journey. Some countries, such as Austria, Estonia and Slovakia, are advanced in technical and operational readiness but not in data governance; and a small group of countries, including Czech Republic, Japan and United Kingdom (Northern Ireland), are not advanced in either dimension (Figure 5).

251. Ten countries were identified with both high data governance and high technical and operational readiness (Tables 1 and 12, Figure 5). These countries are:

- Canada,

- Denmark,

- Finland,

- New Zealand,

- Norway,

- Poland,

- Sweden,

- United Kingdom (England and Scotland), and

- United States.

252. These countries are very well positioned to capitalise upon the opportunity to develop worldclass health information systems that not only support their countries' information needs regarding health system quality, efficiency, and performance reporting; but also create a firm foundation for scientific research and discovery. 
253. All of these countries, however, still face important challenges that may limit their future success; and several other countries are moving forward with strategic plans to overcome obstacles and to eventually match or exceed these countries' current capabilities.

\subsection{Strategic investments to advance the availability of data from EHRs for health system monitoring and research}

254. Eleven countries noted specific recent strategic investments to investigate the potential for the health system to gain valuable information to improve health and health care from the data within EHRs. Sixteen countries reported regular processes to continuously evaluate and improve upon the health information that is already available from EHRs.

255. The United States Meaningful Use Electronic Health Records (EHR) Incentive Program's Public Health Objective, Measure 3, encourages health care providers to submit data for specialized registry reporting. This programme is enabling the National Center for Health Statistics to develop national datasets to monitor health care quality and health system performance. The United States also engages in and sponsors research to increase the ease of routinely capturing health and clinical data in standard formats and terminologies that could eventually reduce the need to require structured data entry while still enabling record interoperability and statistical uses of data.

256. Israel is launching a new "big data" strategy that will be considering how to better govern, integrate and benefit from large volumes of current, de-identified, personal health data from multiple sources. This strategy is intended to address barriers to the systematic use of data in the national health information exchange for research by examining different research scenarios.

257. Australia is developing a secondary use framework that will examine the benefits, risks and costs of enabling the data within the My Health Record system to contribute to national health and health care information and to research.

258. An evaluation of the usability of electronic clinical data for statistics and research purposes was part of explorative work that was recently undertaken in Norway by the Directorate of eHealth that was commissioned by the Ministry of Health and Care Services. The results support an initiative called "One Patient - One record" and are described in a report submitted to the Ministry in January 2016.

259. There is a national program in Denmark that is aiming to increase the accessibility of EHR system data in a secure manner across sectors for relevant statistical and research purposes.

260. France has introduced a law to modernise the health system that facilitates the use and sharing of health data for projects within the public interest. To facilitate its implementation, a reflection group was launched in 2015 to shed light on the development challenges associated with "big data" and on the emerging analytical methods to analyse such data. The group will present its findings in the second half 2016. France also has a committee monitoring studies about the use of medicines in the population using a variety of data sources, such as clinical cohorts, registers, health insurance data and electronic medical records. The committee periodically reviews obstacles to the realization of these studies.

261. New Zealand has a national policy and processes in place to improve the sharing and use of electronic health data among government agencies.

262. In Iceland, real time data are currently being collected and stored within the national hospital database. In the summer of 2016, real time data from primary health care clinics will be collected on a national level creating new opportunities for monitoring and research. In Singapore, data are currently 
manually extracted from the national EHR system to create legally authorised disease registries and studies are underway to determine the feasibility of automating data extraction.

263. Chile is developing a strategy for a national data warehouse populated with data extracted from EMRs. From the data warehouse, datamarts (data sub-sets) will be created for specific purposes. In the meantime, specific datamarts have been developed. Mexico also reports initiatives to build information products from EHRs for statistical, epidemiological and health system planning purposes.

264. Sixteen countries reported that there are processes in place at the national level to regularly assess the usability of EHR data for dataset creation and analysis (Table 14). When assessing potential data sources for national information systems, both Canada and the United Kingdom (England) reported conducting pilot studies at the point of care or at a local level. Canada also noted that it is essential to assess the readiness of jurisdictions to contribute data from EHRs and the readiness of the CIHI organisation to manage new data.

265. Slovakia is planning a future process to evaluate the usability of electronic health data for statistics and research.

\subsection{Outlook for the future}

266. Countries responding to this study were asked to provide their assessment of the likelihood that, over the next five years, any data from EHRs would contribute to regular national monitoring of health care quality.

267. Countries reporting indicators of both high data governance readiness and high technical and operational readiness were Canada, Denmark, Finland, New Zealand, Norway, Poland, Sweden, United Kingdom (England and Scotland) and United States (Figure 5). All of these countries reported that it was likely or very likely that EHR data would contribute to national monitoring of health care quality over the next five years, with the exception of the United States, where the outlook was uncertain.

268. Many other countries also expressed optimism that there will be sufficient political and financial support to overcome any remaining challenges to proceeding to benefit from EHR data for national monitoring of health care quality over the next five years. A few countries, however, were uncertain as to whether there would be sufficient progress over the next five years to enable this data use (Czech Republic, Israel, Slovakia, and Latvia) and six countries indicated that this data use is unlikely (Austria, France, Greece, Japan, Mexico and Switzerland). Reasons given included that the EHR system is not advanced enough and the use of data from the EHR system is not a policy priority. 
Figure 5: EHR data governance and technical/operational readiness

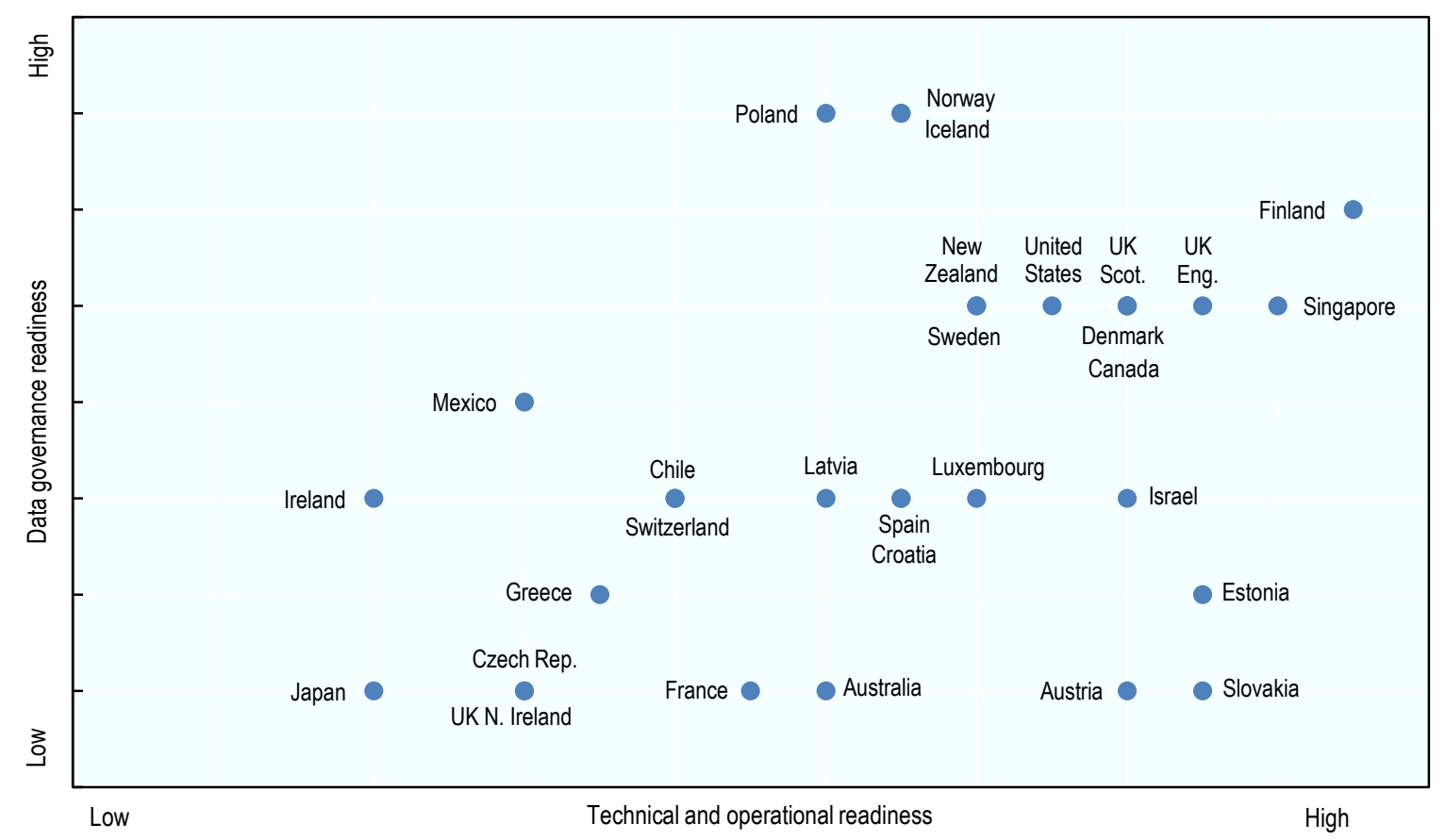

Note: Technical and operational readiness is the cumulative score of nine indicators each valued at one point: EMR coverage, information sharing among physicians and hospitals, defined minimum dataset, use of structured data, unique record identification, national standardisation of terminology and electronic messaging, legal requirements for adoption, software vendor certification and incentives for adoption. Data governance readiness is the cumulative score of four indicators: national plan or priority for secondary data use, dataset creation, and contribution of EHR data to monitoring and research which are each valued at one point; and legal issues impeding dataset creation which subtracts one point. See Table 1 for technical and operational readiness indicators and Table 12 for EHR data governance indicators

Source: HCQI Survey of Electronic Health Record System Development and Use, 2016

\subsection{International cooperation supports harmonisation toward common best practices}

269. The results of this study provide a comprehensive overview of the readiness of OECD countries to begin or further the statistical and research uses of EHR system data to support the quality and performance of health systems, to improve patient experiences and outcomes of care, and to further medical research and other public policy objectives.

270. This study identified many challenges that countries are facing in their efforts to assure that electronic clinical records are complete, accurate, relevant, unique, interpretable and widely available. Solutions adopted in some jurisdictions, and which have been described in this study, could potentially address some the data quality concerns that have been expressed. This would include setting terminology and interoperability standards, creating mandatory requirements or financial incentives to promote structure and standards, creating a standardised minimum dataset, and clinical data content quality auditing, among other strategies.

271. Financial resources are a concern that may limit the advancement of electronic health record systems and the use of data from such systems in several countries. Perhaps the most difficult challenge for the countries that are not yet planning for the statistical and research use of electronic patient data; however, is to proceed in a manner that fosters trust in health systems and governments and that succeeds 
in effective public communication, stakeholder engagement, infrastructure investment and legal reforms to achieve privacy-protective data use for the benefit of patients and society.

272. Among EU Member States, the opportunity to consider and potentially address unnecessary legal limitations to data use is presenting itself, as the new 2016 EU Data Protection Regulation takes effect. ${ }^{13}$ The regulation requires EU members to review current legislation to assure the compatibility of national health data privacy protection frameworks with EU requirements.

273. The results of this study emphasise the importance of continuing to monitor countries' progress in this challenging area in order to share best practices and to foster greater harmonisation of practices which, in turn, will support multinational cooperation in research and monitoring, including continuous improvement in the OECD health care quality indicators.

274. The OECD is also working to support countries in developing national health data governance frameworks that protect patients' privacy and the security of health data, while, at the same time, allowing electronic patient data to be analysed to support monitoring and research that is in the public interest. Eight key health data governance mechanisms were developed by the OECD HCQI with advice from the OECD Working Party on Privacy and Security in the Digital Economy (OECD, 2015a).

\footnotetext{
${ }^{13}$ The Data Protection Regulation (EU) 2016/679 ("General Data Protection Regulation") will replace national laws transposing Directive 95/46/EC as of 25 May 2018. It is providing for clear and uniform rules for the processing of personal data, including sensitive data, which include health, genetic and biometric data.
} 


\section{REFERENCES}

Anderson G and Oderkirk J (eds.) (2015c), Dementia Research and Care: Can Big Data Help? OECD Publishing, Paris. http://www.oecd.org/health/dementia-research-and-care-9789264228429-en.htm; http://dx.doi.org/10.1787/9789264228429-en

Jensen PB, Jensen LL and Brunak S (2012), Mining Electronic Health Records: Towards Better Research Applications and Clinical Care, Nature Reviews, Genetics, Vol. 13.

Liao KP, Cai T, Savova GK et al (2015), Development of phenotype algorithms using electronic medical records and incorporating natural language processing, BMJ; 350:h1885.

OECD (2013), Strengthening Health Information Infrastructure for Health Care Quality Governance: Good Practices, New Opportunities and Data Privacy Protection Challenges, OECD Health Policy Studies, OECD Publishing, Paris. http://www.oecd.org/publications/strengthening-healthinformation-infrastructure-for-health-care-quality-governance-9789264193505-en.htm; http://dx.doi.org/10.1787/9789264193505-en

OECD (2015a), Health Data Governance: Privacy, Monitoring and Research, OECD Health Policy Studies, OECD Publishing, Paris. http://www.oecd.org/publications/health-data-governance9789264244566-en.htm; http://dx.doi.org/10.1787/9789264244566-en

OECD (2015b), Data Driven Innovation for Growth and Well-Being, Chapter 8: The Evolution of Health in a Data Rich Environment, OECD Publishing, Paris. http://www.oecd.org/sti/data-driveninnovation-9789264229358-en.htm; http://dx.doi.org/10.1787/9789264229358-en

Pangalos G, Sfyroeras V, Pagkalos I (2014), E-prescription as a tool for improving services and the financial viability of healthcare systems: the case of the Greek national e-prescription system, Int $\mathbf{J}$ Electron Healthc., 7(4):301-14; http://dx.doi.org/10.1504/IJEH.2014.064331 


\section{ANNEX 1 \\ Countries participating in the 2016 Study of EHR System Development and Data Use}

275. Twenty-eight countries responded to the 2016 survey of the Health Care Quality Indicators (HCQI) Expert Group exploring the development, governance and use of data from electronic health record systems (Table A1).

276. Three members of the United Kingdom are included in this study: England, Northern Ireland and Scotland. The data governance and operational and technical capacities of members of the United Kingdom have important differences that are of interest to OECD countries and, as a result, they are presented separately in this report.

277. This study follows up upon results that were first collected in 2012 and published in 2013 in order to continue to monitor progress toward improving national health information infrastructures that are capable of supporting national health care quality and health system performance monitoring and research for better health and health care in OECD countries (OECD, 2013).

Table A1: Respondents to the 2016 HCQI Survey of EHR Systems Development and Use

\begin{tabular}{|c|c|c|c|}
\hline COUNTRY & NAME & POSITION & ORGANISATION \\
\hline AUSTRALIA & Jessica Fortune & OECD Engagement Team & $\begin{array}{l}\text { Australian Government } \\
\text { Department of Health }\end{array}$ \\
\hline AUSTRIA & Silvia Türk & Head of Department I/C/14 & $\mathrm{l} / \mathrm{C} / 14$ \\
\hline CANADA & Dennis Giokas / Brent Diverty & $\begin{array}{l}\text { Chief Technology Officer / } \\
\text { Vice President Programs }\end{array}$ & $\begin{array}{c}\text { Canada Health Infoway / } \\
\text { Canadian Institute for Health } \\
\text { Information }\end{array}$ \\
\hline CHILE & & & Ministry of Health \\
\hline DENMARK & Kenneth Ahrensberg & Liaison Officer & Danish Health Data Authority \\
\hline ESTONIA & Nele Nisu & $\begin{array}{c}\text { Adviser of Digital } \\
\text { Development Department }\end{array}$ & Ministry of Social Affairs \\
\hline FINLAND & Päivi Hämäläinen & Leading Expert & $\begin{array}{l}\text { National Institute for Health } \\
\text { and Welfare }\end{array}$ \\
\hline
\end{tabular}


DELSA/HEA/WD/HWP(2017)9

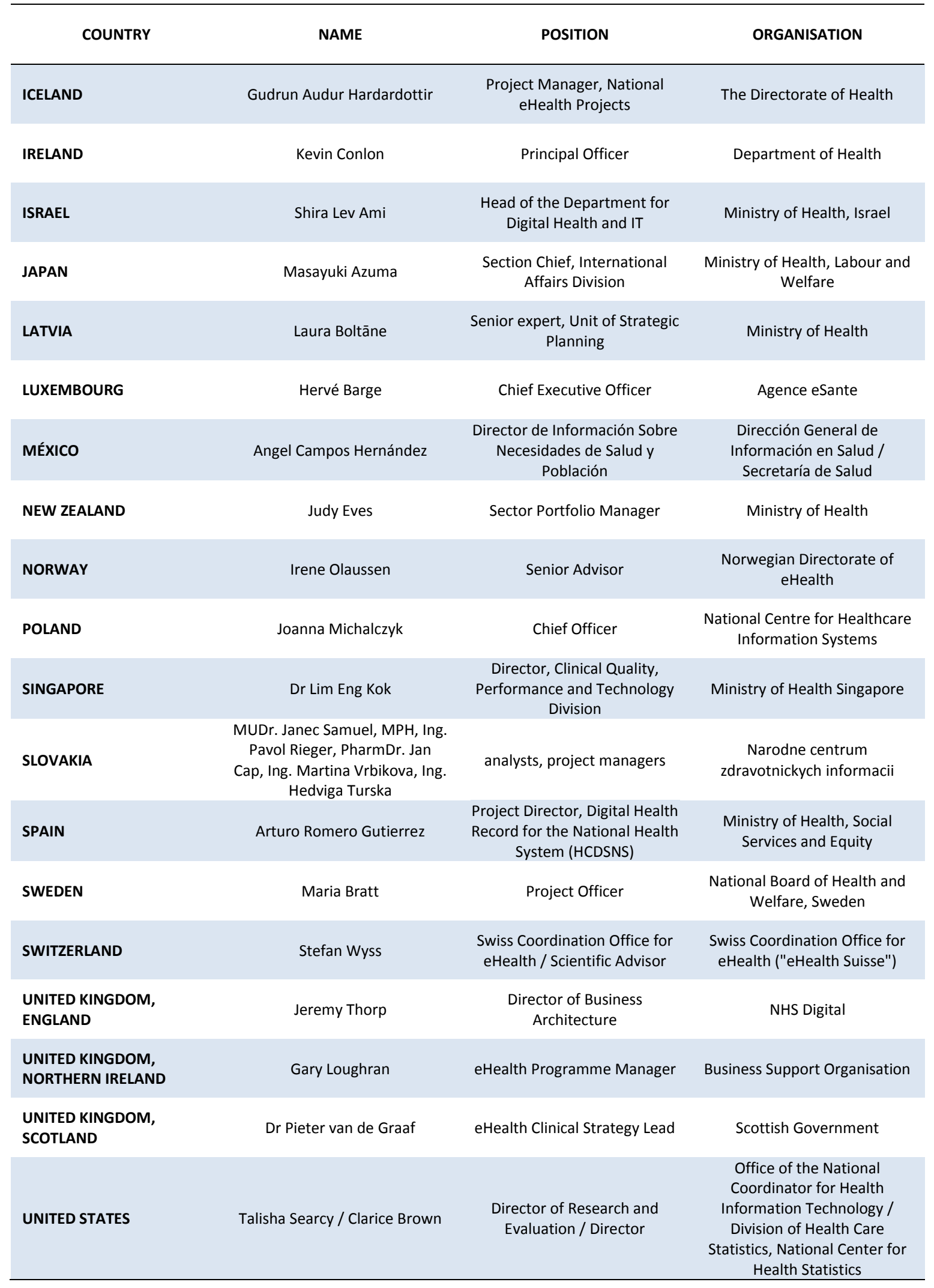




\section{ANNEX 2}

\section{Supplementary Tables}

Table 1: Summary Table of Technical and Operational Readiness to Generate Health Information from EHRs

\begin{tabular}{|c|c|c|c|c|c|c|c|c|c|c|}
\hline Country & $\begin{array}{l}\text { At least } 70 \% \text { of } \\
\text { primary care } \\
\text { physicians and } \\
\text { hospitals are } \\
\text { using EMR/EPR }\end{array}$ & $\begin{array}{l}\text { National system } \\
\text { includes } \\
\text { information } \\
\text { sharing among } \\
\text { physicians and } \\
\text { hospitals about } \\
\text { treatment, } \\
\text { medications, } \\
\text { laboratory tests } \\
\text { and images }\end{array}$ & $\begin{array}{l}\text { Minimum data } \\
\text { set has been } \\
\text { defined }^{3}\end{array}$ & $\begin{array}{l}\text { Key data } \\
\text { elements in all } \\
\text { or most records } \\
\text { are structured } \\
\text { (coded to a } \\
\text { terminology } \\
\text { standard) }^{4}\end{array}$ & $\begin{array}{c}\text { Unique patient } \\
\text { and provider } \\
\text { identifiers in } \\
\text { EHRs }^{5}\end{array}$ & $\begin{array}{l}\text { National } \\
\text { organisation is } \\
\text { responsible for } \\
\text { clinical } \\
\text { terminology } \\
\text { and electronic } \\
\text { messaging } \\
\text { standards }^{6}\end{array}$ & $\begin{array}{l}\text { Legal } \\
\text { requirement to } \\
\text { adopt EHR } \\
\text { systems that } \\
\text { conform to } \\
\text { clinical } \\
\text { terminology } \\
\text { and electronic } \\
\text { messaging } \\
\text { standards }\end{array}$ & $\begin{array}{l}\text { Certification } \\
\text { requires } \\
\text { vendors to } \\
\text { adopt } \\
\text { standards and } \\
\text { use structured } \\
\text { data }^{7}\end{array}$ & $\begin{array}{l}\text { Financial } \\
\text { incentives or } \\
\text { penalties to } \\
\text { adopt and } \\
\text { maintain high } \\
\text { quality EHRs }\end{array}$ & Total $(\max =9)$ \\
\hline Australia & 0 & 1 & 1 & 0 & 1 & 1 & 0 & 0 & 1 & 5 \\
\hline Austria & 1 & 1 & 0 & 1 & 1 & 1 & 1 & n.r. & 1 & 7 \\
\hline Canada & 1 & 1 & 1 & 1 & 1 & 1 & 0 & n.r. & 1 & 7 \\
\hline Chile & 0 & 0 & 0 & 1 & 0 & 1 & 0 & 1 & 1 & 4 \\
\hline Croatia & 0 & 0 & 1 & 1 & 1 & 1 & 0.5 & 1 & 0 & 5.5 \\
\hline Czech Republic & 1 & 0 & 1 & n.r. & 0.5 & 0.5 & 0 & n.r. & 0 & 3 \\
\hline Denmark & 1 & 1 & 1 & 1 & 1 & 1 & 1 & n.r. & 0 & 7 \\
\hline Estonia & 1 & 0.5 & 1 & 1 & 1 & 1 & 1 & n.r. & 1 & 7.5 \\
\hline Finland & 1 & 0.5 & 1 & 1 & 1 & 1 & 1 & 1 & 1 & 8.5 \\
\hline France & 0 & 1 & 1 & 0 & 1 & 0 & 0.5 & 1 & 0 & 4.5 \\
\hline Greece & 0 & 0.5 & 1 & 1 & 1 & 0 & n.r. & n.r. & 0 & 3.5 \\
\hline Iceland & 1 & 0.5 & 1 & 1 & 1 & 1 & 0 & n.r. & 0 & 5.5 \\
\hline Ireland & 0 & 0 & 1 & n.r. & 0.5 & 0 & 0.5 & 0 & 0 & 2 \\
\hline Israel & 1 & 1 & 1 & 1 & 1 & 1 & 0 & n.r. & 1 & 7 \\
\hline Japan & 0 & 0 & 1 & 1 & 0 & 1 & 0 & n.r. & 0 & 3 \\
\hline Latvia & 1 & 0.5 & 1 & 1 & 1 & 0.5 & 0 & n.r. & 0 & 5 \\
\hline Luxembourg & n.r. & 1 & 1 & 0 & 1 & 1 & 1 & 1 & 0 & 6 \\
\hline Mexico & 0 & 0 & 0 & 1 & 1 & 0 & 0 & 1 & 0 & 3 \\
\hline New Zealand & 1 & 1 & 1 & 1 & 1 & 1 & 0 & 0 & 0 & 6 \\
\hline Norway & 1 & 0.5 & 1 & 1 & 1 & 0 & n.r. & 0 & 1 & 5.5 \\
\hline Poland & 0 & 1 & 1 & 0 & 1 & 1 & 1 & n.r. & 0 & 5 \\
\hline Singapore & 1 & 1 & 1 & 1 & 1 & 1 & 0 & 1 & 1 & 8 \\
\hline
\end{tabular}


DELSA/HEA/WD/HWP(2017)9

\begin{tabular}{|c|c|c|c|c|c|c|c|c|c|c|}
\hline Country & $\begin{array}{l}\text { At least } 70 \% \text { of } \\
\text { primary care } \\
\text { physicians and } \\
\text { hospitals are } \\
\text { using EMR/EPR }\end{array}$ & $\begin{array}{l}\text { National system } \\
\text { includes } \\
\text { information } \\
\text { sharing among } \\
\text { physicians and } \\
\text { hospitals about } \\
\text { treatment, } \\
\text { medications, } \\
\text { laboratory tests } \\
\text { and images }\end{array}$ & $\begin{array}{l}\text { Minimum data } \\
\text { set has been } \\
\text { defined }^{3}\end{array}$ & $\begin{array}{l}\text { Key data } \\
\text { elements in all } \\
\text { or most records } \\
\text { are structured } \\
\text { (coded to a } \\
\text { terminology } \\
\text { standard) }{ }^{4}\end{array}$ & $\begin{array}{c}\text { Unique patient } \\
\text { and provider } \\
\text { identifiers in } \\
\text { EHRs }^{5}\end{array}$ & $\begin{array}{c}\text { National } \\
\text { organisation is } \\
\text { responsible for } \\
\text { clinical } \\
\text { terminology } \\
\text { and electronic } \\
\text { messaging } \\
\text { standards }^{6}\end{array}$ & $\begin{array}{l}\text { Legal } \\
\text { requirement to } \\
\text { adopt EHR } \\
\text { systems that } \\
\text { conform to } \\
\text { clinical } \\
\text { terminology } \\
\text { and electronic } \\
\text { messaging } \\
\text { standards }\end{array}$ & $\begin{array}{l}\text { Certification } \\
\text { requires } \\
\text { vendors to } \\
\text { adopt } \\
\text { standards and } \\
\text { use structured } \\
\text { data }^{7}\end{array}$ & $\begin{array}{l}\text { Financial } \\
\text { incentives or } \\
\text { penalties to } \\
\text { adopt and } \\
\text { maintain high } \\
\text { quality EHRs }\end{array}$ & Total $(\max =9)$ \\
\hline Slovakia & 1 & 0.5 & 1 & 1 & 1 & 1 & 1 & 1 & 0 & 7.5 \\
\hline Spain & 1 & 1 & 1 & 0 & 0.5 & 1 & 0 & n.r. & 1 & 5.5 \\
\hline Sweden & 1 & 1 & 1 & 1 & 1 & 1 & 0 & 0 & 0 & 6 \\
\hline Switzerland & 0 & 1 & 1 & 0 & 1 & 1 & 0 & n.r. & 0 & 4 \\
\hline UK England & 1 & 0.5 & 1 & 1 & 1 & 1 & 0 & 1 & 1 & 7.5 \\
\hline $\begin{array}{l}\text { UK Northern } \\
\text { Ireland }\end{array}$ & 1 & 1 & 0 & 0 & 1 & 0 & 0 & 0 & 0 & 3 \\
\hline UK Scotland & 1 & 0.5 & 1 & 1 & 0.5 & 1 & 0 & 1 & 1 & 7 \\
\hline United States & 1 & 0 & 1 & 1 & 0.5 & 1 & 0 & 1 & 1 & 6.5 \\
\hline
\end{tabular}

Source: HCQI Survey of Electronic Health Record System Development and Use, 2016

N.B. Yes is 1 point, a Partial Yes is 0.5 points and No is 0 points

${ }^{1}$ See Table 2

${ }^{2}$ See Table 3. A score of 0.5 indicates that some aspects of data sharing among physicians and hospitals were reported.

${ }^{3}$ See Table 5 .

${ }^{4}$ See Table 6 . A score of 1 indicates that at least 3 of 5 key elements are structured in all or most records.

${ }^{5}$ See Table 8. A score of 0.5 indicates that there is a unique ID for only one group (patients or providers).

${ }^{6}$ See Table 9. A score of 0.5 indicates that there is a national organisation responsible for either clinical terminology or electronic messaging standards (not both)

${ }^{7}$ See Table 10.

${ }^{8} \mathrm{~A}$ score of 0.5 indicates that there is a legal requirement for electronic messaging standards only. 
Table 2: Use of electronic clinical records by physicians and hospitals

\begin{tabular}{|c|c|c|c|c|}
\hline Country & $\begin{array}{l}\text { Primary care physician } \\
\text { offices using EMRs }\end{array}$ & $\begin{array}{l}\text { Medical specialist } \\
\text { offices using EMRs }\end{array}$ & $\begin{array}{l}\text { Hospitals using EPRs } \\
\text { for inpatients }\end{array}$ & $\begin{array}{c}\text { Hospital emergency } \\
\text { rooms using EPRs }\end{array}$ \\
\hline & $\%$ & $\%$ & $\%$ & $\%$ \\
\hline Australia & $96.2 \%$ & $37 \%$ & $20 \%$ & $20 \%$ \\
\hline Austria & $80 \%$ & $90 \%$ & $99 \%$ & $99 \%$ \\
\hline Canada & $77.2 \%^{1}$ & $73.2 \%^{1}$ & $68.8 \%^{2}$ & $68.8 \%^{2}$ \\
\hline Chile & $65 \%^{2}$ & $63 \%^{3}$ & $69 \%$ & $68 \%$ \\
\hline Croatia & $3 \%$ & $1 \%$ & n.r. & n.r. \\
\hline Czech Republic & $77.60 \%$ & $75.80 \%$ & $100 \%$ & $100 \%$ \\
\hline Denmark & $100 \%$ & $100 \%$ & $100 \%$ & $100 \%$ \\
\hline Estonia & $99 \%$ & $55 \%$ & $100 \%$ & n.r. \\
\hline Finland & $100 \%$ & $100 \%$ & $100 \%$ & $90 \%$ \\
\hline France & $80 \%$ & $80 \%$ & $60 \%$ & $60 \%$ \\
\hline Greece & $\approx 100 \%$ & $\approx 100 \%$ & $\approx 50 \%$ & $\approx 50 \%$ \\
\hline Iceland & $100 \%$ & $90 \%$ & $100 \%$ & $100 \%$ \\
\hline Ireland & $>95 \%$ & n.r. & $30-40 \%$ & $50-60 \%$ \\
\hline Israel & $100 \%$ & $50 \%$ & $100 \%$ & n.r. \\
\hline Japan & $35.6 \%$ & $35.6 \%$ & $34.2 \%$ & $34.2 \%$ \\
\hline Latvia & $70 \%$ & n.r. & $90 \%$ & n.r. \\
\hline Luxembourg & n.r. & n.r. & n.r. & n.r. \\
\hline Mexico & $30.25 \%$ & n.r. & $49.42 \%$ & n.r. \\
\hline New Zealand & $95 \%$ & 65 & $100 \%$ & $100 \%$ \\
\hline Norway & $100 \%$ & $>95 \%$ & $100 \%$ & $100 \%$ \\
\hline Poland & $30 \%$ & $45 \%$ & $10 \%$ & $10 \%$ \\
\hline Singapore & $<100 \%{ }^{4}$ & $<100 \%{ }^{4}$ & $100 \%^{5}$ & n.r. \\
\hline Slovakia & $89 \%$ & $91 \%$ & $100 \%$ & $100 \%$ \\
\hline Spain & $99 \%$ & $70 \%$ & $80 \%$ & $80 \%$ \\
\hline Sweden & $100 \%$ & $100 \%$ & $100 \%$ & $100 \%$ \\
\hline Switzerland & $\approx 40 \%$ & $18 \%$ & $\approx 100 \%$ & $\approx 100 \%$ \\
\hline UK England & $99 \%$ & $30 \%$ & $100 \%$ & $100 \%$ \\
\hline UK Northern Ireland & $100 \%$ & n.r. & $100 \%$ & $100 \%$ \\
\hline UK Scotland & $100 \%$ & $100 \%$ & $100 \%$ & $100 \%$ \\
\hline United States & $83 \%$ & $\approx \% 80$ & $76 \%$ & n.r. \\
\hline
\end{tabular}

Source: HCQI Survey of Electronic Health Record System Development and Use, 2016

${ }^{1} \%$ of physicians (not offices)

${ }^{2} \%$ of hospitals at stage 2 or above

${ }^{3} \%$ of practices

${ }^{4}$ All public sector primary care offices have implemented EMRs/EPRs and an estimated $54 \%$ of private sector primary care physicians and medical specialists have implemented them.

${ }^{5} \%$ of acute care hospitals 
DELSA/HEA/WD/HWP(2017)9

Table 3: National electronic health record systems

\begin{tabular}{|c|c|c|c|c|c|c|c|c|c|c|c|c|}
\hline \multirow[b]{3}{*}{ COUNTRY } & \multirow[b]{3}{*}{ 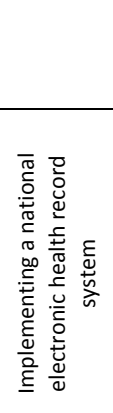 } & \multirow{2}{*}{\multicolumn{3}{|c|}{ Type of national system: }} & \multicolumn{8}{|c|}{ National system includes information sharing among: } \\
\hline & & & & & \multicolumn{4}{|c|}{ Physician offices about: } & \multicolumn{4}{|c|}{ Physician offices and hospitals about: } \\
\hline & & 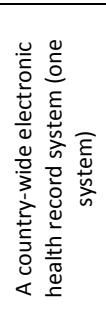 & 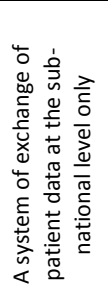 & 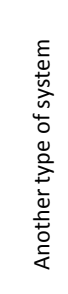 & 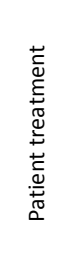 & 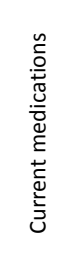 & 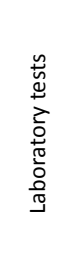 & 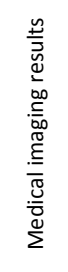 & 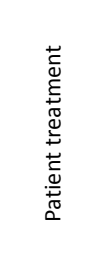 & 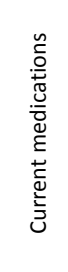 & 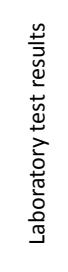 & 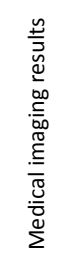 \\
\hline Australia & Yes & Yes & & & Yes & Yes & Yes & Yes & Yes & Yes & Yes & Yes \\
\hline Austria & Yes & Yes & & & Yes & Yes & Yes & Yes & Yes & Yes & Yes & Yes \\
\hline Canada & Yes & & Yes & & Yes & Yes & Yes & Yes & Yes & Yes & Yes & Yes \\
\hline Chile & No & & & & & & & & & & & \\
\hline Croatia & No & & & & & & & & & & & \\
\hline Czech Republic & No & & & & & & & & & & & \\
\hline Denmark & No & & & Yes & & Yes & Yes & Yes & Yes & Yes & Yes & Yes \\
\hline Estonia & Yes & Yes & & & Yes & Yes & & Yes & Yes & Yes & & Yes \\
\hline Finland & Yes & Yes & & Yes & Yes & Yes & Yes & & Yes & Yes & Yes & \\
\hline France & Yes & Yes & & & Yes & Yes & Yes & Yes & Yes & Yes & Yes & Yes \\
\hline Greece & Yes & Yes & & & Yes & Yes & & & Yes & Yes & & \\
\hline Iceland & Yes & Yes & & & Yes & Yes & & & Yes & Yes & & \\
\hline Ireland & Yes & Yes & & Yes & & & & & & & & \\
\hline Israel & Yes & Yes & & & Yes & Yes & Yes & Yes & Yes & Yes & Yes & Yes \\
\hline Japan & No & & & & & & & & & & & \\
\hline Latvia & Yes & Yes & & & Yes & Yes & & Yes & Yes & Yes & & Yes \\
\hline Luxembourg & Yes & Yes & & & Yes & Yes & Yes & Yes & Yes & Yes & Yes & Yes \\
\hline Mexico & No & & & & & & & & & & & \\
\hline New Zealand & Yes & Yes & & & Yes & Yes & Yes & Yes & Yes & Yes & Yes & Yes \\
\hline Norway & Yes & Yes & & & Yes & Yes & & & Yes & Yes & & \\
\hline Poland & Yes & Yes & Yes & & Yes & Yes & Yes & Yes & Yes & Yes & Yes & Yes \\
\hline Singapore & Yes & Yes & Yes & Yes & Yes & Yes & Yes & Yes & Yes & Yes & Yes & Yes \\
\hline Slovakia & Yes & Yes & & & Yes & Yes & Yes & & Yes & Yes & Yes & \\
\hline Spain & Yes & & Yes & & Yes & Yes & Yes & Yes & Yes & Yes & Yes & Yes \\
\hline Sweden & Yes & & & Yes & Yes & Yes & Yes & Yes & Yes & Yes & Yes & Yes \\
\hline Switzerland & Yes & & Yes $^{1}$ & & Yes $^{1}$ & Yes $^{1}$ & Yes $^{1}$ & Yes $^{1}$ & Yes $^{1}$ & Yes $^{1}$ & Yes $^{1}$ & Yes $^{1}$ \\
\hline UK England & Yes & Yes & & & Yes & Yes & Yes & Yes & Yes & Yes & & Yes \\
\hline $\begin{array}{l}\text { UK Northern } \\
\text { Ireland }\end{array}$ & Yes & Yes & & & Yes & Yes & Yes & Yes & Yes & Yes & Yes & Yes \\
\hline UK Scotland & Yes & Yes & Yes & Yes & Yes & Yes & & & Yes & Yes & & \\
\hline United States & No & & & & & & & & & & & \\
\hline
\end{tabular}

Source: HCQI Survey of Electronic Health Record System Development and Use, 2016

(1) Planned and legally authorised. 
DELSA/HEA/WD/HWP(2017)9

Table 4: Patients can view or interact with their own electronic health record

\begin{tabular}{|c|c|c|}
\hline Country & $\begin{array}{l}\text { Patients can view information } \\
\text { contained in their own record }\end{array}$ & $\begin{array}{l}\text { Patients can interact with their own } \\
\text { record }\end{array}$ \\
\hline Australia & Yes & Yes \\
\hline Austria & Yes & No \\
\hline Canada & Yes $^{1}$ & Yes $^{1}$ \\
\hline Chile & No & No \\
\hline Croatia & No & No \\
\hline Czech Republic & No & No \\
\hline Denmark & Yes & Yes \\
\hline Estonia & Yes & Yes \\
\hline Finland & Yes & No \\
\hline France & Yes & Yes \\
\hline Greece & Yes & Yes \\
\hline Iceland & n.r. & Yes \\
\hline Ireland & No & No \\
\hline Israel & No & No \\
\hline Japan & No & No \\
\hline Latvia & Yes & Yes \\
\hline Luxembourg & Yes & Yes \\
\hline Mexico & Yes & No \\
\hline New Zealand & Yes & Yes \\
\hline Norway & Yes & No \\
\hline Poland & No & No \\
\hline Singapore & No & No \\
\hline Slovakia & Yes & No \\
\hline Spain & Yes & Yes \\
\hline Sweden & Yes & Yes \\
\hline Switzerland & Yes & Yes \\
\hline United Kingdom (England) & Yes & No \\
\hline United Kingdom (Northern Ireland) & No & No \\
\hline United Kingdom (Scotland) & Yes & Yes \\
\hline United States & Yes & n.r. \\
\hline
\end{tabular}

Source: HCQI Survey of Electronic Health Record System Development and Use, 2016

Notes: n.r. Not reported

(1) Some provinces and territories 
Table 5: National minimum dataset

ELEMENTS OF THE MINIMUM DATA SET:

\begin{tabular}{|c|c|c|c|c|c|c|c|c|c|c|c|}
\hline Country & 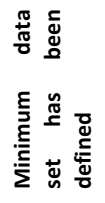 & 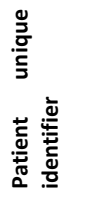 & 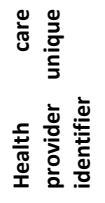 & 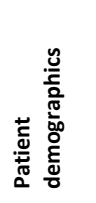 & 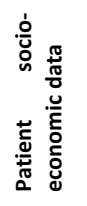 & 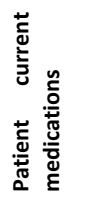 & 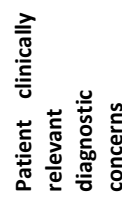 & 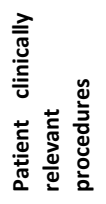 & 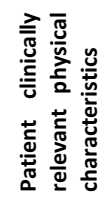 & 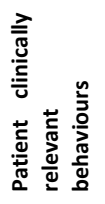 & 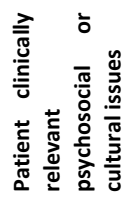 \\
\hline Australia & Yes & Yes & Yes & Yes & No & $\mathrm{Yes}^{3}$ & Yes & Yes & No & No & No \\
\hline Austria & No & n.a. & n.a. & n.a. & n.a. & n.a. & n.a. & n.a. & n.a. & n.a. & n.a. \\
\hline Canada & Yes & Yes4 & Yes4 & Yes & Yes & Yes & Yes & Yes & Yes & Yes & Yes \\
\hline Chile & No & n.a. & n.a. & n.a. & n.a. & n.a. & n.a. & n.a. & n.a. & n.a. & n.a. \\
\hline Croatia & Yes & Yes & Yes & Yes & No & Yes & Yes & No & No & No & No \\
\hline Czech Republic & Yes & Yes & Yes & Yes & Yes & Yes & Yes & Yes & Yes & No & No \\
\hline Denmark & Yes & Yes & Yes & Yes & Yes $^{2}$ & Yes & Yes & Yes & Yes & Yes & No \\
\hline Estonia & Yes & Yes & Yes & Yes & No5 & Yes & Yes & Yes & No & No & No \\
\hline Finland & Yes & Yes & Yes & Yes & Yes & Yes & Yes & Yes & No & No & No \\
\hline France & Yes & Yes & Yes & Yes & No & Yes & Yes & Yes & Yes & No & No \\
\hline Greece & Yes & Yes & No & Yes & No & Yes & Yes & n.r. & No & No & No \\
\hline Iceland & Yes & Yes & Yes & Yes & Yes & Yes & Yes & Yes & Yes & Yes & Yes \\
\hline Ireland & Yes6 & n.a. & n.a. & n.a. & n.a. & n.a. & n.a. & n.a. & n.a. & n.a. & n.a. \\
\hline Israel & Yes & Yes & Yes & Yes & No & Yes & Yes & Yes & No & No & No \\
\hline Japan & Yes & n.r. & n.r. & n.r. & n.r. & n.r. & n.r. & n.r. & n.r. & n.r. & n.r. \\
\hline Latvia & Yes & Yes & Yes & Yes & No & Yes & Yes & Yes7 & No & No & No \\
\hline Luxembourg & Yes & Yes & Yes & Yes & Yes & Yes & Yes & Yes & Yes & Yes & No \\
\hline Mexico & $\mathrm{No}^{1}$ & n.a. & n.a. & n.a. & n.a. & n.a. & n.a. & n.a. & n.a. & n.a. & n.a. \\
\hline New Zealand & Yes & Yes & Yes & Yes & Yes $^{2}$. & Yes $^{2}$ & Yes & Yes & Yes & Yes & Yes $^{2}$ \\
\hline Norway & Yes & Yes & Yes & Yes & $\mathrm{Yes}^{8}$ & Yes $^{9}$ & Yes $^{10}$ & No & No & No & No \\
\hline Poland & Yes $^{1}$ & Yes & Yes & Yes & No & Yes & Yes & Yes & Yes & Yes & No \\
\hline Singapore & Yes & Yes & Yes & Yes & Yes & Yes & Yes & Yes & No & No & No \\
\hline Slovakia & Yes & Yes & Yes & Yes & Yes & Yes & Yes & Yes & Yes & $\mathrm{No}^{11}$ & $\mathrm{No}^{11}$ \\
\hline Spain & Yes & Yes & Yes & Yes & No & Yes & Yes & Yes & Yes & Yes & Yes $^{12}$ \\
\hline Sweden $^{17}$ & Yes & Yes & Yes & Yes & No & Yes & Yes & Yes & No & Yes & No \\
\hline Switzerland & Yes $^{1}$ & Yes & Yes & Yes & d.k. & Yes & Yes & Yes & Yes & Yes & Yes \\
\hline UK England & Yes & Yes & Yes & Yes & No & No & Yes & Yes & No & No & No \\
\hline $\begin{array}{l}\text { UK Northern } \\
\text { Ireland }\end{array}$ & No & n.a. & n.a. & n.a. & n.a. & n.a. & n.a. & n.a. & n.a. & n.a. & n.a. \\
\hline UK Scotland & Yes & Yes & Yes & Yes & No & Yes & Yes & Yes & No & No & No \\
\hline United States & Yes & Yes $^{13}$ & Yes & Yes & No & Yes & Yes & Yes $^{15}$ & Yes & Yes $^{16}$ & No \\
\hline
\end{tabular}

Source: HCQI Survey of Electronic Health Record System Development and Use, 2016

Notes: n.r. Not reported // n.a. Not applicable // d.k. Unknown

(1) In planning. (2) Partly included. (3) Specification applies to only certain clinical documents. (4) Each province/territory defines its own identifiers. (5) Voluntary reporting of occupation and body mass index. (6) Dataset elements are in planning except for patient and provider unique identifiers which are being implemented. (7) Includes surgeries, implants and prostheses and excludes laboratory tests. (8) Excludes occupation. (9) Includes prescriptions filled by pharmacies. (10) Data element is not fully populated. (11) Optional reporting. (12) Caregivers are included. (13) US government is legally prohibited from developing or promoting a patient unique identifying number. Patient identification includes name, birthdate, address and race. (14) National provider identifier is legally required for publically-reimbursed services. Not all summary records exchanged contain the identifier. (15) Data elements included are optional according to the patients' clinical circumstances. (16) Smoking status only. (17) This relates to the National Patient Summary. For more information see http://www.telemedicine-momentum.eu/testimonial23/ 
Table 6: Use of structured elements in electronic health records

\begin{tabular}{|c|c|c|c|c|c|c|c|}
\hline \multicolumn{8}{|c|}{ Data elements: } \\
\hline Country & $\begin{array}{l}\text { Patient } \\
\text { diagnosis }\end{array}$ & $\begin{array}{c}\text { Patient } \\
\text { medications }\end{array}$ & $\begin{array}{c}\text { Patient } \\
\text { laboratory } \\
\text { test results }\end{array}$ & $\begin{array}{c}\text { Patient } \\
\text { medical } \\
\text { imaging } \\
\text { results }\end{array}$ & $\begin{array}{c}\text { Patient } \\
\text { surgical } \\
\text { procedures }\end{array}$ & $\begin{array}{l}\text { Count of } \\
\text { TA and TM }\end{array}$ & $\begin{array}{l}\text { Count of } \\
\text { TA and TM } \\
\text { in } 2012\end{array}$ \\
\hline Australia & TS & TM & TS & TS & TS & 1 & n.a. \\
\hline Austria & TM & TM & $\mathrm{TM}$ & TM & $\mathrm{F}$ & 4 & 4 \\
\hline Canada & TM & TM & TM & TM & TS & 4 & 1 \\
\hline Chile & TA & TA & TS & TS & TM & 3 & n.a. \\
\hline Croatia & TA & TA & TA & $\mathrm{F}$ & TA & 4 & n.a. \\
\hline Czech Republic & n.a. & n.a. & n.a. & n.a. & n.a. & n.a. & n.a. \\
\hline Denmark & TA & TA & TA & TA & TA & 5 & 5 \\
\hline Estonia & TA & TA & TA & TA & TA & 5 & 5 \\
\hline Finland & TA & TM & TA & TM & TA & 5 & 5 \\
\hline France & TS & TS & TS & TS & TS & 0 & 5 \\
\hline Greece & TA & TA & n.r. & n.r. & TA & 3 & n.a. \\
\hline Iceland & TA & TA & $\mathrm{TM}$ & TM & TA & 5 & 5 \\
\hline Ireland & n.a. & n.a. & n.a. & n.a. & n.a. & n.a. & n.a. \\
\hline Israel & TM & TM & $\mathrm{TM}$ & TS & TM & 4 & 4 \\
\hline Japan & TA & TA & TA & TA & TA & 5 & n.r. \\
\hline Latvia & TA & $\mathrm{TM}$ & n.i. & TM & TA & 4 & n.a. \\
\hline Luxembourg & TS & TS & TS & TS & TS & 0 & n.a. \\
\hline Mexico & TA & TA & TS & TM & TA & 4 & 5 \\
\hline New Zealand & TM & TM & $\mathrm{TM}$ & TM & TA & 5 & n.a. \\
\hline Norway & TA & TS & TA & $\mathrm{F}$ & TA & 3 & n.a. \\
\hline Poland & TA & TS & TS & $\mathrm{F}$ & TA & 2 & 2 \\
\hline Singapore & TM & $\mathrm{TM}$ & $\mathrm{TM}$ & TM & TM & 5 & 3 \\
\hline Slovakia & TA & $\mathrm{F}$ & TA & n.i. & TA & 3 & 5 \\
\hline Spain & TS & TS & TS & TS & TS & 0 & 0 \\
\hline Sweden & TM & $\mathrm{TM}$ & TM & $\mathrm{F}$ & TS & 3 & 3 \\
\hline Switzerland & TS & TS & TS & TS & $\mathrm{TM}^{1}$ & 1 & 0 \\
\hline UK England & TA & TA & TA & TA & TA & 5 & 5 \\
\hline UK Scotland & TM & TM & $\mathrm{TM}$ & TS & TM & 4 & 4 \\
\hline $\begin{array}{l}\text { UK Northern } \\
\text { Ireland }\end{array}$ & TS & TM & TM & TS & n.i. & 2 & n.a. \\
\hline United States & TA & TA & TM & TS & TM & 4 & 4 \\
\hline
\end{tabular}

Source: HCQI Survey of Electronic Health Record System Development and Use, 2016

TA-True All

TM-True Most

TS-True Some

F-False

n.i.-Not included

n.a.-Not applicable

n.r.-Not reported

(1) True for billing purposes. 
Table 7: Clinical terminology standards

DATA ELEMENTS:

\begin{tabular}{|c|c|c|c|c|c|c|c|c|c|c|}
\hline Country & $\begin{array}{l}\text { Patient socio- } \\
\text { economic } \\
\text { data }\end{array}$ & $\begin{array}{c}\text { Patient } \\
\text { medications }\end{array}$ & $\begin{array}{c}\text { Patient } \\
\text { diagnosis }\end{array}$ & $\begin{array}{l}\text { Patient } \\
\text { laboratory test } \\
\text { results }\end{array}$ & $\begin{array}{l}\text { Patient medical } \\
\text { imaging results }\end{array}$ & $\begin{array}{l}\text { Patient surgical } \\
\text { procedures }\end{array}$ & $\begin{array}{l}\text { Patient physical } \\
\text { characteristics }\end{array}$ & $\begin{array}{c}\text { Patient } \\
\text { clinically } \\
\text { relevant } \\
\text { behaviours }\end{array}$ & $\begin{array}{c}\text { Patient } \\
\text { clinically } \\
\text { relevant } \\
\text { psychosocial or } \\
\text { cultural issues }\end{array}$ & $\begin{array}{c}\text { Patient } \\
\text { reported } \\
\text { outcomes or } \\
\text { experiences of } \\
\text { care (PROMs or } \\
\text { PREMS) }\end{array}$ \\
\hline AUSTRALIA & & $\begin{array}{l}\text { Australian } \\
\text { Medicines } \\
\text { Terminology } \\
\text { (AMT) }^{1}\end{array}$ & $\begin{array}{c}\text { SNOMED CT- } \\
\text { AU }\end{array}$ & SNOMED CT-AU & SNOMED CT-AU & SNOMED CT-AU & & & & \\
\hline AUSTRIA & $\begin{array}{l}\text { HL7 Marital } \\
\text { Status }\end{array}$ & $\mathrm{PZN}^{2}, \mathrm{ATC}$ & ICD-10 & LOINC & & & LOINC & & & \\
\hline CANADA & HL7 V3 & $\begin{array}{c}\text { Drug } \\
\text { Identification } \\
\text { Number (DIN); } \\
\text { ATC }\end{array}$ & $\begin{array}{l}\text { ICD-10-CA, } \\
\text { DSM-IV, } \\
\text { SNOMED CT }\end{array}$ & LOINC & $\begin{array}{c}\text { DICOM / } \\
\text { SNOMED CT }\end{array}$ & $\begin{array}{l}\text { Canadian } \\
\text { Classification of } \\
\text { Health } \\
\text { Intervention } \\
(\text { CCI) / } \\
\text { SNOMED CT }\end{array}$ & $\begin{array}{l}\text { This could be } \\
\text { units of } \\
\text { measure - } \\
\text { UCUM, Imperial } \\
\text { or Metric }\end{array}$ & $\begin{array}{l}\text { CIHI Primary } \\
\text { Health Care } \\
\text { database and } \\
\text { RAI datasets } \\
\text { SNOMED CT }\end{array}$ & & $\begin{array}{l}\text { Canadian } \\
\text { Patient } \\
\text { Experiences } \\
\text { Survey- } \\
\text { Inpatient Care } \\
\text { (CPES-IC) })^{5}\end{array}$ \\
\hline CHILE & Decreto $820^{6}$ & SNOMED-CT & SNOMED-CT & & & SNOMED-CT & SNOMED-CT & SNOMED-CT & SNOMED-CT & \\
\hline CROATIA & & $\begin{array}{l}\text { CHIF list based } \\
\text { on ATC }\end{array}$ & MKB-10 & CHIF list & & CHIF list & & & & \\
\hline
\end{tabular}


DELSA/HEA/WD/HWP(2017)9

DATA ELEMENTS:

\begin{tabular}{|c|c|c|c|c|c|c|c|c|c|c|}
\hline Country & $\begin{array}{l}\text { Patient socio- } \\
\text { economic } \\
\text { data }\end{array}$ & $\begin{array}{c}\text { Patient } \\
\text { medications }\end{array}$ & $\begin{array}{c}\text { Patient } \\
\text { diagnosis }\end{array}$ & $\begin{array}{c}\text { Patient } \\
\text { laboratory test } \\
\text { results }\end{array}$ & $\begin{array}{l}\text { Patient medical } \\
\text { imaging results }\end{array}$ & $\begin{array}{l}\text { Patient surgical } \\
\text { procedures }\end{array}$ & $\begin{array}{l}\text { Patient physical } \\
\text { characteristics }\end{array}$ & $\begin{array}{l}\text { Patient } \\
\text { clinically } \\
\text { relevant } \\
\text { behaviours }\end{array}$ & $\begin{array}{c}\text { Patient } \\
\text { clinically } \\
\text { relevant } \\
\text { psychosocial or } \\
\text { cultural issues }\end{array}$ & $\begin{array}{c}\text { Patient } \\
\text { reported } \\
\text { outcomes or } \\
\text { experiences of } \\
\text { care (PROMs or } \\
\text { PREMS) }\end{array}$ \\
\hline CZECH REPUBLIC & & ATC / SUKL ${ }^{7}$ & $\begin{array}{l}\text { ICD-10 } \\
\text { (Czech } \\
\text { translation) }\end{array}$ & $N C L P^{8}$ & & $\mathrm{GHIC}^{9}$ & & & & \\
\hline DENMARK & & ATC & $\begin{array}{l}\text { ICD10 and } \\
\text { ICPC }\end{array}$ & IUPAC & ICD10 & $\begin{array}{l}\text { NOMESCO } \\
\text { classification of } \\
\text { surgical } \\
\text { procedures } \\
\text { (NCSP) }\end{array}$ & & & & $\begin{array}{l}\text { HL7 CDA is being } \\
\text { considered }\end{array}$ \\
\hline ESTONIA & $\begin{array}{l}\text { national } \\
\text { standards }\end{array}$ & ATC & ICD-10 & LOINC & DICOM & NCSP & $\begin{array}{c}\text { national } \\
\text { standards }^{12}\end{array}$ & $\begin{array}{c}\text { national } \\
\text { standards }^{12}\end{array}$ & $\begin{array}{c}\text { national } \\
\text { standards }^{12}\end{array}$ & \\
\hline FINLAND & $\begin{array}{l}\text { National } \\
\text { classifi- } \\
\text { cation }^{13}\end{array}$ & ATC & ICD-10 & $\begin{array}{l}\text { National classifi- } \\
\text { cation }^{13}\end{array}$ & $\begin{array}{l}\text { National classif- } \\
\text { ication }^{13}\end{array}$ & $\begin{array}{l}\text { Nordic classifi- } \\
\text { cation }^{13}\end{array}$ & FINLOINC & $\begin{array}{l}\text { National classifi- } \\
\text { cation }^{13}\end{array}$ & $\begin{array}{c}\text { Nordic } \\
\text { classification on } \\
\text { surgical } \\
\text { procedures }^{13}\end{array}$ & \\
\hline FRANCE & & $\mathrm{CIS}^{14}, \mathrm{CIP}^{14}$ & ICD-10 & $\mathrm{NABM}^{15}$ & HL7 v3/DICOM & ICD-10 & $\begin{array}{c}\text { Units of } \\
\text { measure UCUM }\end{array}$ & & & \\
\hline GREECE & & ATC & $\begin{array}{c}\text { ICD-10, ICPC- } \\
2\end{array}$ & $\begin{array}{l}\text { EDMA (gr } \\
\text { KEOKEE) }\end{array}$ & & & & & & \\
\hline
\end{tabular}


DELSA/HEA/WD/HWP(2017)9

DATA ELEMENTS

\begin{tabular}{|c|c|c|c|c|c|c|c|c|c|c|}
\hline Country & $\begin{array}{l}\text { Patient socio- } \\
\text { economic } \\
\text { data }\end{array}$ & $\begin{array}{c}\text { Patient } \\
\text { medications }\end{array}$ & $\begin{array}{l}\text { Patient } \\
\text { diagnosis }\end{array}$ & $\begin{array}{l}\text { Patient } \\
\text { laboratory test } \\
\text { results }\end{array}$ & $\begin{array}{l}\text { Patient medical } \\
\text { imaging results }\end{array}$ & $\begin{array}{l}\text { Patient surgical } \\
\text { procedures }\end{array}$ & $\begin{array}{l}\text { Patient physical } \\
\text { characteristics }\end{array}$ & $\begin{array}{c}\text { Patient } \\
\text { clinically } \\
\text { relevant } \\
\text { behaviours }\end{array}$ & $\begin{array}{c}\text { Patient } \\
\text { clinically } \\
\text { relevant } \\
\text { psychosocial or } \\
\text { cultural issues }\end{array}$ & $\begin{array}{c}\text { Patient } \\
\text { reported } \\
\text { outcomes or } \\
\text { experiences of } \\
\text { care (PROMs or } \\
\text { PREMS) }\end{array}$ \\
\hline ICELAND & Local codes & ATC & ICD-10, ICNP & $\begin{array}{l}\text { SNOMED-CT, } \\
\text { LOINC }\end{array}$ & DICOM & NCSP, NCSP-IS & ICNP, ICF & ICD-10, ICNP & ICD-10, ICNP & \\
\hline
\end{tabular}

IRELAND ICD-10 CM ICD-10 CM LONIC NIMIS
I6

\begin{tabular}{|c|c|c|c|c|c|c|c|c|}
\hline ISRAEL & Local codes & $\begin{array}{l}\text { Israeli drug } \\
\text { catalog } \\
\text { (YARPA) }\end{array}$ & ICD9-CM & Local codes & Local codes & ICD9-CM & & \\
\hline JAPAN & & $\begin{array}{l}\text { Pharmaceutica } \\
\text { I HOT Code } \\
\text { Master }^{17}\end{array}$ & ICD-10 & $\begin{array}{c}\text { Clinical Trial } \\
\text { Master }^{18}\end{array}$ & $\begin{array}{l}\mathrm{HIS}^{19}, \mathrm{RIS}^{19} \\
\text { PACS }^{19}\end{array}$ & $\begin{array}{c}\text { Standard } \\
\text { surgery/proced } \\
\text { ure master }{ }^{20}\end{array}$ & & \\
\hline LATVIA & & $\begin{array}{l}\text { INN and } \\
\text { Latvian list of } \\
\text { registered } \\
\text { products }\end{array}$ & ICD-10 & & DICOM & NCSP & & \\
\hline LUXEMBOURG & HL7 & ATC, Cefip & ICD-10 & LOINC & $\begin{array}{l}\text { Snomed CT, } \\
\text { ICD10 }\end{array}$ & & Snomed & Snomed \\
\hline
\end{tabular}


DELSA/HEA/WD/HWP(2017)9

DATA ELEMENTS:

\begin{tabular}{|c|c|c|c|c|c|c|c|c|c|c|}
\hline Country & $\begin{array}{l}\text { Patient socio- } \\
\text { economic } \\
\text { data }\end{array}$ & $\begin{array}{c}\text { Patient } \\
\text { medications }\end{array}$ & $\begin{array}{l}\text { Patient } \\
\text { diagnosis }\end{array}$ & $\begin{array}{c}\text { Patient } \\
\text { laboratory test } \\
\text { results }\end{array}$ & $\begin{array}{l}\text { Patient medical } \\
\text { imaging results }\end{array}$ & $\begin{array}{l}\text { Patient surgical } \\
\text { procedures }\end{array}$ & $\begin{array}{l}\text { Patient physical } \\
\text { characteristics }\end{array}$ & $\begin{array}{l}\text { Patient } \\
\text { clinically } \\
\text { relevant } \\
\text { behaviours }\end{array}$ & $\begin{array}{c}\text { Patient } \\
\text { clinically } \\
\text { relevant } \\
\text { psychosocial or } \\
\text { cultural issues }\end{array}$ & $\begin{array}{c}\text { Patient } \\
\text { reported } \\
\text { outcomes or } \\
\text { experiences of } \\
\text { care (PROMs or } \\
\text { PREMS) }\end{array}$ \\
\hline MEXICO & $\begin{array}{l}\text { Institute for } \\
\text { Statistics and } \\
\text { Geographic } \\
\text { Information }\end{array}$ & $\begin{array}{l}\text { National } \\
\text { formulary }^{22}\end{array}$ & $\begin{array}{c}\text { ICD-10 } \\
\text { (Spanish) }\end{array}$ & LOINC & DICOM & $\begin{array}{l}\text { ICD-9 CLINICAL } \\
\text { MODIFICATION } \\
\text { (SPANISH) }\end{array}$ & & & $\begin{array}{l}\text { Institute for } \\
\text { Statistics and } \\
\text { Geographic } \\
\text { Information }^{21}\end{array}$ & \\
\hline NEW ZEALAND & $\begin{array}{l}\text { Consumer } \\
\text { Health } \\
\text { Standard } \\
(\mathrm{NHI})^{23}\end{array}$ & $\begin{array}{l}\text { NZ Medicines } \\
\text { Terminology }{ }^{24} \text {; } \\
\text { SNOMED CT }\end{array}$ & $\begin{array}{l}\text { ICD10 AM; } \\
\text { ACHI, Read } \\
\text { codes }^{25}\end{array}$ & $\begin{array}{c}\text { NZPOCS }^{26}- \\
\text { LOINC, SNOMED }\end{array}$ & DICOM & ICD10 AM & & $\begin{array}{l}\text { PRIMHDD }^{27} \\
\text { SNOMED CT }\end{array}$ & $\begin{array}{l}\text { InterRai, } \\
\text { PRIMHD }^{28}\end{array}$ & \\
\hline NORWAY & & ATC & ICD-10 & NLK (NPU) & NCRP & NCSP & & & & \\
\hline POLAND & & $\begin{array}{l}\text { Central Drug } \\
\text { Vocabulary, } \\
\text { OSOZ, BLOZ }\end{array}$ & ICD-10 & & DICOM & ICD-9 & $\begin{array}{l}\text { Body Mass } \\
\text { Index }\end{array}$ & & & \\
\hline SINGAPORE & $\begin{array}{l}\text { National } \\
\text { Healthcare } \\
\text { Data } \\
\text { Dictionary }\end{array}$ & $\begin{array}{l}\text { Singapore } \\
\text { Drug } \\
\text { Dictionary }\end{array}$ & $\begin{array}{l}\text { ICD-9-CM, } \\
\text { ICD-10-AM, } \\
\text { SNOMED-CT }\end{array}$ & LOINC & DICOM & $\begin{array}{l}\text { Table of Surgical } \\
\text { Procedures }\end{array}$ & & & & \\
\hline
\end{tabular}


DELSA/HEA/WD/HWP(2017)9

DATA ELEMENTS

\begin{tabular}{|c|c|c|c|c|c|c|c|c|c|c|}
\hline Country & $\begin{array}{l}\text { Patient socio- } \\
\text { economic } \\
\text { data }\end{array}$ & $\begin{array}{c}\text { Patient } \\
\text { medications }\end{array}$ & $\begin{array}{c}\text { Patient } \\
\text { diagnosis }\end{array}$ & $\begin{array}{l}\text { Patient } \\
\text { laboratory test } \\
\text { results }\end{array}$ & $\begin{array}{l}\text { Patient medical } \\
\text { imaging results }\end{array}$ & $\begin{array}{l}\text { Patient surgical } \\
\text { procedures }\end{array}$ & $\begin{array}{l}\text { Patient physical } \\
\text { characteristics }\end{array}$ & $\begin{array}{c}\text { Patient } \\
\text { clinically } \\
\text { relevant } \\
\text { behaviours }\end{array}$ & $\begin{array}{c}\text { Patient } \\
\text { clinically } \\
\text { relevant } \\
\text { psychosocial or } \\
\text { cultural issues }\end{array}$ & $\begin{array}{c}\text { Patient } \\
\text { reported } \\
\text { outcomes or } \\
\text { experiences of } \\
\text { care (PROMs or } \\
\text { PREMS) }\end{array}$ \\
\hline SLOVAKIA & $\begin{array}{l}\text { SNOMED CT, } \\
\text { ICD-10, } \\
\text { Alliance NNN, } \\
\text { EC } 13606 \\
\text { archetypes }\end{array}$ & $\begin{array}{l}\text { ATC, EDQM, } \\
\text { INN }\end{array}$ & ICD-10 & LOINC & DICOM & $\begin{array}{l}\text { codebook of } \\
\text { medical } \\
\text { procedures }\end{array}$ & units of SI & ICD-10 & ICD-10 & \\
\hline SPAIN & & $\begin{array}{c}\text { National } \\
\text { codes }^{32} \\
\text { SNOMED CT }\end{array}$ & $\begin{array}{l}\text { ICD-9\&10 } \\
\text { CM, } \\
\text { SNOMED CT }\end{array}$ & $\begin{array}{c}\text { LOINC/ } \\
\text { SNOMED CT }\end{array}$ & $\begin{array}{l}\text { SERAM and } \\
\text { SEMNIM } \\
\text { Cataloge }\end{array}$ & $\begin{array}{c}\text { ICD-9 CM, ICD- } \\
10 \text { PCS, } \\
\text { SNOMED CT }\end{array}$ & & & & \\
\hline \multicolumn{11}{|l|}{ SWEDEN } \\
\hline SWITZERLAND & d.k. & $\begin{array}{c}\text { ATC, MedDRA, } \\
\text { WHO-ART }\end{array}$ & $\begin{array}{c}\text { ICD-10, ICPC- } \\
2\end{array}$ & $\begin{array}{c}\text { local } \\
\text { codes/LOINC }\end{array}$ & DICOM & CHOP & d.k. & d.k. & ICF & $\begin{array}{c}\text { ICNP, LEP (care), } \\
\text { NIC/NOC, } \\
\text { PLAISIR, PRN, } \\
\text { RAI-HC }\end{array}$ \\
\hline UK ENGLAND & & $\begin{array}{c}\mathrm{dm}+\mathrm{d} \\
(\mathrm{SNOMED} \\
\text { extension })^{10}\end{array}$ & ICD10 & LOINC & DICOM & $\mathrm{OPCS}^{11}$ & & & & \\
\hline $\begin{array}{l}\text { UK NORTHERN } \\
\text { IRELAND }\end{array}$ & READ & $D M+d$ & ICD 10, READ & READ & & OPCS 4, READ & & & & \\
\hline
\end{tabular}


DELSA/HEA/WD/HWP(2017)9

DATA ELEMENTS:

\begin{tabular}{|c|c|c|c|c|c|c|c|c|c|c|}
\hline Country & $\begin{array}{l}\text { Patient socio- } \\
\text { economic } \\
\text { data }\end{array}$ & $\begin{array}{c}\text { Patient } \\
\text { medications }\end{array}$ & $\begin{array}{c}\text { Patient } \\
\text { diagnosis }\end{array}$ & $\begin{array}{l}\text { Patient } \\
\text { laboratory test } \\
\text { results }\end{array}$ & $\begin{array}{l}\text { Patient medical } \\
\text { imaging results }\end{array}$ & $\begin{array}{l}\text { Patient surgical } \\
\text { procedures }\end{array}$ & $\begin{array}{l}\text { Patient physical } \\
\text { characteristics }\end{array}$ & $\begin{array}{l}\text { Patient } \\
\text { clinically } \\
\text { relevant } \\
\text { behaviours }\end{array}$ & $\begin{array}{c}\text { Patient } \\
\text { clinically } \\
\text { relevant } \\
\text { psychosocial or } \\
\text { cultural issues }\end{array}$ & $\begin{array}{c}\text { Patient } \\
\text { reported } \\
\text { outcomes or } \\
\text { experiences of } \\
\text { care (PROMs or } \\
\text { PREMS) }\end{array}$ \\
\hline UK SCOTLAND & $\begin{array}{l}\text { READ, SMR, } \\
\text { OSIAF }^{30}\end{array}$ & $\begin{array}{l}\text { DM+d, Drug } \\
\text { dictionaries }^{31}\end{array}$ & $\begin{array}{l}\text { ICD-10, } \\
\text { READ }\end{array}$ & ICD-10, READ ${ }^{30}$ & $\begin{array}{l}\text { Clinical Imaging } \\
\text { Procedure } \\
\text { Codes }^{30}\end{array}$ & ICD-10, READ ${ }^{30}$ & ICD-10, READ ${ }^{30}$ & ICD-10, READ ${ }^{30}$ & ICD-10, READ ${ }^{30}$ & \\
\hline United States & & $\begin{array}{c}\text { RxNorm, } \\
\text { National Drug } \\
\text { Code (NDC), } \\
\text { National Drug } \\
\text { File (NDF-RT) }\end{array}$ & $\begin{array}{l}\text { SNOMED-CT, } \\
\text { ICD-10 CM }\end{array}$ & LOINC & LOINC, DICOM & $\begin{array}{l}\text { SNOMED-CT, } \\
\text { ICD-10 CM, } \\
\text { HCPCS }\end{array}$ & LOINC & LOINC & & \\
\hline
\end{tabular}

Source: HCQI Survey of Electronic Health Record System Development and Use, 2016

Notes:

d.k. Unknown

(1) http://www.nehta.gov.au/get-started-with-ehealth/what-is-ehealth/clinical-terminology/australian-medicines-terminology

(2) https://termpub.gesundheit.gv.at:443/TermBrowser/gui/main/main.zul?loadType=CodeSystem\&loadName=ASP-Liste Liste der humanen Arzneispezialitaeten gelistet nach PZN

20160127

(3) http://www.cihi.ca/ClHI-ext-portal/internet/en/document/standards+and+data+submission/standards/classification+and+coding/codingclass_cci

InfoCentral: https://ic.infoway-inforoute.ca/en/resources/standards/infoway-standards

(4) www.interrai.org // InfoCentral: https://infocentral.infoway-inforoute.ca/2 Standards/1_pan-Canadian_Standards/Terminology/pan-

Canadian_Subset_Library/Primary_Health_Care_(PHC)_Reference_Sets (login required) // Terminology Gateway: https://tgateway.infoway-inforoute.ca/subsets. html

(5) https://www.cihi.ca/en/health-system-performance/quality-of-care-and-outcomes/patient-experience

(6) http://www.deis.cl/wp-content/uploads/2011/09/Decreto_Norma_TecnicaEstandares_de_Informacion_DEIS.pdf

(7) http://www.sukl.cz/ciselnik-klk

(8) http://ciselniky.dasta.mzcr.cz/CD/hypertext/DSAMA.htm 
(9) https://www.vzp.cz/poskytovatele/ciselniky/zdravotni-vykony

DELSA/HEA/WD/HWP(2017)9

(10) http://systems.hscic.gov.uk/eps/dispensing/dmd

(11) http://systems.hscic.gov.uk/data/clinicalcoding/codingstandards

(12) http//pub.e-tervis.ee

(13) http://koodistopalvelu.kanta.fi/codeserver/

(14) http://afssaps-prd.afssaps.fr/php/ecodex/telecharger/telecharger.php

(15) http://www.ameli.fr/professionnels-de-sante/directeurs-de-laboratoires-d-analyses-medicales/exercer-au-quotidien/codage-des-actes-biologiques-nabm_ardeche.php

(16) http://www.hse.ie/eng/services/news/newsfeatures/NIMIS

(17) http://www2.medis.or.jp/master/hcode/

(18) http://www2.medis.or.jp/master/kensa/index.html

(19) http://www2.medis.or.jp/master/gazoukensa/index.html

(20) http://www2.medis.or.jp/stdcd/shujutu/index.html

(21) http://www.inegi.org.mx/est/contenidos/proyectos/aspectosmetodologicos/clasificadoresycatalogos/

(22) http://www.csg.gob.mx/contenidos/CB2013/cuadro_basico.html

(23) http://healthitboard.health.govt.nz/hiso-10046-consumer-health-identity-standard

(24) http://www.nzulm.org.nz/

(25) https://www.accd.net.au/Downloads.aspx, http://www.achi.org.au/

(26) http://healthitboard.health.govt.nz/standards/approved-standards/hiso-100042015-new-zealand-pathology-observation-code-sets

(27) http://healthitboard.health.govt.nz/health-it-groups/health-information-standards-organisation-hiso/hiso-100232015-project-integration

(28) http://healthitboard.health.govt.nz/our-programmes/shared-health-information/common-clinical-information/comprehensive-clinical-0k

(29) http://csioz.gov.pl/, http://www.osoz.pl/osoz-www/leki/szuka, http://www.bloz.pl/bloz/main/wiecejj

(30) http://www.isdscotland.org/Products-and-Services/Terminology-Services/Coding-and-Terminology-Systems/

(31) http://www.nhsbsa.nhs.uk/1121.aspx

(32) http://www.aemps.gob.es/cima/fichasTecnicas.do?metodo=detalleForm

(33) http://www.semnim.es/index.php?option=com_content\&view=article\&id=205\&ltemid=92

http://seram.es/index.php?option=com_content\&view=article\&id=353\&catid=44\&ltemid=74

(34) https://www.healthit.gov/standards-advisor 
Table 8: Unique identification of patients and providers in EHR systems

\begin{tabular}{|c|c|c|c|c|}
\hline COUNTRY & $\begin{array}{l}\text { Unique number to ID } \\
\text { patients in EHRs }\end{array}$ & $\begin{array}{l}\text { Unique number to ID } \\
\text { providers entering data } \\
\text { into EHRs }\end{array}$ & Smart cards for patients & $\begin{array}{l}\text { Smart cards for health } \\
\text { care providers }\end{array}$ \\
\hline Australia & Yes & Yes & No & Yes \\
\hline Austria & Yes & Yes & Yes & Partly \\
\hline Canada & Yes & Yes & No & No \\
\hline Chile & No & No & No & No \\
\hline Croatia & Yes & Yes & No & Yes \\
\hline Czech Republic & Yes & No & No & No \\
\hline Denmark & Yes & Yes & No & No \\
\hline Estonia & Yes & Yes & Yes & Yes \\
\hline Finland & Yes & Yes & No & Yes \\
\hline France & Yes & Yes & Yes & Yes \\
\hline Greece & Yes & Yes & No & No \\
\hline Iceland & Yes & Yes & Yes & Yes \\
\hline Ireland & Yes & No & No & No \\
\hline Israel & Yes & Yes & No & Yes \\
\hline Japan & No & No & No & No \\
\hline Latvia & Yes & Yes & No & No \\
\hline Luxembourg & Yes & Yes & Yes & Yes \\
\hline Mexico & Yes & Yes & No & No \\
\hline New Zealand & Yes & Yes & No & No \\
\hline Norway & Yes & Yes & No & Yes \\
\hline Poland & Yes & Yes & No & No \\
\hline Singapore & Yes & Yes & No & No \\
\hline Slovakia & Yes & Yes & Yes & Yes \\
\hline Spain & Yes & No & Yes & Yes \\
\hline Sweden & Yes & Yes & No & Yes \\
\hline Switzerland & Yes & Yes & Yes & Yes \\
\hline UK England & Yes & Yes & No & Yes \\
\hline UK Northern Ireland & Yes & Yes & No & No \\
\hline UK Scotland & Yes & No & No & No \\
\hline United States & No & Yes & No & No \\
\hline
\end{tabular}

Source: HCQI Survey of Electronic Health Record System Development and Use, 2016 
DELSA/HEA/WD/HWP(2017)9

Table 9: National organisation responsible for EHR system infrastructure and standards

\begin{tabular}{|c|c|c|c|}
\hline COUNTRY & $\begin{array}{l}\text { National organisation is responsible for EHR system } \\
\text { infrastructure }\end{array}$ & $\begin{array}{l}\text { National organisation sets } \\
\text { standards for clinical } \\
\text { terminology }\end{array}$ & $\begin{array}{l}\text { National } \\
\text { organisation sets } \\
\text { standards for } \\
\text { electronic messaging }\end{array}$ \\
\hline Australia & Australian Digital Health Agency & Yes & Yes \\
\hline Austria & ELGA GmbH & Yes & Yes \\
\hline Canada & Canada Health Infoway & Yes & Yes \\
\hline Chile & Ministry of Health & Yes & Yes \\
\hline Croatia & Croatian Health Insurance Fund & Yes & Yes \\
\hline Czech Republic & No national organisation & No & Yes \\
\hline Denmark & $\begin{array}{l}\text { Danish Health Data Authority (standards) and National Board for } \\
\text { Health IT (infrastructure development coordination) }\end{array}$ & Yes & Yes \\
\hline Estonia & Estonian E-Health Foundation & Yes & Yes \\
\hline Finland & The National Institute for Health and Welfare, THL & Yes & Yes \\
\hline France & $\begin{array}{l}\text { National Health Insurance (Caisse Nationale d'Assurance Maladie } \\
\text { des Travailleurs Salariés) }\end{array}$ & No & No \\
\hline Greece & E-government for Social Security Services (IDIKA SA) & No & No \\
\hline Iceland & Directorate of Health & Yes & Yes \\
\hline Ireland & eHealth Ireland & No & No \\
\hline Israel & Ministry of Health & Yes & Yes \\
\hline Japan & Not named ${ }^{1}$ & Yes & Yes \\
\hline Latvia & National Health Service (NHS) & No & Yes \\
\hline Luxembourg & eHealth Agency (Agence eSanté) & Yes & Yes \\
\hline Mexico & No national organisation & n.r. & n.r. \\
\hline New Zealand & Ministry of Health & Yes & Yes \\
\hline Norway & National Health Net & No & No \\
\hline Poland & National Center for Healthcare Information Systems (CSIOZ) & Yes & Yes \\
\hline Singapore & Ministry of Health & Yes & Yes \\
\hline Slovakia & $\begin{array}{l}\text { National Health Information Centre (Narodne centrum } \\
\text { zdravotnickych informacii) }\end{array}$ & Yes & Yes \\
\hline Spain & $\begin{array}{l}\text { Ministry of Health, Social Services and Equality coordinates with } \\
\text { strong collaboration of Autonomous Communities }\end{array}$ & Yes & Yes \\
\hline Sweden & $\begin{array}{l}\text { Responsibilities shared among the Swedish Association of Local } \\
\text { Authorities and Regions (SALAR/Inera), the National Board of } \\
\text { Health and Welfare and the Swedish eHealth Agency }\end{array}$ & Yes & Yes \\
\hline Switzerland & $\begin{array}{l}\text { IT infrastructure is steered by regions (cantons) with regional } \\
\text { systems interoperability coordinated by eHealth Suisse }\end{array}$ & Yes & Yes \\
\hline $\begin{array}{l}\text { UK Northern } \\
\text { Ireland }\end{array}$ & Regional Business Services Organisations & No & No \\
\hline UK England & NHS Digital & Yes & Yes \\
\hline UK Scotland & Scottish Government eHealth Division & Yes & Yes \\
\hline United States & No national organisation & Yes & Yes \\
\hline
\end{tabular}

Source: HCQI Survey of Electronic Health Record System Development and Use, 2016

${ }^{1}$ An organisation has been entrusted by the government to set standards. 
Table 10: Policy levers to encourage the adoption and maintenance of high quality EHRs

Laws or regulations require health care providers to:

\begin{tabular}{|c|c|c|c|c|c|c|c|c|}
\hline Country & $\begin{array}{c}\text { Adopt } \\
\text { electronic } \\
\text { health records }\end{array}$ & $\begin{array}{l}\text { Adopt EHR } \\
\text { systems that } \\
\text { conform to } \\
\text { clinical } \\
\text { terminology } \\
\text { standards }\end{array}$ & $\begin{array}{l}\text { Adopt EHR } \\
\text { systems that } \\
\text { conform to } \\
\text { electronic } \\
\text { messaging } \\
\text { standards }\end{array}$ & $\begin{array}{c}\text { Certification } \\
\text { process for } \\
\text { vendors }\end{array}$ & $\begin{array}{c}\text { Certification } \\
\text { requires } \\
\text { vendors to } \\
\text { adopt } \\
\text { standards and } \\
\text { use structured } \\
\text { data }\end{array}$ & $\begin{array}{l}\text { Incentives or } \\
\text { penalties for } \\
\text { physicians }\end{array}$ & $\begin{array}{l}\text { Incentives or } \\
\text { penalties for } \\
\text { hospitals }\end{array}$ & $\begin{array}{c}\text { Incentives or } \\
\text { penalties for } \\
\text { other } \\
\text { providers }\end{array}$ \\
\hline Australia & No & No & No & Yes & No & Yes & No & No \\
\hline Austria & Yes & Yes & Yes & No & n.r. & Yes & Yes & No \\
\hline Canada & No & No & No & Yes & n.r. & Yes & Yes & Yes \\
\hline Chile & No & n.r. & n.r. & No & Yes & Yes & Yes & Yes \\
\hline Croatia & Yes & No & Yes & Yes & Yes & No & No & No \\
\hline Czech Republic & No & n.r. & n.r. & No & n.r. & No & No & No \\
\hline Denmark & Yes & Yes & Yes & No & n.r. & No & No & No \\
\hline Estonia & Yes & Yes & Yes & No & n.r. & Yes & Yes & Yes \\
\hline Finland & Yes & Yes & Yes & Yes & Yes & No & Yes & Yes \\
\hline France & Yes & No & Yes & Yes & Yes & No & No & No \\
\hline Greece & n.r. & n.r. & n.r. & No & n.r. & No & No & n.r. \\
\hline Iceland & No & n.r. & n.r. & No & n.r. & No & No & No \\
\hline Ireland & Yes & n.r. & Yes & Yes & No & No & No & No \\
\hline Israel & Yes & No & No & No & n.r. & Yes & Yes & Yes \\
\hline Japan & No & No & n.r. & No & n.r. & No & No & No \\
\hline Latvia & Yes & No & No & No & n.r. & No & No & No \\
\hline Luxembourg & Yes & Yes & Yes & Yes & Yes & No & No & No \\
\hline Mexico & No & n.r. & n.r. & Yes & Yes & No & No & No \\
\hline New Zealand & No & n.r. & n.r. & No & No & No & No & No \\
\hline Norway & n.r. & n.r. & n.r. & No & No & Yes & Yes & Yes \\
\hline Poland & Yes & Yes & Yes & No & n.r. & No & No & No \\
\hline Singapore & No & n.r. & n.r. & Yes & Yes & Yes & Yes & Yes \\
\hline Slovakia & Yes & Yes & Yes & Yes & Yes & No & No & No \\
\hline Spain & No & n.r. & n.r. & No & n.r. & No & No & Yes \\
\hline Sweden & No & n.r. & n.r. & Yes & No & No & No & No \\
\hline Switzerland & Yes & No & No & No & n.r. & No & No & No \\
\hline UK England & No & No & No & Yes & Yes & No & Yes & Yes \\
\hline $\begin{array}{l}\text { UK Northern } \\
\text { Ireland }\end{array}$ & No & n.r. & n.r. & No & No & No & No & No \\
\hline UK Scotland & No & n.r. & n.r. & Yes & Yes & Yes & Yes & Yes \\
\hline United States & No & n.r. & n.r. & Yes & Yes & Yes & Yes & Yes \\
\hline
\end{tabular}

Source: HCQI Survey of Electronic Health Record System Development and Use, 2016

n.r. Not reported 
Table 11: Data set creation progress and challenges

Difficulties developing datasets from EHRs:

\begin{tabular}{|c|c|c|c|c|c|c|c|c|c|}
\hline & & & & & & EHRs: & & & \\
\hline Country & $\begin{array}{l}\text { Concerns } \\
\text { with the } \\
\text { quality of } \\
\text { EHR data }\end{array}$ & $\begin{array}{l}\text { Electronic } \\
\text { record } \\
\text { quality } \\
\text { auditing }\end{array}$ & $\begin{array}{c}\text { Creating } \\
\text { datasets } \\
\text { from EHR } \\
\text { records }\end{array}$ & $\begin{array}{l}\text { Number of } \\
\text { custodians } \\
\text { of datasets } \\
\text { from EHR } \\
\text { records }\end{array}$ & $\begin{array}{l}\text { Legal } \\
\text { barriers to } \\
\text { the creation } \\
\text { and/or } \\
\text { analysis of } \\
\text { databases }\end{array}$ & $\begin{array}{l}\text { Lack of } \\
\text { resources or } \\
\text { technical } \\
\text { capacity to } \\
\text { extract data } \\
\text { to create } \\
\text { databases }\end{array}$ & $\begin{array}{l}\text { Concerns } \\
\text { with the } \\
\text { quality of } \\
\text { E.H.R. data } \\
\text { that limit } \\
\text { the ability to } \\
\text { develop } \\
\text { databases }\end{array}$ & $\begin{array}{l}\text { Lack of } \\
\text { resources or } \\
\text { technical } \\
\text { capacity to } \\
\text { de-identify } \\
\text { databases } \\
\text { from E.H.R. } \\
\text { records }\end{array}$ & $\begin{array}{l}\text { Barriers to } \\
\text { the use of } \\
\text { EHR data for } \\
\text { health care } \\
\text { quality } \\
\text { monitoring }\end{array}$ \\
\hline Australia & Yes & Yes & No & n.r. & n.r. & n.r. & n.r. & n.r. & n.r. \\
\hline Austria & Yes & No & No & n.r. & n.r. & n.r. & n.r. & n.r. & Yes \\
\hline Canada & Yes & No & Yes & 2 to 5 & Yes & Yes & Yes & Yes & Yes \\
\hline Chile & n.r. & n.r. & No & n.r. & n.r. & n.r. & n.r. & n.r. & n.r. \\
\hline Croatia & Yes & No & No & n.r. & n.a. & n.a. & n.a. & n.a. & No \\
\hline $\begin{array}{l}\text { Czech } \\
\text { Republic }\end{array}$ & No & No & No & 2 to 5 & No & No & No & No & Yes \\
\hline Denmark & No & No & Yes & $20+$ & Yes & Yes & No & Yes & Yes \\
\hline Estonia & Yes & Yes & No & 1 & No & Yes & Yes & No & Yes \\
\hline Finland & Yes & No & Yes & $20+$ & Yes & Yes & Yes & No & Yes \\
\hline France & n.r. & No & No & n.r. & Yes & No & No & No & n.r. \\
\hline Greece & n.r. & n.r. & Yes & n.r. & n.r. & n.r. & n.r. & n.r. & n.r. \\
\hline Iceland & Yes & Yes & Yes & 2 to 5 & Yes & No & Yes & No & Yes \\
\hline Ireland & n.r. & No & Yes & $20+$ & Yes & Yes & Yes & Yes & n.r. \\
\hline Israel & Yes & Yes & Yes & n.r. & Yes & No & No & No & Yes \\
\hline Japan & No & No & & n.r. & n.r. & n.r. & n.r. & n.r. & n.r. \\
\hline Latvia & n.r. & No & No & n.r. & No & Yes & No & Yes & No \\
\hline Luxembourg & n.r. & No & No & n.r. & No & No & No & No & No \\
\hline Mexico & Yes & No & Yes & 2 to 5 & No & Yes & Yes & No & No \\
\hline $\begin{array}{l}\text { New } \\
\text { Zealand }\end{array}$ & Yes & Yes & Yes & 1 & No & No & Yes & No & n.r. \\
\hline Norway & Yes & Yes & Yes & 2 to 5 & Yes & Yes & Yes & Yes & Yes \\
\hline Poland & n.r. & No & Yes & 2 to 5 & Yes & Yes & Yes & No & n.r. \\
\hline Singapore & Yes & Yes & Yes & 1 & No & No & Yes & No & Yes \\
\hline Slovakia & n.r. & No & No & 1 & No & No & No & No & No \\
\hline Spain & Yes & Yes & Yes & $20+$ & No & No & Yes & Yes & Yes \\
\hline Sweden & Yes & No & Yes & $20+$ & Yes & Yes & Yes & No & Yes \\
\hline Switzerland & n.r. & No & No & n.r. & Yes & n.r. & n.r. & n.r. & No \\
\hline UK England & Yes & Yes & No & $20+$ & Yes & No & No & No & Yes \\
\hline $\begin{array}{l}\text { UK } \\
\text { Northern } \\
\text { Ireland }\end{array}$ & Yes & No & No & n.r. & n.r. & No & No & No & Yes \\
\hline UK Scotland & Yes & No & Yes & $20+$ & Yes & Yes & Yes & No & Yes \\
\hline $\begin{array}{l}\text { United } \\
\text { States }\end{array}$ & n.r. & No & Yes & $20+$ & No & Yes & Yes & No & n.r. \\
\hline
\end{tabular}

Source: HCQI Survey of Electronic Health Record System Development and Use, 2016

n.r. Not reported 
Table 12: Summary Table of Data Governance Readiness to Generate Health Information from EHRs

\begin{tabular}{|c|c|c|c|c|c|}
\hline COUNTRY & $\begin{array}{l}\text { Legal issues impeding } \\
\text { the creation of } \\
\text { datasets and/or } \\
\text { analysis of data from }\end{array}$ & $\begin{array}{c}\text { Three or more key secondary } \\
\text { data uses included in national } \\
\text { plans or priorities }\end{array}$ & $\begin{array}{l}\text { Creating datasets } \\
\text { from EHR records }\end{array}$ & $\begin{array}{l}\text { EHR data contributes } \\
\text { to } 3 \text { or more key } \\
\text { monitoring or } \\
\text { research domains }\end{array}$ & Total $(\max =3)$ \\
\hline
\end{tabular}

\begin{tabular}{|c|c|c|c|c|c|}
\hline Australia & n.r. & 0 & 0 & 0 & 0 \\
\hline Austria & n.r. & 0 & 0 & 0 & 0 \\
\hline Canada & -1 & 1 & 1 & 1 & 2 \\
\hline Chile & n.r. & 1 & 0 & 0 & 1 \\
\hline Croatia & n.a. & 1 & 0 & 0 & 1 \\
\hline Czech Republic & 0 & n.r. & 0 & 0 & 0 \\
\hline Denmark & -1 & 1 & 1 & 1 & 2 \\
\hline Estonia & -1 & 1 & 0 & 0.5 & 0.5 \\
\hline Finland & 0 & 1 & 1 & 0.5 & 2.5 \\
\hline France & -1 & 0 & 0 & 0 & 0 \\
\hline Greece & -1 & n.r. & 1 & 0.5 & 0.5 \\
\hline Iceland & n.r. & 1 & 1 & 1 & 3 \\
\hline Ireland & -1 & 1 & 1 & 0 & 1 \\
\hline Israel & -1 & 0 & 1 & 1 & 1 \\
\hline Japan & -1 & 0 & n.r. & 0.5 & 0 \\
\hline Latvia & n.r. & 1 & 0 & 0 & 1 \\
\hline Luxembourg & 0 & 1 & 0 & 0 & 1 \\
\hline Mexico & 0 & n.r. & 1 & 0.5 & 1.5 \\
\hline New Zealand & 0 & n.r. & 1 & 1 & 2 \\
\hline Norway & 0 & 1 & 1 & 1 & 3 \\
\hline Poland & n.r. & 1 & 1 & 1 & 3 \\
\hline Singapore & -1 & 1 & 1 & 1 & 2 \\
\hline Slovakia & -1 & 1 & 0 & 0 & 0 \\
\hline Spain & 0 & 0 & 1 & 0 & 1 \\
\hline Sweden & -1 & 1 & 1 & 1 & 2 \\
\hline Switzerland & 0 & 1 & 0 & 0 & 1 \\
\hline UK England & 0 & 1 & 0 & 1 & 2 \\
\hline UK Northern Ireland & -1 & 0 & 0 & 1 & 0 \\
\hline UK Scotland & -1 & 1 & 1 & 1 & 2 \\
\hline United States & 0 & 1 & 1 & 0 & 2 \\
\hline
\end{tabular}

Source: HCQI Survey of Electronic Health Record System Development and Use, 2016

N.B. Yes is 1 point, a Partial Yes is 0.5 points and No is 0 points

(1) See Table 11. A score of -1 indicates that legal issues impeding dataset creation or data analysis were reported.

(2) See Table 13.

(3) See Table 11.

(4) See Table 14. A score of 0.5 indicates 1-2 key statistical or research programs were reported. 
DELSA/HEA/WD/HWP(2017)9

Table 13: Secondary uses of data are planned within national plans or priorities for electronic health records

\begin{tabular}{|c|c|c|c|c|c|c|}
\hline COUNTRY & $\begin{array}{c}\text { Public health } \\
\text { monitoring }\end{array}$ & $\begin{array}{l}\text { Health system } \\
\text { performance } \\
\text { monitoring }\end{array}$ & $\begin{array}{l}\text { Patient safety } \\
\text { monitoring }\end{array}$ & $\begin{array}{l}\text { Facilitating and } \\
\text { contributing to } \\
\text { clinical trials }\end{array}$ & $\begin{array}{l}\text { Supporting } \\
\text { physician } \\
\text { treatment } \\
\text { decisions }\end{array}$ & Research \\
\hline Australia & No & No & No & No & No & No \\
\hline Austria & No & No & No & No & Yes & No \\
\hline Chile & Yes & Yes & Yes & No & No & No \\
\hline Croatia & Yes & Yes & Yes & No & No & No \\
\hline Denmark & Yes & Yes & Yes & Yes & Yes & Yes \\
\hline Estonia & Yes & Yes & Yes & Yes & Yes & Yes \\
\hline Finland & Yes & Yes & Yes & No & Yes & No \\
\hline France & No & No & No & No & No & No \\
\hline Ireland & Yes & Yes & Yes & No & Yes & No \\
\hline Israel & No & No & No & No & No & No \\
\hline Japan & n.r. & n.r. & n.r. & n.r. & n.r. & n.r. \\
\hline Latvia & Yes & Yes & No & No & No & Yes \\
\hline Luxembourg & Yes & No & No & Yes & Yes & Yes \\
\hline New Zealand & n.r. & n.r. & n.r. & n.r. & n.r. & n.r. \\
\hline Norway & Yes & Yes & Yes & Yes & Yes & Yes \\
\hline Poland & Yes & Yes & Yes & Yes & Yes and $\mathrm{No}^{1}$ & Yes \\
\hline Singapore & Yes & Yes & Yes & Yes & Yes & Yes \\
\hline Slovakia & Yes & Yes & Yes & No & No & No \\
\hline Spain & No & No & No & No & No & No \\
\hline UK England & Yes & Yes & Yes & Yes & Yes & Yes \\
\hline UK Northern Ireland & No & No & No & No & Yes & No \\
\hline UK Scotland & Yes & Yes & Yes & Yes & Yes & Yes \\
\hline United States & Yes & Yes & Yes & Yes & Yes & Yes \\
\hline
\end{tabular}

Source: HCQI Survey of Electronic Health Record System Development and Use, 2016

n.r. Not reported

(1) Physicians may only query data from their own patients (unless they have the informed consent of other patients). 
Table 14: EHR system data is regularly contributing to national statistics or research

Data in EHR systems is regularly contributing to national statistics or research for:

\begin{tabular}{|c|c|c|c|c|c|c|c|}
\hline Country & $\begin{array}{l}\text { Process to evaluate } \\
\text { the usability of EHR } \\
\text { data for dataset } \\
\text { creation and } \\
\text { analysis }\end{array}$ & $\begin{array}{l}\text { Public health } \\
\text { monitoring }\end{array}$ & $\begin{array}{c}\text { Health system } \\
\text { performance } \\
\text { monitoring }\end{array}$ & $\begin{array}{c}\text { Patient } \\
\text { safety } \\
\text { monitoring }\end{array}$ & $\begin{array}{l}\text { Facilitating and } \\
\text { contributing to } \\
\text { clinical trials }\end{array}$ & $\begin{array}{l}\text { Enabling } \\
\text { physicians to } \\
\text { query the } \\
\text { data }\end{array}$ & $\begin{array}{l}\text { Research to } \\
\text { improve health } \\
\text { and health care }\end{array}$ \\
\hline Australia & Yes & No & No & No & No & No & No \\
\hline Austria & No & No & No & No & No & No & No \\
\hline Canada & Yes & Yes & Yes & Yes & No & No & Yes \\
\hline Chile & Yes $_{1}$ & No & No & No & No & No & No \\
\hline Croatia & No & No & No & No & No & No & No \\
\hline Czech Republic & No & No & No & No & No & No & No \\
\hline Denmark & No & Yes & Yes & Yes & Yes & Yes & Yes \\
\hline Estonia & Yes & Yes & No & No & No & No & No \\
\hline Finland & Partly & No & Yes & No & No & No & No \\
\hline France & No & No & No & No & No & No & No \\
\hline Greece & Yes & Yes & No & No & No & No & No \\
\hline Iceland & Yes & Yes & No & Yes & No & No & Yes \\
\hline Ireland & Yes & No & No & No & No & No & No \\
\hline Israel & Yes & Yes & Yes & Yes & No & No & Yes \\
\hline Japan & n.r. & Yes & No & No & No & No & No \\
\hline Latvia & No & No & No & No & No & No & No \\
\hline Luxembourg & No & No & No & No & No & No & No \\
\hline Mexico & Yes & Yes & Yes & No & No & No & No \\
\hline New Zealand & Yes & Yes & Yes & Yes & No & Yes & Yes \\
\hline Singapore & Yes & Yes & Yes & Yes & No & Yes & No \\
\hline Slovakia & No & No & No & No & No & No & No \\
\hline Spain & No & No & No & No & No & No & No \\
\hline Sweden & No & Yes & Yes & Yes & Yes & Yes & Yes \\
\hline Switzerland & No & No & No & No & No & No & No \\
\hline UK England & Yes & Yes & Yes & No & Yes & Yes & Yes \\
\hline $\begin{array}{l}\text { UK Northern } \\
\text { Ireland }\end{array}$ & No & Yes & Yes & Yes & No & Yes & Yes \\
\hline UK Scotland & Yes & Yes & Yes & Yes & Yes & Yes & Yes \\
\hline United States & n.r. & No & No & No & No & No & No \\
\hline
\end{tabular}

Source: HCQI Survey of Electronic Health Record System Development and Use, 2016

n.r. Not reported

(1) Evaluation of data extracted from Electronic Medical Records. 
DELSA/HEA/WD/HWP(2017)9

Table 15: Projects where data from Electronic Health Records are used to regularly monitor and report on health care quality at the health system level

\begin{tabular}{|c|c|c|}
\hline COUNTRY & PROJECT & \\
\hline \multirow[t]{14}{*}{ CANADA } & Title & Continuing Care and Residential Care Reporting Systems \\
\hline & Purpose & $\begin{array}{l}\text { To capture demographic, clinical, functional and resource utilization information on individuals receiving } \\
\text { continuing care services in hospitals or long-term care homes in Canada and use this information to support } \\
\text { secondary uses such as decision-making regarding funding and resource allocation (for example). }\end{array}$ \\
\hline & Description & $\begin{array}{l}\text { The clinical data standard for the CCRS was developed by interRAI, an international research network, and } \\
\text { modified with permission by CIHI for Canadian use. The interRAI Resident Assessment Instrument Minimum Data } \\
\text { Set (RAI-MDS 2.0) C is used to identify the preferences, needs and strengths of continuing care hospital patients } \\
\text { or long-term care home residents and provides a snapshot of their services. The information, gathered } \\
\text { electronically at the point of care, provides real-time decision support for front-line care planning and } \\
\text { monitoring, as well as for health system uses such as facility management, resource allocation and funding. Pan- } \\
\text { Canadian reports are regularly published using point of care information, with evidence that this information has } \\
\text { been used by decision-makers within their respective jurisdiction/organization. }\end{array}$ \\
\hline & Publications & Depression Among Seniors in Residential Care \\
\hline & & https://secure.cihi.ca/estore/productFamily.htm?pf=PFC1432\&locale=en\&lang=EN\&mediatype=0 \\
\hline & & $\begin{array}{l}\text { Caring for Seniors with Alzheimer's Disease and Other Forms of Dementia } \\
\text { https://secure.cihi.ca/estore/productFamily.htm?locale=en\&pf=PFC1534\&lang=en\&media=0 }\end{array}$ \\
\hline & & Resident Safety: Characteristics Associated with Falling in Ontario Complex Continuing Care \\
\hline & & $\underline{\text { https://secure.cihi.ca/estore/productFamily.htm?pf=PFC1032\&locale=en\&lang=EN\&mediatype=0 }}$ \\
\hline & Title & Acute and Ambulatory Care Information Services Demonstration Projects \\
\hline & Purpose & $\begin{array}{l}\text { The purpose of the AACIS data supply demonstration projects is to identify opportunities to improve or } \\
\text { streamline the flow/reporting of data to } \mathrm{CIHI} \text { by leveraging eHealth or digital health solutions such as electronic } \\
\text { health records. Improvements of particular interest include reducing the burden of manual data collection, } \\
\text { increasing data timeliness, expanding data coverage and evolving data relevancy. }\end{array}$ \\
\hline & Description & The benefits anticipated from this project include \\
\hline & & - Understanding extent to which an Electronic Health Record (EHR) system contains data elements required for \\
\hline & & Discharge Abstract Database (DAD) and National Ambulatory Reporting System (NACRS) \\
\hline & & $\begin{array}{l}\text { - Quantifying the benefits that can be realized by healthcare organizations, jurisdictions, } \mathrm{CIHI} \text { and the health care } \\
\text { system by leveraging electronic data sources for health system reporting, planning and management purposes }\end{array}$ \\
\hline \multirow[t]{13}{*}{ DENMARK } & Title & Health Data Program \\
\hline & Purpose & To make health data from national databases and registries available for secondary use \\
\hline & Description & A national program aiming at making data available in a secure manner across sectors and for relevant purposes \\
\hline & Publications & Information about publications provided upon request \\
\hline & Title & Danish Clinical Registries (RKKP) \\
\hline & Purpose & Improve the use of registries for clinical, research and managerial purposes \\
\hline & Description & 67 joint regional databases used for analysing clinical data from various sources \\
\hline & Publications & Homepage of RKKP in Danish \\
\hline & & http://www.rkkp.dk/ \\
\hline & & English RKKP homepage \\
\hline & & http://www.rkkp.dk/in-english/ \\
\hline & & Internet link to the 67 databases \\
\hline & & https://www.sundhed.dk/sundhedsfag \\
\hline
\end{tabular}

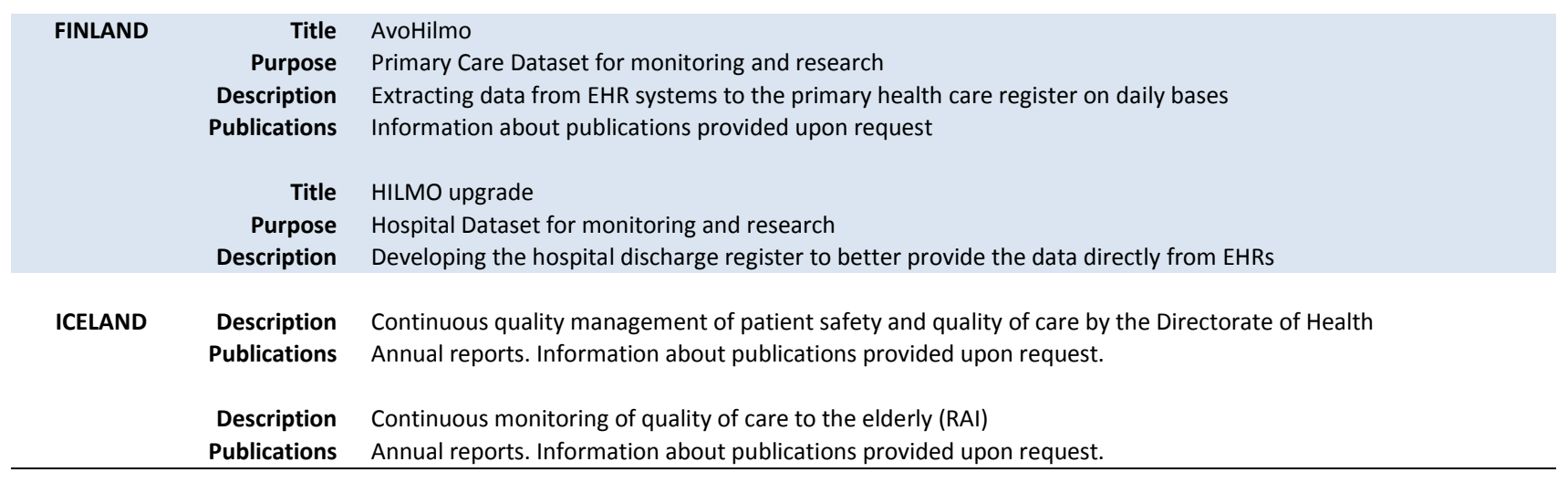


DELSA/HEA/WD/HWP(2017)9

\begin{tabular}{|c|c|c|}
\hline JAPAN & $\begin{array}{r}\text { Title } \\
\text { Purpose } \\
\text { Description }\end{array}$ & $\begin{array}{l}\text { Monitoring of cancer incidence in Japan } \\
\text { To estimate national cancer incidence on the basis of data from regional cancer registries. } \\
\text { Internet link provided to a summary in English. } \\
\text { http://ganjoho.jp/data/reg stat/statistics/brochure/mcij2011 report.pdf }\end{array}$ \\
\hline & $\begin{array}{r}\text { Title } \\
\text { Purpose } \\
\text { Description }\end{array}$ & $\begin{array}{l}\text { Cancer statistics in japan } \\
\text { To collect information about cancer statistics. } \\
\text { Information about publications provided upon request. Internet link provided to a summary in English. } \\
\text { http://ganjoho.jp/data/reg stat/statistics/brochure/2015/cancer statistics 2015.pdf }\end{array}$ \\
\hline $\begin{array}{l}\text { NEW } \\
\text { ZEALAND }\end{array}$ & $\begin{array}{r}\text { Title } \\
\text { Purpose } \\
\text { Description }\end{array}$ & $\begin{array}{l}\text { National Patient Flow } \\
\text { Gather information on the outcome of referrals into secondary care and the time to access treatment to } \\
\text { understand demand. } \\
\text { A national system to collect health care information tracking patient movement and events from first referral to } \\
\text { treatment. }\end{array}$ \\
\hline POLAND & $\begin{array}{r}\text { Purpose } \\
\text { Description }\end{array}$ & $\begin{array}{l}\text { Data collection and analysis } \\
\text { Electronic Platform of Collection, analysis and dissemination of digital resources for medical events }\end{array}$ \\
\hline SPAIN & $\begin{array}{r}\text { Title } \\
\text { Description }\end{array}$ & $\begin{array}{l}\text { BDCAP } \\
\text { A database where the data have been extracted from EHRs in the domain of Primary Care. The system is } \\
\text { operated by Regions and is coordinated at the National level. }\end{array}$ \\
\hline & $\begin{array}{r}\text { Title } \\
\text { Description }\end{array}$ & $\begin{array}{l}\text { RAE-CMBD } \\
\text { A database where information is extracted from EHRs and paper records manually regarding hospital specialties. } \\
\text { The database is operated by the Regions and is coordinated at the national level by the Ministry of Health. }\end{array}$ \\
\hline & $\begin{array}{r}\text { Title } \\
\text { Description }\end{array}$ & $\begin{array}{l}\text { BIFAP } \\
\text { A system where information is extracted from EHRs regarding prescription medications, based on notifications } \\
\text { on a voluntary basis from health care providers. The database is managed by the Spanish Agency of Drugs and } \\
\text { Medical Products. }\end{array}$ \\
\hline & $\begin{array}{r}\text { Title } \\
\text { Description }\end{array}$ & $\begin{array}{l}\text { Pharmacovigilance system: } \\
\text { This system automates the extraction of data from EHRs at the regional level. The data is aggregated at the } \\
\text { national level. }\end{array}$ \\
\hline SWEDEN & $\begin{array}{r}\text { Title } \\
\text { Purpose } \\
\text { Description }\end{array}$ & $\begin{array}{l}\text { IT-tool for Healthcare-associated infections } \\
\text { To prevent healthcare associated infections } \\
\text { When antibiotics are prescribed the cause is recorded in the EHR for follow up and inclusion in Quality registries } \\
\text { used for monitoring and improvement. }\end{array}$ \\
\hline & Publications & $\begin{array}{l}\text { Information about publications provided upon request. Internet link provided to a summary in English. } \\
\text { http://skl.se/halsasjukvard/patientsakerhet/vardrelateradeinfektioner.746.html }\end{array}$ \\
\hline & $\begin{array}{r}\text { Title } \\
\text { Purpose } \\
\text { Description }\end{array}$ & $\begin{array}{l}\text { Quality Registries in Sweden } \\
\text { To monitor quality in health care and to encourage and refine best practice guidelines for clinical care } \\
\text { A system of National Quality Registries has been established in the Swedish health and medical services in the } \\
\text { last decades. There are about } 100 \text { registries that receive central funding in Sweden. }\end{array}$ \\
\hline & Publications & $\begin{array}{l}\text { Information about publications provided upon request. Internet link provided to a summary in English. } \\
\text { http://www.kvalitetsregister.se/englishpages/aboutqualityregistries.2422.html }\end{array}$ \\
\hline $\begin{array}{c}\text { UNITED } \\
\text { KINGDOM } \\
\text { (ENGLAND) }\end{array}$ & $\begin{array}{r}\text { Title } \\
\text { Purpose } \\
\text { Description } \\
\text { Title } \\
\text { Purpose } \\
\text { Description }\end{array}$ & $\begin{array}{l}\text { National Tariff System } \\
\text { Re-imbursement } \\
\text { Capture of data from acute providers to support statistics and re-imbursement } \\
\text { CQRS (Calculating Quality and reporting service) } \\
\text { Monitoring quality of primary care } \\
\text { Extraction of data from primary care systems to support monitoring (e.g. against Quality and Outcomes } \\
\text { Frameworks) }\end{array}$ \\
\hline
\end{tabular}




$\begin{array}{crl}\text { UNITED } & \text { Title } & \text { NHS NSS Discovery } \\ \text { KINGDOM } & \text { Purpose } & \text { Quality improvement } \\ \text { (SCOTLAND) } & \text { Description } & \begin{array}{l}\text { NSS Discovery is an information system that provides approved users with access to a range of comparative } \\ \text { information to support performance and quality improvement. }\end{array}\end{array}$

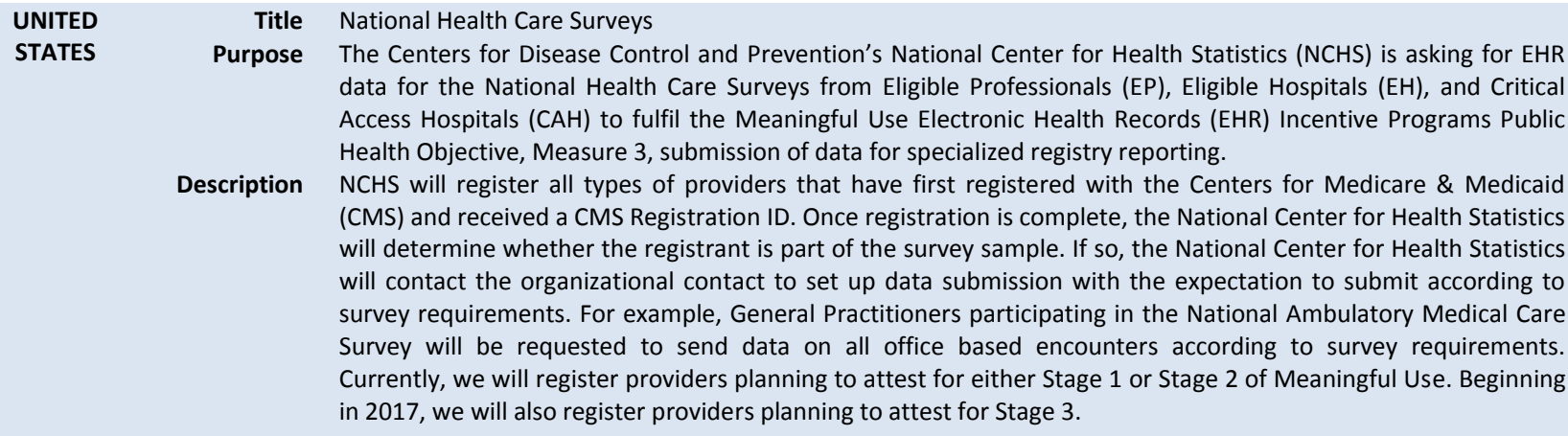

STATES Purpose The Centers for Disease Control and Prevention's National Center for Health Statistics (NCHS) is asking for EHR data for the National Health Care Surveys from Eligible Professionals (EP), Eligible Hospitals (EH), and Critical Access Hospitals (CAH) to fulfil the Meaningful Use Electronic Health Records (EHR) Incentive Programs Public Health Objective, Measure 3, submission of data for specialized registry reporting.

Description NCHS will register all types of providers that have first registered with the Centers for Medicare \& Medicaid (CMS) and received a CMS Registration ID. Once registration is complete, the National Center for Health Statistics will determine whether the registrant is part of the survey sample. If so, the National Center for Health Statistics will contact the organizational contact to set up data submission with the expectation to submit according to survey requirements. For example, General Practitioners participating in the National Ambulatory Medical Care Survey will be requested to send data on all office based encounters according to survey requirements. Currently, we will register providers planning to attest for either Stage 1 or Stage 2 of Meaningful Use. Beginning in 2017, we will also register providers planning to attest for Stage 3.

Title National Hospital Care Survey

Purpose The National Hospital Care Survey is an annual survey conducted by the Centers for Disease Control and Prevention's National Center for Health Statistics (NCHS) in order to gather critical information from hospitals on important issues facing the US health care system.

Description NCHS Data first determines hospital eligibility to participate, which is followed by an annual interview on the hospital's characteristics. Lastly, hospitals are asked to send in an electronic data component, where eligible hospitals are asked to submit electronic health record (EHR) or Uniform Bill (UB)-04 administrative claims data for all inpatient discharges and Emergency Department and Outpatient Department visits.

Source: HCQI Survey of Electronic Health Record System Development and Use, 2016 
ANNEX 3

WEB LINKS TO NATIONAL PLANS AND POLICIES

WEB-LINK OR PUBLICATION REFERENCE FOR THE NATIONAL PLAN OR POLICY TO IMPLEMENT ELECTRONIC HEALTH RECORDS

http://www.health.gov.au/internet/main/publishing.nsf/Content/ehealth-mou

AUSTRALIA http://health.gov.au/internet/main/publishing.nsf/Content/National+Ehealth+Strategy https://www.legislation.gov.au/Details/F2016L00070/Explanatory\%20Statement/Text

\section{AUSTRIA}

Herbek, S., u. a. „The Electronic Health Record in Austria: A Strong Network between Health Care and Patients“. European Surgery 44, Nr. 3 (Juni 2012): 155-63. doi:10.1007/s10353-012-0092-9

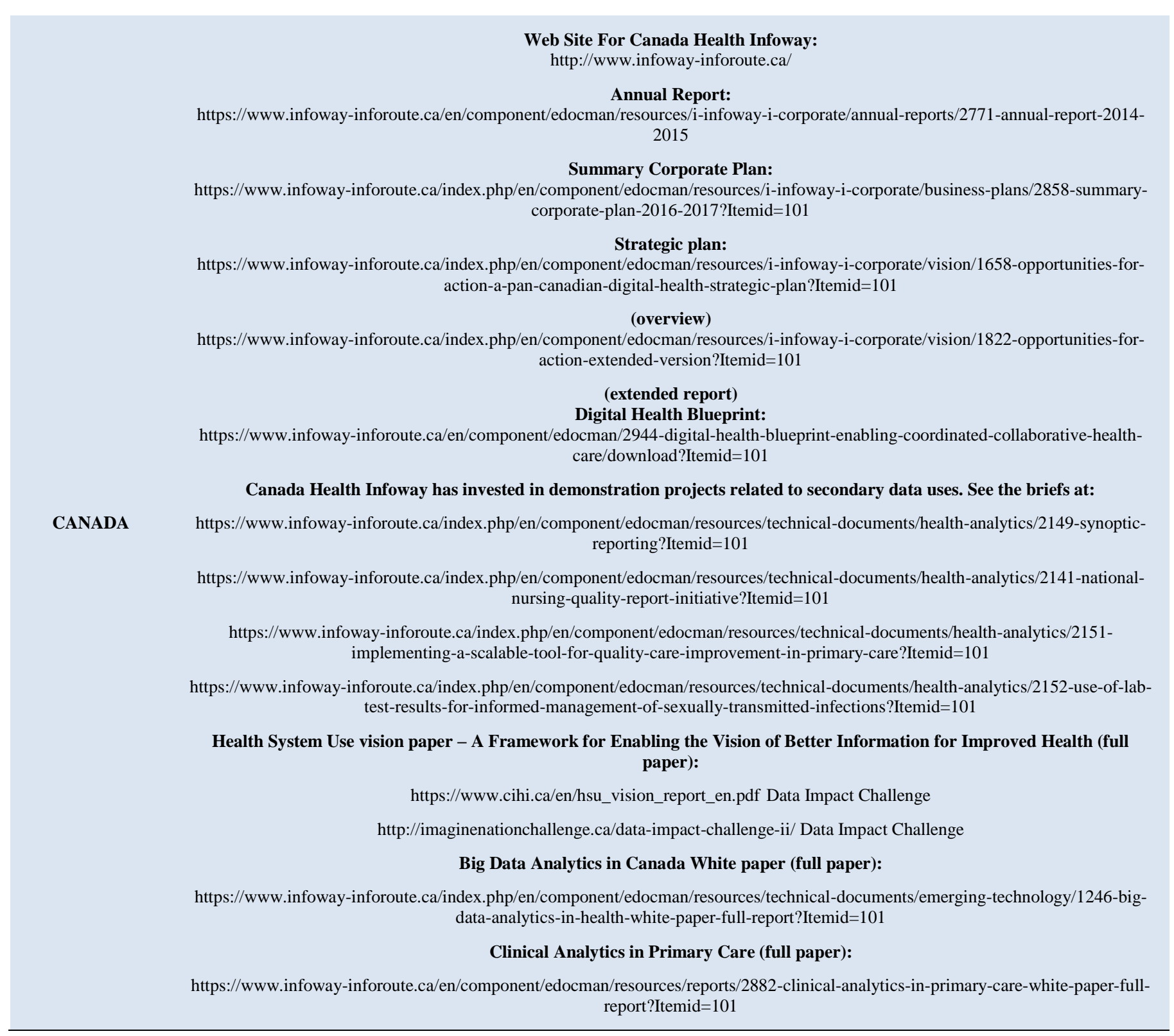


COUNTRY

WEB-LINK OR PUBLICATION REFERENCE FOR THE NATIONAL PLAN OR POLICY TO IMPLEMENT ELECTRONIC HEALTH RECORDS

\begin{tabular}{cc}
\hline CHILE & $\begin{array}{c}\text { Strategic Plan for eHealth 2011-2020 (Spanish): } \\
\text { http://www.salud-e.cl/biblioteca/libro-mapa-de-ruta/ }\end{array}$ \\
National Strategy for Health 2012-2020 (Croatian): \\
CROATIA & https://zdravlje.gov.hr/UserDocsImages/dokumenti/Programi,\%20projekti\%20i\%20strategije/Strateški-plan_razvoja_eZdravlja.pdf \\
eHealth Strategic Plan (Croatian):
\end{tabular}

FINLAND

Information to Support Well-Being and Service Renewal eHealth and eSocial Strategy 2020:

http://www.julkari.fi/handle/10024/125955

FRANCE

National EHR (Dossier Médical Partagé - DMP) home page (French):

http://dmp.gouv.fr

ICELAND

National eHealth Strategy:

http://www.landlaeknir.is/servlet/file/store93/item28955/National_eHealth_Strategies_January_2016 final.pdf

eHealth Strategy:

IRELAND

http://health.gov.ie/blog/publications/ehealth-strategy-for-ireland/

eHealth Knowledge and Information Plan:

http://www.ehealthireland.ie/Knowledge-Information-Plan/

JAPAN

eHealth strategies are presented within the "Japan Revitalization Strategy" (Japanese):

https://www.kantei.go.jp/jp/singi/keizaisaisei/

LUXEMBOURG

eHealth homepage:

https://www.esante.lu/

SLOVAKIA

eHealth Programme homepage:

http://www.ezdravotnictvo.sk/en/eHealth_Programme/Pages/default.aspx; http://www.nczisk.sk/en/eHealth/Pages/default.aspx 

ELECTRONIC HEALTH RECORDS

SPAIN

National Health Service Digital Records home page (Spanish):

http://www.msssi.gob.es/en/profesionales/hcdsns/home.htm

NHS Electronic Health Record System (English)

http://www.msssi.gob.es/en/organizacion/sns/planCalidadSNS/docs/HCDSNS_English.pdf

Progress update 2015 (Spanish)

http://www.msssi.gob.es/en/profesionales/hcdsns/contenidoDoc/Inf_Sit_HCDSNS_Marzo2016.pdf

\section{National eHealth strategy and an action plan for 2013-2018}

SWEDEN

\section{National eHealth Strategy 2010:}

http://www.government.se/contentassets/65d092eda66b437e9cb5e54bb4e41319/national-ehealth---the-strategy-for-accessible-andsecure-information-in-health-and-social-care-s2011.023

\section{Swiss eHealth strategy homepage:}

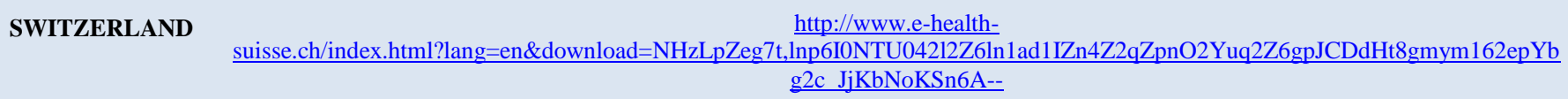

\section{Personalised Health and Care 2020:}

https://www.gov.uk/government/uploads/system/uploads/attachment_data/file/384650/NIB Report.pdf

Information and Technology for Better Care: HSCIC Strategy 2015-20

https://www.gov.uk/government/publications/hscic-strategy-2015-20

UNITED

KINGDOM

\section{Northern Ireland Electronic Care Record:}

http://www.nidirect.gov.uk/index/information-and-services/health-and-well-being/health-services/managing-your-healthcare/northernireland-electronic-care-record-niecr.htm

Scotland eHealth Strategy 2014-2017:

http://www.gov.scot/Publications/2015/03/5705

Health and Biomedical Informatics Research Strategy for Scotland:

http://www.gov.scot/Resource/0047/00475145.pdf

UNITED

STATES

\section{Federal Health IT Strategic Plan 2015- 2020:}

https://www.healthit.gov/policy-researchers-implementers/health-it-strategic-planning

Source: HCQI Survey of Electronic Health Record System Development and Use, 2016 


\section{OECD HEALTH WORKING PAPERS}

A full list of the papers in this series can be found on the OECD website: http://www.oecd.org/els/health-systems/health-workingpapers.htm

No.98 NURSES IN ADVANCED ROLES IN PRIMARY CARE: POLICY LEVERS FOR IMPLEMENTATION (2017) Claudia B. Maier*, Linda H. Aiken** and Reinhard Busse*

No. 97 UNDERSTANDING EFFECTIVE APPROACHES TO PROMOTING MENTAL HEALTH AND PREVENTING MENTAL ILLNESS (2017) David McDaid, Emily Hewlett, A-La Park

No. 96 THE ECONOMICS OF PATIENT SAFETY: STRENGTHENING A VALUE-BASED APPROACH TO REDUCING PATIENT HARM AT NATIONAL LEVEL (2017) Luke Slawomirski, Ane Auraaen and Niek Klazinga

No. 95 FUTURE TRENDS IN HEALTH CARE EXPENDITURE: A MODELLING FRAMEWORK FOR CROSS-COUNTRY FORECASTS (2017) Alberto Marino, Chris James, David Morgan and Luca Lorenzoni

No. 94 UNDERSTANDING VARIATIONS IN HOSPITAL LENGTH OF STAY AND COST: RESULTS OF A PILOT PROJECT (2017) Luca Lorenzoni and Alberto Marino

No. 93 MEASURING SOCIAL PROTECTION FOR LONG-TERM CARE (2017) Tim Muir

No. 92 CYCLICAL VS STRUCTURAL EFFECTS ON HEALTH CARE EXPENDITURE TRENDS IN OECD COUNTRIES (2017) Luca Lorenzoni, Jonathan Millar, Franco Sassi, Douglas Sutherland

No. 91 AN OECD ANALYSIS OF HEALTH SPENDING IN NORWAY (2017) David Morgan, Michael Gmeinder, Jens Wilkens

No. 90 HOW OECD HEALTH SYSTEMS DEFINE THE RANGE OF GOOD AND SERVICES TO BE FINANCED COLLECTIVELY (2016) Ane Auraaen1, Rie Fujisawa, Grégoire de Lagasnerie, Valérie Paris

No. 89 THE ORGANISATION OF OUT-OF-HOURS PRIMARY CARE IN OECD COUNTRIES (2016) Caroline Berchet, Carol Nader

No. 88 HEALTH CARE COVERAGE IN OECD COUNTRIES IN 2012 (2016) Valérie Paris, Emily Hewlett, Ane Auraaen, Jan Alexa, Lisa Simon

No. 87 PHARMACEUTICAL EXPENDITURE AND POLICIES: PAST TRENDS AND FUTURE CHALLENGES (2016) Annalisa Belloni, David Morgan, Valérie Paris

No. 86 THE LABOUR MARKET IMPACTS OF OBESITY, SMOKING, ALCOHOL USE AND RELATED CHRONIC (2016) Marion Devaux, Franco Sassi

No. 85 INTERNATIONAL COMPARISON OF SOUTH AFRICAN PRIVATE HOSPITALS PRICE LEVELS (2015) Luca Lorenzoni, Tomas Roubal 


\section{RECENT RELATED OECD PUBLICATIONS}

COUNTRY HEALTH PROFILES (2017)

HEALTH AT A GLANCE (2017)

OECD HEALTH STATISTICS (2017) (database available from http://www.oecd.org/health/health-data.htm)

OBESITY UPDATE (2017)

http://www.oecd.org/health/obesity-update.htm (Electronic Format Only)

PRIMARY CARE REVIEW OF DENMARK (2017)

NEW HEALTH TECHNOLOGIES - MANAGING ACCESS, VALUE AND SUSTAINABILITY (2017)

TACKLING WASTEFUL SPENDING ON HEALTH (2017)

OECD REVIEWS OF HEALTH SYSTEMS: LATVIA (2016)

HEALTH AT A GLANCE: EUROPE (2016)

HEALTH AT A GLANCE: ASIA/PACIFIC (2016)

BETTER WAYS TO PAY FOR HEALTH CARE (2016)

HEALTH WORKFORCE POLICIES IN OECD COUNTRIES: RIGHT JOBS, RIGHT SKILLS, RIGHT PLACES (2016)

OECD REVIEWS OF HEALTH CARE QUALITY: UNITED KINGDOM (2016)

OECD REVIEWS OF HEALTH SYSTEMS: MEXICO (2016)

OECD REVIEWS OF HEALTH SYSTEMS: COLOMBIA (2015)

HEALTH DATA GOVERNANCE: PRIVACY, MONITORING AND RESEARCH (2015)

FISCAL SUSTAINABILITY OF HEALTH SYSTEMS: BRIDGING HEALTH AND FINANCE PERSPECTIVES (2015)

ADDRESSING DEMENTIA - THE OECD RESPONSE (2015)

CARDIOVASCULAR DISEASE AND DIABETES - POLICIES FOR BETTER HEALTH AND QUALITY OF CARE (2015)

DEMENTIA RESEARCH AND CARE: CAN BIG DATA HELP? (2015)

FIT MIND, FIT JOB - FROM EVIDENCE TO PRACTICE IN MENTAL HEALTH AND WORK (2015)

TACKLING HARMFUL ALCOHOL USE - ECONOMICS AND PUBLIC HEALTH POLICY (2015)

MAKING MENTAL HEALTH COUNT: THE SOCIAL AND ECONOMIC COSTS OF NEGLECTING MENTAL HEALTH CARE (2014)

GEOGRAPHIC VARIATIONS IN HEALTH CARE: WHAT DO WE KNOW AND WHAT CAN BE DONE TO IMPROVE HEALTH SYSTEM PERFORMANCE? (2014)

PAYING FOR PERFORMANCE IN HEALTH CARE: IMPLICATIONS FOR HEALTH SYSTEM PERFORMANCE AND ACCOUNTABILITY (2014)

OECD REVIEWS OF HEALTH CARE QUALITY -AUSTRALIA (2015)

OECD REVIEWS OF HEALTH CARE QUALITY - JAPAN (2015)

OECD REVIEWS OF HEALTH CARE QUALITY - ITALY (2015)

OECD REVIEWS OF HEALTH CARE QUALITY - PORTUGAL (2015)

OECD REVIEWS OF HEALTH CARE QUALITY - CZECH REPUBLIC (2014)

OECD REVIEWS OF HEALTH CARE QUALITY - NORWAY (2014)

For a full list, consult the OECD health web page at http://www.oecd.org/health/ 